INSTITUTO DE PESQUISAS ENERGÉTICAS E NUCLEARES

Autarquia associada à Universidade de São Paulo

\title{
APLICAÇÃO DA TOMOGRAFIA COMPUTADORIZADA INDUSTRIAL NA ANÁLISE DE ROCHAS
}

GUARACIABA DE CAMPOS TETZNER

Dissertação apresentada como parte dos requisitos para obtenção do Grau de Mestre em Ciências na Área de Tecnologia - Aplicações.

Orientador:

Dr. Carlos Henrique de Mesquita

São Paulo

2008 
"Sem saber que era impossível, ele foi lá e fez" (Jean Cocteau) 
Dedico este trabalho ao meu pai:

Paulo Frederico Tetzner 


\section{AGRADECIMENTOS}

Ao Instituto de Pesquisas Energéticas e Nucleares pela infra-estrutura e a oportunidade de realizar este trabalho, especialmente ao Centro de Tecnologia das Radiações.

Ao Dr. Carlos Henrique de Mesquita, pela orientação, paciência e amizade.

Ao Dr. Wilson Aparecido Parejo Calvo, Gerente do Centro de Tecnologia das Radiações do IPEN-CNEN/SP, pelas importantes sugestões dadas no exame de Qualificação e no Seminário de Área.

À Dra. Margarida Mizue Hamada pela assistência prestada no Centro de Tecnologia das Radiações.

Ao Dr. Ismar Bancovsky pela instrução recebida nos primeiros contatos com o Centro de Tomografia Computadorizada - Hospital 9 de Julho.

Ao laboratório de Tomografia do Instituto de Geociências da Universidade do Texas e em especial ao professor Richard Ketcham pela acolhida e colaboração.

Ao programa Bolsa Mestrado do Governo do Estado de São Paulo pela ajuda financeira.

Ao companheiro Robert Mark Foley pelo estímulo e apoio prestado durante todo o trabalho.

Aos alunos da Iniciação Científica, João Carlos e João F. Martins pelo auxílio na ocasião das tomadas de medidas no tomógrafo do CTR-IPEN/CNEN/SP.

À Senhora Cláudia R. Nolla e ao Senhor Marcos Cardoso responsáveis pela secretaria do Centro de Tecnologia das Radiações por toda a colaboração.

A todos da Divisão de Ensino e da Comissão de Pós-Graduação do IPEN/USP, em especial às Senhoras Ana Maria, Ilze e Magali, por todo o auxílio.

Ao Dr. Nelson Minoru Omi pela assistência e conhecimentos de informática.

Aos meus filhos: Rita pela paciência da leitura e correção dos erros de Português e ao Rafael e à Raquel pela ajuda na digitação e compreensão pelo tempo que não pude estar com vocês. Aos meus alunos, também agradeço a compreensão pela minha ausência.

Aos meus colegas pelo carinho e colaboração.

$\mathrm{E}$ a todos que de alguma forma contribuíram para a realização deste trabalho. 


\title{
APLICAÇÃO DA TOMOGRAFIA COMPUTADORIZADA INDUSTRIAL NA ANÁLISE DE ROCHAS
}

\author{
Guaraciaba de Campos Tetzner
}

\begin{abstract}
RESUMO
Este trabalho consiste no estudo das possibilidades de aplicações técnicas de Tomografia Computadorizada (TC) utilizando-se um equipamento desenvolvido no Centro de Tecnologia das Radiações (CTR), do Instituto de Pesquisas Energéticas e Nucleares (IPEN-CNEN/SP). O equipamento é formado por uma fonte de radiação gama $\left({ }^{60} \mathrm{Co}\right)$, um detector de cintilação de iodeto de sódio dopado com Tálio, $\mathrm{NaI}(\mathrm{Tl})$, um sistema mecânico para movimentação (rotação e translação) do objeto e o sistema computacional. Todo este sistema operacional foi elaborado e desenvolvido pela equipe de TC do CTR-IPEN-CNEN/SP e seus colaboradores usando recursos e tecnologia nacional. O primeiro teste de validação do equipamento foi feito com uma amostra cilíndrica de polipropileno (fantoma) com duas cavidades (orifícios) cilíndricas de $5 \times 25$ $\mathrm{cm}$ (diâmetro e comprimento). Nos testes, estes orifícios foram preenchidos com materiais de densidades diferentes (ar, óleo e metal) cujos coeficientes de atenuação são conhecidos. O objetivo deste teste foi avaliar a qualidade de resposta do equipamento. Neste trabalho apresenta-se o estudo comparativo entre o equipamento de tomografia computadorizada do CTR-IPEN-CNEN/SP que utilizou uma fonte de radiação gama $\left({ }^{60} \mathrm{Co}\right)$ e outro equipamento disponibilizado pelo Departamento de Geociências da Universidade do Texas (CTUT), o qual utilizou nos testes uma fonte de raios X (450 kV e 3,2 mA). Como resultado, as imagens obtidas e o estudo da abrangente utilidade do equipamento aqui desenvolvido reforçaram a proposta de que o desenvolvimento da tomografia computadorizada industrial constitui um passo importante na pesquisa e desenvolvimento da tecnologia nacional.
\end{abstract}




\title{
THE INDUSTRIAL COMPUTERIZED TOMOGRAPHY APPLIED ON THE ROCK ANALYSIS
}

\author{
Guaraciaba de Campos Tetzner
}

\begin{abstract}
This work is a study of the possibilities of the technical applications of Computerized Tomography (CT) by using a device developed in the Radiation Technology Center (CTR), Institute for Energy and Nuclear Research (IPEN-CNEN/SP). The equipment consists of a gamma radiation source $\left({ }^{60} \mathrm{Co}\right)$, a scintillation detector of sodium iodide doped with thallium ( $\mathrm{NaI}(\mathrm{Tl})$ ), a mechanical system to move the object (rotation and translation) and a computer system. This operating system has been designed and developed by the CTR-IPEN-CNEN/SP team using national resources and technology. The first validation test of the equipment was carried out using a cylindrical sample of polypropylene (phantom) with two cylindrical cavities (holes) of $5 \times 25 \mathrm{~cm}$ (diameter and length). In these tests, the holes were filled with materials of different density (air, oil and metal), whose attenuation coefficients are well known. The goal of this first test was to assess the response quality of the equipment. The present report is a study comparing computerized tomography equipment CTR-IPEN-CNEN/SP which uses a source of gamma radiation $\left({ }^{60} \mathrm{Co}\right)$ and other equipment provided by the Department of Geosciences in the University of Texas (CTUT), which uses an X-ray source $(450 \mathrm{kV}$ and $3.2 \mathrm{~mA}$ ). As a result, the images obtained and the comprehensive study of the usefulness of the equipment developed here strengthened the proposition that the development of industrial computerized tomography is an important step toward consolidating the national technology.
\end{abstract}




\section{SUMÁRIO}

Página

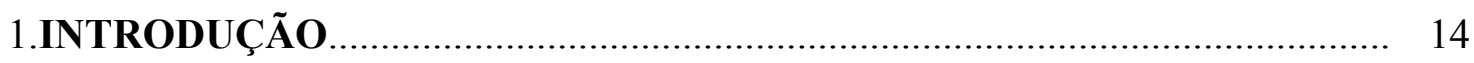

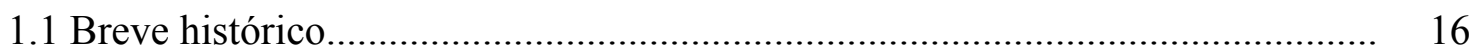

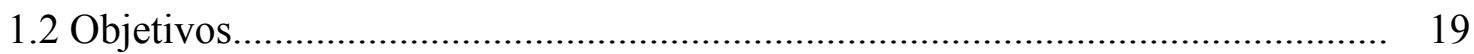

2.FUNDAMENTOS TEÓRICOS ............................................................ 20

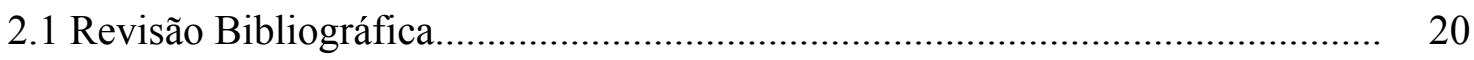

2.2 A interação da radiação com a matéria......................................................... 22

2.2.1 A probabilidade de ocorrência das interações............................................. 30

2.2.2 Alcance e atenuação dos diferentes tipos de radiação na matéria..................... 32

2.2.3 Considerações sobre a energia dos raios X e radiação gama............................ 33

2.2.4 A detecção de raios gama................................................................. 35

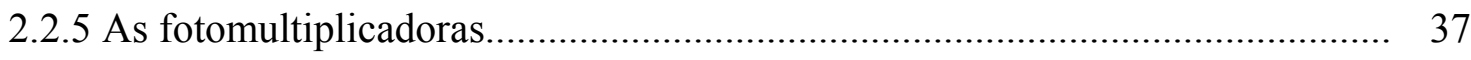

3.PRINCÍPIOS DE TOMOGRAFIA ....................................................... 38

3.1 A construção da imagem de TC ........................................................................ 38

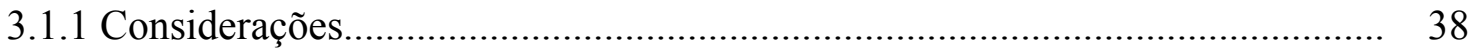

3.2 A obtenção da imagem....................................................................... 40

3.2.1 A transformada de Radon..................................................................... 40

3.2.2 A reconstrução da imagem..................................................................... 41

3.2.3 Digitalização da imagem........................................................................ 44

3.2.4 Tratamento matemático das imagens: A Transformada de Fourier................. 44

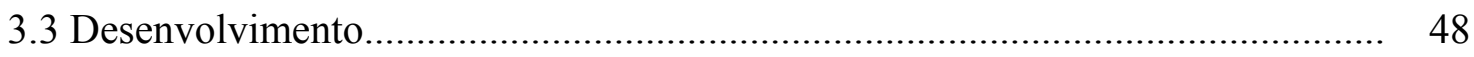

3.3.1 Tomografia Computadorizada de $1^{\mathrm{a}}$ e $2^{\mathrm{a}}$ gerações........................................ 48 


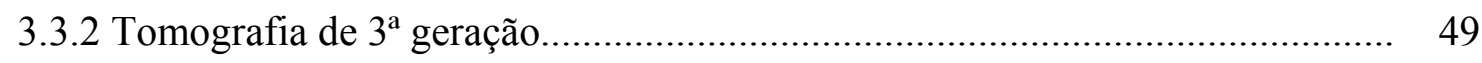

3.3.3 Tomografia de $4^{\mathrm{a}}$ geração...................................................................... 49

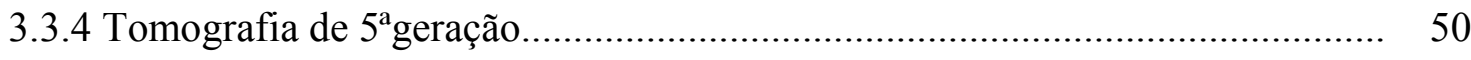

3.3.5 Aplicações científicas e industriais........................................................ 52

4. MATERIAL E MÉTODOS................................................................ 54

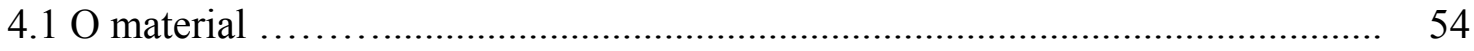

$4.2 \mathrm{O}$ tomógrafo que utiliza raios X da CTUT................................................. 55

4.3 O tomógrafo do CTR-IPEN-CNEN/SP ................................................... 57

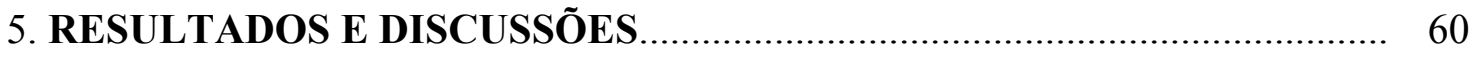

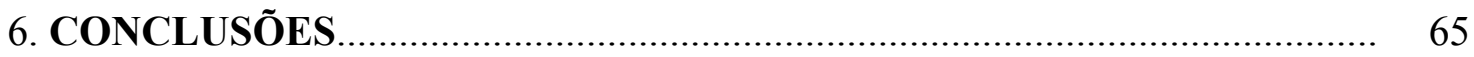

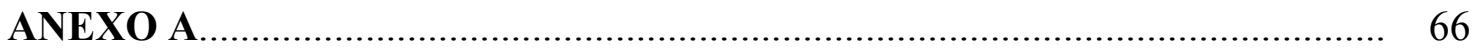

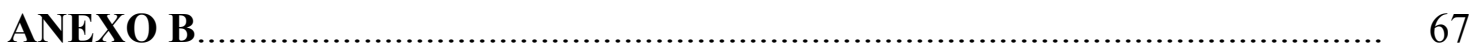

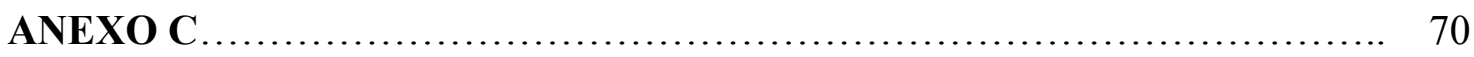

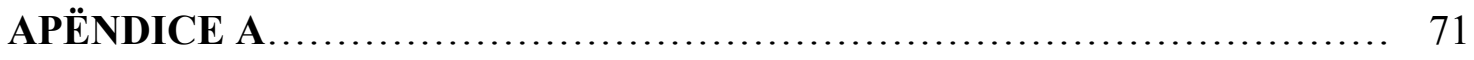

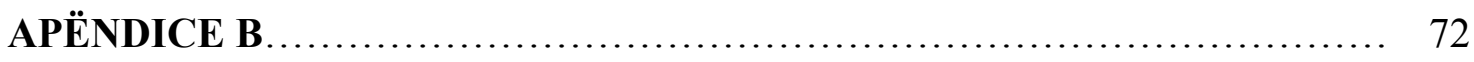

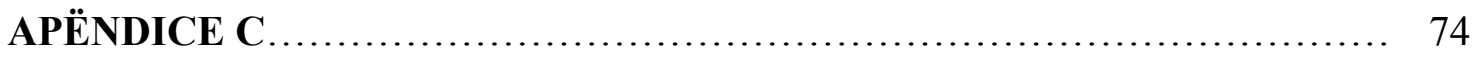

REFERÊNCIAS BIBLIOGRÁFICAS................................................... 82 


\section{LISTA DE TABELAS}

página

TABELA 2.1: Representação do número relativo de processos (efeito fotoelétrico, espalhamento Compton e produção de pares) e energia depositada por elétron em cada processo (\%) em função da energia do fóton incidente

TABELA 3.1: Relação entre o tecido do corpo humano, com densidade conhecida e os respectivos números de CT, para fins de calibração de tomógrafos. Disponível em: <http://www.if.ufrgs.br/ast/med/images/node4.htm>. Acesso em 20 jul.2008

TABELA 5.1: Relação entre valores experimentais e teóricos dos coeficientes de atenuação de materiais inseridos colocados nos orifícios do phantom.

ANEXO A: Coeficientes de atenuação de massa $\left(\mathrm{cm}^{2} / \mathrm{g}\right)$, referentes ao efeito fotoelétrico, Compton, Rayleigh e produção de pares, em função da energia dos fótons incidentes para dois meios diferentes: ar e água.

ANEXO C: Esquema de uma matriz de unidades tomográficas ou número de CT. Os números em vermelho na área central representam a matriz selecionada para a determinação do valor médio de $C T$ dos materiais usados na calibração do tomógrafo. 


\section{LISTA DE FIGURAS}

Página

FIGURA 1.1: Representação geral de um sistema SPECT. Adaptado de: $<$ http://www.asnt.orgpublicationsMaterialsevalbasicsmay00basicsmay00basfig1.htm>. Acesso em 20 jul.2008. 15

FIGURA 1.2: Representação de um sistema PET utilizado em medicina nuclear. Adaptado de: $<$ http://en.wikipedia.org/wiki/Positron_emission_tomography $>$ Acesso em 28 jul. 2008 .

FIGURA 2.1: Representação da atenuação (a) fótons incidentes em função da espessura de um meio absorvedor de coeficiente de atenuação $\mu=01 / \mathrm{cm}$ e (b) gráfico que representa esta atenuação (b). Adaptado de:

$<$ http://www..ndted.org/EducationResources/CommunityCollege/Radiography $>$. Acesso em 20 jul. 2008 .

FIGURA 2.2: Ilustrações do efeito fotoelétrico, (a) esquema nas camadas eletrônicas e (b) elétron ejetado da matéria. Adaptado de: $<$ http://mxp.physics.umn.edu $>$. Acesso em: 20 ab. 2008 24

FIGURA 2.3: Secção de choques para o efeito fotoelétrico em função do ângulo e a distribuição de energia do feixe de radiação. Figura modificada (Sauter,1931).

FIGURA 2.4: Ilustrações do espalhamento Compton. (a) fóton incidente e o elétron ejetado e (b) os ângulos de espalhamento $\theta$ e $\varphi$ e os comprimentos de onda $\lambda i_{\text {(incidente) }} \lambda f$. Adaptado de: <http://en.wikibooks.org/wiki/Basic.cph-theory. persiangig.com/1197>. Acesso em: 20 ab. 2008.

FIGURA 2.5: Gráficos representativos das diferentes energias dos fótons incidentes e os 
correspondentes valores da secção de choque diferencial de Compton. Figura modificada (John, 1983)

FIGURA 2.6: Coeficientes de atenuação parcial e total na água. Adaptado de: $<$ http://physics.nist.gov/cgi-bin/Xcom/xcom>.Acesso em: 14 set. 2008

FIGURA 2.7: Probabilidade de ocorrência de efeito fotoelétrico, espalhamento Compton e produção de pares, em função da energia da radiação eletromagnética incidente e do número atômico $\mathrm{Z}$ do absorvedor. Disponível em:

$<$ http://www.fsc.ufsc.br/ canzian/intrort/fig-schoque> .Acesso em 03 jan.2008

FIGURA 3.1: Representação dos elementos de volume e retrato: (a) voxels e (b) pixels.

FIGURA 3.2: As projeções $\mathrm{P}(\mu, \theta)$ são compostas das somas das contagens de radioatividade do volume ao longo de linhas perpendiculares ao detector, em um determinado ângulo $\theta$.

FIGURA 3.3: Representação de um pulso retangular (a) que pode ser integrado de forma a se obter uma amplitude de sinal compatível com o pulso (b).

FIGURA 3.4: Representação de tomógrafos de $1^{a}$ geração em (a) e $2^{a}$ geração em (b)....... 48

FIGURA 3.5: Representação do sistema de tomografia de $3^{\text {a }}$ geração, (a) objeto centralizado em relação ao sistema fonte/detectores e (b) objeto descentralizado. Nesta geração utiliza-se um sistema de múltiplos detectores.

FIGURA 3.6: Representação da tomografia de $4^{a}$ geração mostrando a fonte de radiação, o objeto centralizado e o anel de detectores (Quoirin, 2004).

FIGURA 3.7: Representação esquemática de tomografia de $5^{\text {a }}$ geração. Adaptado de: $<$ http://www.prorad.com.br/pro/Tomo.pdf $>$ Acesso em: 24 jul. 2008. 
FIGURA 3.8: Sistema tomográfico constituído (a) fonte radioativa objeto a ser tomografado e conjunto de detectores, (b) Sistema tomográfico considerando a matriz reticulada ("pixelizada")

FIGURA 3.9: Equipamento em desenvolvimento no CTR-IPEN-CNEN/SP: (a) Sistema de múltiplos detectores de radiação e (b) sistema detector de radiação único de plástico cintilador, sensível à posição

FIGURA 4.1: Rochas ígneas brasileiras (a) com texturas microlíticas, aberta e polida, de considerável beleza em sua estrutura interna cristalina e (b) amostras "in natura"

FIGURA 4.2: Fotografia do tomógrafo do CTUT.

FIGURA 4.3: Fotografias do equipamento utilizado no exame tomográfico computadorizado da rocha no CTUT. 56

FIGURA 4.4: Reprodução do equipamento tomográfico computadorizado desenvolvido no CTR-IPEN-CNEN/SP

FIGURA 4.5: Vista lateral do tomógrafo computadorizado experimental instalado no CTR- IPEN-CNEN/SP

FIGURA 4.6: Phantom construído com polipropileno contendo dois orifícios de $5 \mathrm{~cm}$ de diâmetro. Este phantom foi especialmente preparado e construído na Universidade de Bergen, Noruega para servir como controle de qualidade em laboratórios participantes do projeto internacional de desenvolvimento de tomografia computadorizada financiado pela Agência Internacional de Energia Atômica (AIEA)

FIGURA 4.7: (a) Posicionamento da rocha no tomógrafo do CTR-IPEN-CNEN/SP e (b) a rocha na posição inicial para ser submetida ao exame tomográfico.

FIGURA 5.1: Imagens tomográficas do phantom: (a) figura tomográfica utilizando o 
tomógrafo do CTR-IPEN-CNEN/SP, com os dois orifícios contendo apenas ar e (b) um dos orifícios preenchido com óleo de canola

FIGURA 5.2: Imagens tomográficas obtidas: (a) tomógrafo CTUT (Texas-USA) e (b) tomógrafo do CTR-IPEN-CNEN/SP. Cortes longitudinais na região central do interior da rocha. A imagem obtida com a radiação gama $\left({ }^{60} \mathrm{Co}, \mathrm{E} \approx 1250 \mathrm{keV}\right)$ observa-se melhor diferenciação de densidade comparativamente à imagem obtida com raios $\mathrm{X}(415 \mathrm{kV}, \mathrm{E}$ $\approx 140 \mathrm{keV})$

FIGURA 5.3: Na fotografia é mostrada a rocha ígnea seccionada ao meio

FIGURA 5.4: Imagem tomográfica da região onde a rocha foi seccionada obtida no CTR-IPEN-CNEN/SP. Os valores da coluna esquerda da figura referem-se ao coeficiente de atenuação do material interno da rocha $\left(\mathrm{cm}^{-1}\right)$ 


\section{INTRODUÇÃO}

A utilização da Tomografia Computadorizada $\left(\mathrm{TC}^{1}\right)$ iniciou-se na área médica e tornou-se indispensável em alguns exames diagnósticos. A introdução do primeiro aparelho comercial de TC é atribuída ao engenheiro britânico Godfrey Newbold Hounsfield (光28/08/1919 - や12/08/2004), que pela sua contribuição recebeu o prêmio Nobel de Medicina em 1979. As aplicações da TC foram ampliadas para vários campos da atividade humana e abriram um vasto campo na pesquisa e em diversas áreas do conhecimento, principalmente nas aplicações industriais.

Os investimentos para aprimorar métodos de obtenção de imagens tomográficas são justificados, uma vez que a TC possibilita um detalhamento preciso das características tridimensionais no interior dos objetos. A TC pertence ao universo dos ensaios não destrutivos que permitem avaliação não invasiva do objeto e, consequentemente, sem danificá-lo. Trata-se de um ensaio que, em princípio, pode ser realizado sem interromper o funcionamento do objeto. $\mathrm{E}$, neste particular, atende às necessidades da indústria, pois permite avaliar o interior de componentes $\mathrm{e}$ equipamentos da produção industrial, sem necessitar interromper o processo de produção. Neste caso, só será necessário interromper a atividade da produção industrial para efetuar as devidas correções, quando forem comprovadas pela TC as avarias internas e comprometedoras nos objetos da linha de produção.

Basicamente, distinguem-se dois tipos de TC, a saber: $1^{\circ}$ ) quando o objeto interfere externamente a algum sinal físico, como por exemplo, a atenuação de um feixe de radiação $\mathrm{X}$ ou gama oriundo de uma fonte externa ao objeto e $2^{\circ}$ ) quando o sinal físico tem origem no interior do objeto, como por exemplo, o objeto contém material radioativo em seu interior. No primeiro caso trata-se da tomografia por transmissão, SPECT (Single Photon Emission Computed Tomography), cuja FIG 1.1 mostra uma representação deste sistema.

\footnotetext{
${ }^{1} \mathrm{O}$ termo tomografia computadorizada será abreviado por TC. A sigla CT é utilizada especialmente na área médica no Brasil.
} 


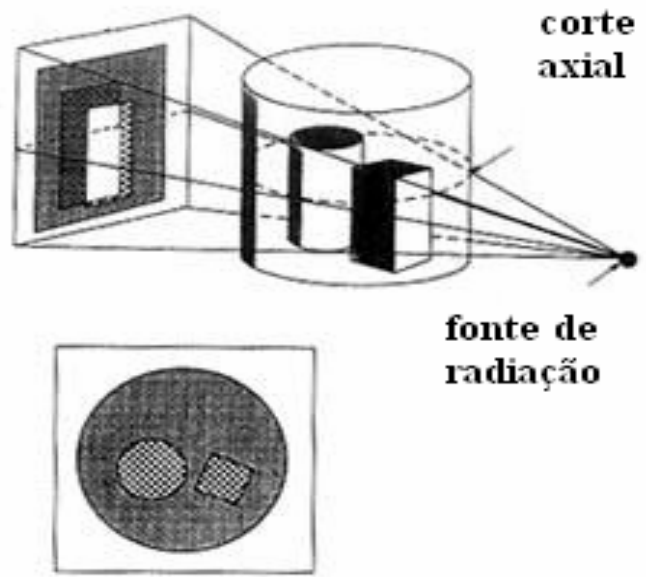

imagem de $\mathrm{TC}$

FIGURA 1.1: Representação geral de um sistema SPECT. Adaptado de: $<$ http://www.asnt.orgpublicationsMaterialsevalbasicsmay00basicsmay00basfig1.htm>. Acesso em 20 jul.2008

O segundo caso é denominado de TC por emissão, PET (Pósitron Emission Tomography), cuja representação é mostrada na FIG. 1.2.

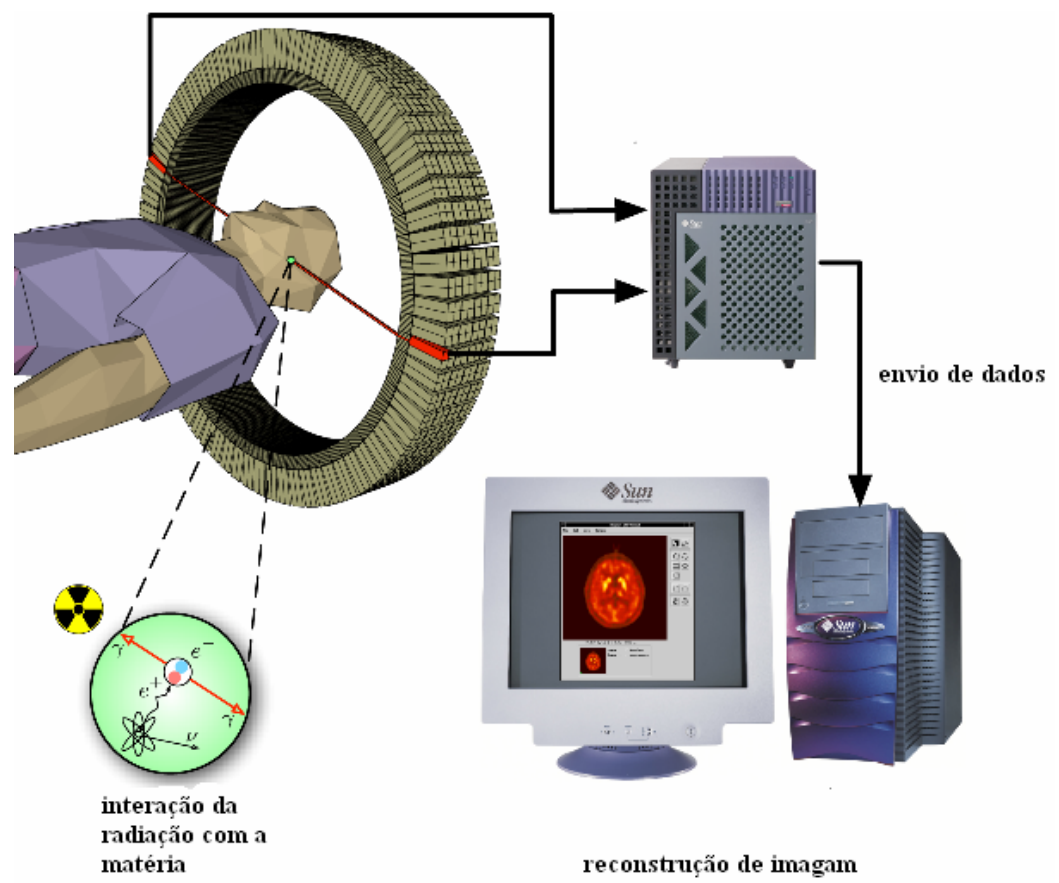

FIGURA 1.2: Representação de um sistema PET utilizado em medicina nuclear. Adaptado de: $<$ http://en.wikipedia.org/wiki/Positron_emission_tomography>. Acesso em 28 jul. 2008. 
$\mathrm{O}$ reconhecimento das diferentes densidades referentes às substâncias que compõem o interior de um objeto permite a obtenção das imagens tomográficas. As densidades são identificadas com a medida da atenuação de feixes de radiação que o atravessam e que são sistematicamente analisadas a posteriori. Ao atravessar o interior de uma amostra, os feixes de radiação atingem os detectores posicionados ao lado oposto do objeto de estudo, de modo que este objeto fique posicionado entre a fonte radioativa e o sistema de detectores. Existem algumas variações nas técnicas mecânicas em tomografia, de forma que os detectores podem ser fixos. Neste caso o objeto sofre rotação e translação ou, os detectores e a fonte podem ser colocados dentro de uma estrutura denominada "granty", que se movimenta ao redor do objeto. O objetivo é fazer uma análise da atenuação do feixe de radiação, que atravessa o objeto utilizando-se os dados registrados em vários ângulos de tomadas de medidas, até que se complete uma rotação de $360^{\circ}$ ao redor do objeto.

Ao interagir com as diferentes densidades do material interno da amostra, o feixe que atinge o detector gera sinais que são registrados e em seguida processados em um sistema computacional, constituindo-se em uma imagem digital. Isto tudo é possível porque quando a radiação interage com o detector, os fótons de luz se espalham dentro deste e, sinais gerados podem ser fotos multiplicados ou processados.

Diversos arranjos de detectores podem ser utilizados ao redor do objeto e a obtenção dos dados promove resultados quantitativos, através do uso de algoritmos matemáticos de reconstrução e subseqüente digitalização das imagens.

\subsection{Breve histórico}

Nos anos 30, com o uso de uma fonte de raios $\mathrm{X}$ e detectores de radiação, colocados no lado oposto ao objeto, já se obtinham imagens bidimensionais a partir de objetos tridimensionais, estes detectores se movimentavam durante a formação da imagem completando uma rotação completa. As imagens nesta época eram obtidas por meio de cálculos matriciais, que além de mais demorados, compunham imagens com muitos ruídos e em função da pouca nitidez, eram impraticáveis para o uso médico diagnóstico. Hoje, alguns pesquisadores chamam aquela técnica de "tomografia clássica" (Jaszczak, 2006). 
Nos anos 70, com a introdução dos sistemas computacionais associados às técnicas tomográficas que já vinham sendo desenvolvidas, foram introduzidos no mercado os aparelhos tomográficos então primeiramente denominados de Computed Axial Tomograph (CAT) (Mallard, 2003).

No início do século XX também foram desenvolvidas as bases matemáticas de construção de imagens que fundamentaram os cálculos matriciais da TC. O matemático austríaco Johann Radon (1887-1956), em 1917, desenvolveu as bases algébricas de projeções espaciais. Estas projeções espaciais constituem-se de uma série de integrais em duas dimensões, que ao serem projetadas ao longo de uma linha definida, considerando um número delimitado de linhas, fornecem uma fórmula de inversão que possibilitam a construção algébrica da imagem. As integrais conhecidas como integrais de Radon (Kirsch, 1996) transformam as informações bidimensionais em algoritmos para imagem plana.

As teorias matemáticas necessárias para formação de imagens tomográficas se fundamentaram inicialmente nas técnicas de projeções bidimensionais de Radon e foram complementadas pelo físico sul africano, naturalizado americano, Allan Macleod Comarck (1924-).

Comarck foi prêmio Nobel de Medicina e Fisiologia em 1979 junto com Hounsfield pelo desenvolvimento da Tomografia Computadorizada. Ele pressupôs (Comarck, 1963) que um feixe planar de radiação penetrante, ao ser projetado em diferentes ângulos sobre um determinado corpo, pode fornecer uma imagem muito melhor do que as então conhecidas imagens radiográficas convencionais. A técnica que ele então propôs, mostrou-se mais eficiente porque com múltiplas tomadas de dados, as imagens são mais confiáveis uma vez que são formadas com maiores quantidades de informações.

As técnicas tomográficas propostas naquela época na obtenção de imagens consagraram-se no uso médico diagnóstico e em outras áreas de pesquisas, uma vez que elas permitem uma visão espacial do objeto estudado. Estas imagens foram se tornando cada vez mais nítidas e como já foi referida anteriormente, não invasiva.

Hounsfield desenvolveu o primeiro tomógrafo comercial com as bases fundamentadas no trabalho de Comarck (1963). Existem, entretanto, relatos de 
experimentos utilizando-se a tomografia computadorizada com emissão de fótons, desde meados de 1950 (Jaszczak, 2006).

Denominou-se tomografia por transmissão, a técnica em que a fonte de radiação é posicionada externamente ao corpo a ser estudado. A fonte também pode ser introduzida no corpo a ser estudado utilizando-se as mesmas técnicas; esta versão tomográfica foi denominada de tomografia por emissão. Conforme foi demonstrado por Edwards e Kuhl (Kuhl, 1963) podem-se obter imagens morfológicas e funcionais usando-se o SPECT (Single Photon Emission Computed Tomography). Depois, outro tomógrafo foi desenvolvido utilizando-se emissores de pósitrons, por exemplo, o Flúor $18\left({ }^{18} \mathrm{~F}\right)^{2}$, o sistema foi denominado de PET (Positron Emission Tomography). As imagens morfológicas e funcionais mostradas pelo SPECT e PET, são hodiernamente de ampla aplicação nos campos da neurologia, oncologias, cardiologia, urologia, músculo esquelético, dentre outros.

Entre 1958 e meados de 70, os cientistas americanos Edwards e Kuhl (Kuhl \& Edwards, 1968) no Hospital da Universidade da Pensilvânia, iniciaram inúmeras pesquisas em tomografia por emissão. De acordo com o próprio Kuhl' em contribuição ao artigo de Jaszczak (2006) o marco inicial da aplicação das técnicas de TC foram os trabalhos realizados por ele e sua equipe. Segundo o próprio Kuhl (1963): “inventamos uma série de tomógrafos computadorizados por emissão e os correspondentes procedimentos que favoreceram a compreensão da seção de choque da tomografia por emissão para a medicina e estes foram os verdadeiros precursores dos atuais SPECT, PET e CT", pode-se entender o que eles também se consideram inventores da TC.

John R. Mallard (2003) reforçou a importância de seu trabalho em pesquisas de TC e de seus colegas da seguinte forma: "A tomografia foi realizada inicialmente em 1964 por Dave Kuhl, um especialista em medicina nuclear na Filadélfia, por uma técnica análoga a que utilizamos em nossas pesquisas naquela época. Minha equipe em Aberdeen construiu o primeiro TC digital para distribuições de radioisótopos entre 1967 e 1969. Desde então, diversas pesquisas em tomografia computadorizada vêm se desenvolvendo rapidamente em todo o mundo".

\footnotetext{
${ }^{2} \mathrm{O}{ }^{18} \mathrm{~F}$ é um radioisótopo de meia-vida de 109,74 min. Este radioisótopo é produzido em acelerador ciclotron no IPEN-CNEN/SP.
} 
Por outro lado, nos últimos dez anos, as técnicas de obtenção de imagens por TC vêm sendo desenvolvidas para campos de pesquisa científica e seu uso entendido em diversos setores industriais.

\subsection{Objetivos}

Neste trabalho propõe-se prestar uma contribuição da tomografia computadorizada nas aplicações científicas e industriais. Este trabalho tem como objetivo desenvolver no ambiente do $\mathrm{CTR}^{3}-\mathrm{IPEN}^{4}-\mathrm{CNEN}^{5} / \mathrm{SP}$ um sistema tomográfico voltado para as aplicações industriais.

Como qualquer nova proposta metodológica é requerida que a mesma seja comparada com outra já aceita pela comunidade científica. Assim o tomógrafo proposto neste trabalho será comparado com o tomógrafo do laboratório de tomografia de raios $\mathrm{X}$ de alta resolução da Universidade do Texas $\left(\mathrm{CTUT}^{6}\right)$. Neste laboratório o objeto do presente estudo (pedra proveniente de uma rocha ígnea) foi tomografada utilizando-se a fonte de raios X. O CTUT foi construído há mais de dez anos no Instituto de Geociências da Universidade do Texas e é considerado como referência de qualidade.

Além da comparação inter-laboratórios o tomógrafo aqui desenvolvido será submetido aos ensaios de controle de qualidade utilizando-se um phantom especialmente projetado pela Universidade de Bergen, na Noruega e fornecido pela AIEA (Agência Internacional de Energia Atômica).

O objeto de estudo neste trabalho constituiu da análise tomográfica de uma pedra ígnea cujo conteúdo interior era desconhecido na fase inicial do projeto, antes das medidas realizadas na Universidade do Texas e das tomadas tomográficas no Brasil. Após as imagens tomográficas a pedra foi seccionada e comparada com as imagens obtidas.

\footnotetext{
${ }^{3}$ CTR é a abreviação para designar o Centro de Tecnologia das Radiações

${ }^{4}$ IPEN - Instituto de Pesquisas Energéticas e Nucleares.

${ }^{5}$ CNEN - Comissão Nacional de Energia Nuclear, órgão vinculado ao Ministério de Ciência e Tecnologia.

${ }^{6}$ CTUT - Computadorized Tomography of the University of Texas.
} 


\section{FUNDAMENTOS TEÓRICOS}

\subsection{Revisão Bibliográfica}

Em 1972, Hounsfield desenvolveu o primeiro tomógrafo comercial com as bases fundamentadas no trabalho de Allan Macleod Comarck (1963), físico sul africano, naturalizado americano. Existem, entretanto, relatos de experimentos utilizando-se a tomografia computadorizada com emissão de fótons, Positrons Emission Tomography (PET) desde meados de 1950 e por transmissão, Single Photon Emission Computed Tomography (SPECT), relatados por Kuhl \& Edwards (1963).

Denominou-se tomografia por transmissão ou SPECT (Single Photon Emission Computed Tomography), conforme foi demonstrado por Kuhl \& Edwards (1963). A técnica consistia basicamente em uma fonte de radiação posicionada externamente ao corpo a ser estudado e um detector. Depois, outro tomógrafo foi desenvolvido utilizando-se emissores de pósitrons, por exemplo, o ${ }^{18} \mathrm{~F}$ e o sistema foi denominado PET (Positron Emission Tomography). A fonte é introduzida no objeto a ser estudado utilizando-se as mesmas técnicas, esta versão tomográfica foi denominada de tomografia por emissão (Tanaka, 1995; Jaszczak, 2006).

De acordo com John R. Mallard (2003), desde 1064, diversas pesquisas em tomografia computadorizada vêm se desenvolvendo rapidamente em todo o mundo, uma vez que a descoberta desta técnica é considerada um marco na área de medicina diagnóstica. As imagens morfológicas e funcionais mostradas pelo SPECT e PET, são hodiernamente de ampla aplicação nos campos da neurologia, oncologias, cardiologia, urologia, músculo esquelético e outros.

$\mathrm{Na}$ Universidade de Bergen (UiB) foi criado em 1986 um Programa de Instrumentação Industrial no Departamento de Física. A finalidade deste programa foi de fortalecer a criação e desenvolvimento das tecnologias orientadas para ensino e investigação científica. A investigação concentrada em instrumentação para a indústria petrolífera introduziu, em 1993, na UiB, um projeto de obtenção de imagens por tomografia computadorizada, que teve como propósito de se reconhecer os níveis das 
fases componentes nos campos de petróleo do Departamento de Física e Tecnologia da Universidade de Bergen (2004) ${ }^{7}$.

Em 1997, o Departamento de Ciências Geológicas da Universidade de Austin, Texas, inaugurou o primeiro laboratório de $\mathrm{TC}$ com raios $\mathrm{X}$ de alta resolução, cujo equipamento é dedicado às pesquisas acadêmicas. $O$ sistema de varredora de Universidade do Texas (UT) pode resolver pequenos detalhes, a partir de décimos de mícron, dentro de objetos constituídos por material de alta densidade como rocha, osso, cerâmica ou metal. Estudos sobre os artefatos gerados pelo endurecimento do feixe de raios $\mathrm{X}$ e as imagens geradas com utilização de filtros metálicos são trabalhos desenvolvidos por Ketcham (2001).

No Brasil há alguns grupos de pesquisas em imagens tomográficas como, por exemplo, o grupo de Física das radiações do Centro Federal de Educação Tecnológica do Paraná (CEFET-PR), onde se desenvolvem pesquisas em tomografia industrial, dosimetria, proteção radiológica, densitometria, processamento de imagens tomográficas e softwares para reconstrução de imagens tomográficas (Souza, 2002). Outro grupo importante de pesquisas nesta área é o da Universidade Federal do Rio de Janeiro, cuja linha de pesquisa é de Reconstrução de Imagens por Tomografia Computadorizada.

Alguns grupos de pesquisas na área de tomografia industrial têm como foco principal o desenvolvimento de técnicas de obtenção de imagens tomográficas, sendo um desafio científico a utilização destas técnicas desenvolvidas nos sistemas multifásicos. Um trabalho inicial visando especificamente a área de engenharia de petróleo foi desenvolvido na Universidade Estadual de Campinas (Paiva, 1990; Holleben, 1993).

O grupo de pesquisa do IPEN-CNEN/SP de acordo com o Plano Diretor de 2005 se comprometeu a desenvolver um sistema computadorizado de tomografia com raios gama para fins industriais (Mesquita et al, 2005).

\footnotetext{
${ }^{7}$ Disponível em: <http://web.ift.uib.no/ie/inst/ptib.html>. Acesso em: 24 nov. 2007
} 


\subsection{A interação da radiação com a matéria}

Ao atravessar a matéria, a radiação pode ser absorvida por vários processos conhecidos, dependendo da natureza e da energia do feixe e também das características do meio por onde se propaga. Algumas situações de cálculos de blindagem podem ser resolvidas pelo conhecimento dos processos pelos quais as radiações eletromagnéticas interagem com a matéria.

A equação de atenuação do feixe de radiação incidente de intensidade I é muito conhecida (EQ.2.1):

$$
\mathbf{I}=\mathbf{I}_{0} \mathrm{e}^{-\mu x}
$$

Sendo $\mathbf{I}_{\mathbf{0}}$ é a intensidade inicial do feixe que diminui com a passagem deste dependendo das características e espessura do meio absorvedor, ou seja, do coeficiente de atenuação $\boldsymbol{\mu}$ e espessura x. A FIG. 2.1 mostra a atenuação dos fótons incidentes em função da espessura de um meio absorvedor de coeficiente de atenuação $\mu=0,1 / \mathrm{cm}$.

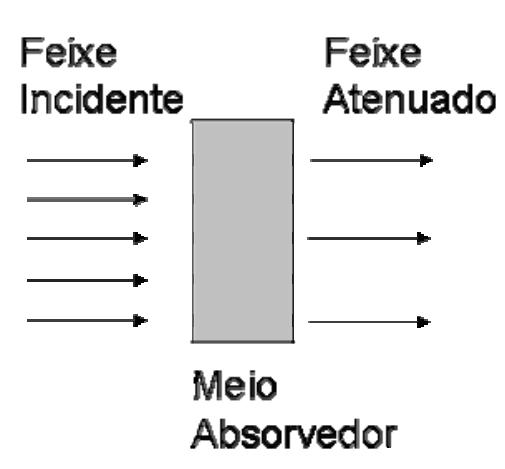

(a)

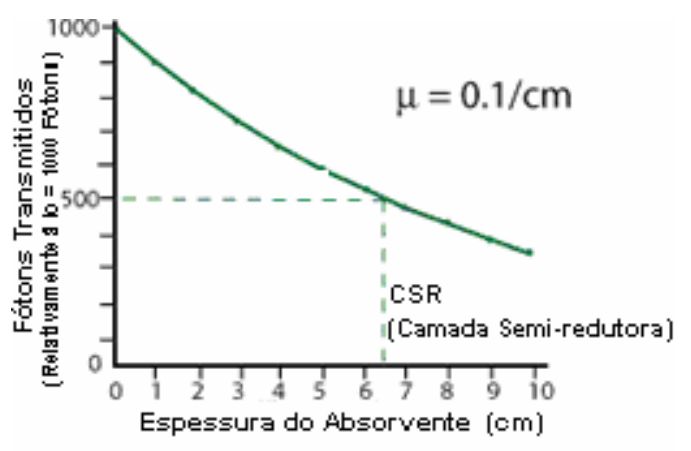

(b)

FIGURA 2.1: Representação da atenuação (a) fótons incidentes em função da espessura de um meio absorvedor de coeficiente de atenuação $\mu=01 / \mathrm{cm}$ e (b) gráfico que representa esta atenuação (b). Adaptado de:

$<$ http://www.ndted.org/EducationResources/CommunityCollege/Radiography $>$. Acesso em 20 jul. 2008. 
Os processos de interação da radiação com a matéria depositam parte da energia incidente dos fótons com a interação, ou ainda, excitam o átomo de forma que os efeitos produzidos dependerão de alguns fatores conhecidos. A atenuação da radiação eletromagnética, por exemplo, os raios $\mathrm{X}$ e raios gama, através da matéria, envolve principalmente quatro interações: efeito fotoelétrico, espalhamento Rayleigh, efeito Compton e produção de pares (John, 1983).

No efeito fotoelétrico o fóton dissipa toda essa energia no choque com o elétron do átomo (Kambic, 1977; Serway, 1990). Uma análise quantizada do efeito fotoelétrico utiliza as equações de Einstein, EQ. 2.2 (energia do fóton = energia necessária para remover um elétron + Energia cinética do elétron emitido). As equações que se seguem, representam um estudo da energia envolvida no efeito fotoelétrico a partir das equações de Einstein e Planck:

$$
h f=\phi+E_{c \max }
$$

Na qual $\boldsymbol{h}$ é a constante de Planck, e $\boldsymbol{f}$ é a frequência do foton incidente, e

$$
\phi=h f_{0}
$$

Ф é a função trabalho, ou energia mínima exigida para remover um elétron de sua ligação atômica, e:

$$
E_{c \max }=\frac{1}{2} m v_{m}^{2}
$$

$\mathbf{E}_{\mathbf{c m a x}}$ é a energia cinética máxima dos elétrons expelidos, $\boldsymbol{f}_{\boldsymbol{0}}$ é a frequência mínima para o efeito fotoelétrico ocorrer, $\boldsymbol{m}$ é a massa de repouso do elétron expelido, e $v_{\boldsymbol{m}}$ é a velocidade dos elétrons expelidos.

Se a energia do fóton $(\boldsymbol{h} f)$ for menor do que a função trabalho $(\boldsymbol{\varphi})$, nenhum elétron será emitido. A FIG. 2.2 (a) é uma representação do efeito fotoelétrico no átomo e (b) na matéria. 


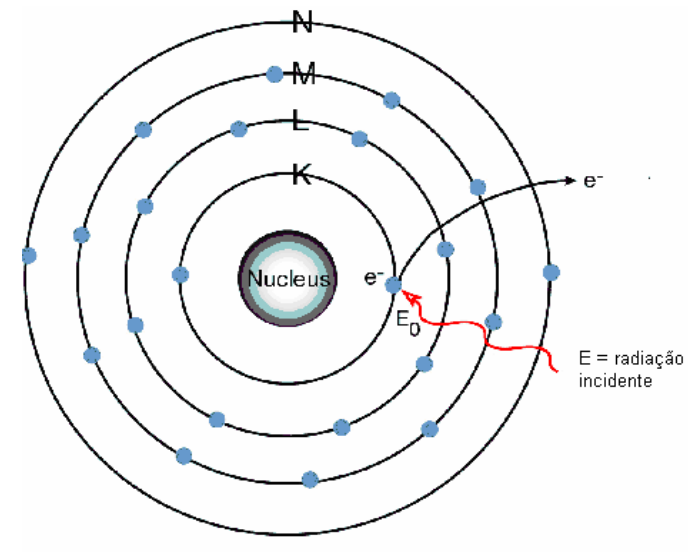

(a)

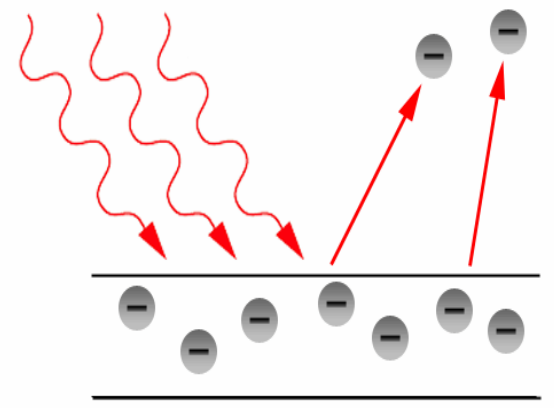

(b)

FIGURA 2.2: Ilustrações do efeito fotoelétrico, (a) esquema nas camadas eletrônicas e (b) elétron ejetado da matéria. Adaptado de: $<$ http://mxp.physics.umn.edu $>$. Acesso em: 20 ab. 2008.

Para absorvedores de baixo número atômico, a energia $\mathbf{E}$ é pequena de forma que o elétron adquire toda a energia do fóton. Os ângulos em que os elétrons são ejetados costumam compatibilizar com o nível de energia de ejeção e a secção de choque, para o efeito fotoelétrico, é conhecida em alguns materiais.

A incidência do efeito fotoelétrico de acordo com a energia do feixe de radiação emitido é encontrada na literatura, como se pode observar no gráfico a seguir (FIG. 2.3), no qual é mostrada a distribuição angular dos fotoelétrons para várias energias gama. Este gráfico foi obtido por Sauter, 1931.

Verifica-se que o pico mais acentuado deve-se à energia de feixe na faixa dos 1,3 MeV sendo que com energia de valores menores do que este a probabilidade de ocorrência do efeito fotoelétrico diminui enquanto aumenta o ângulo de espalhamento. 


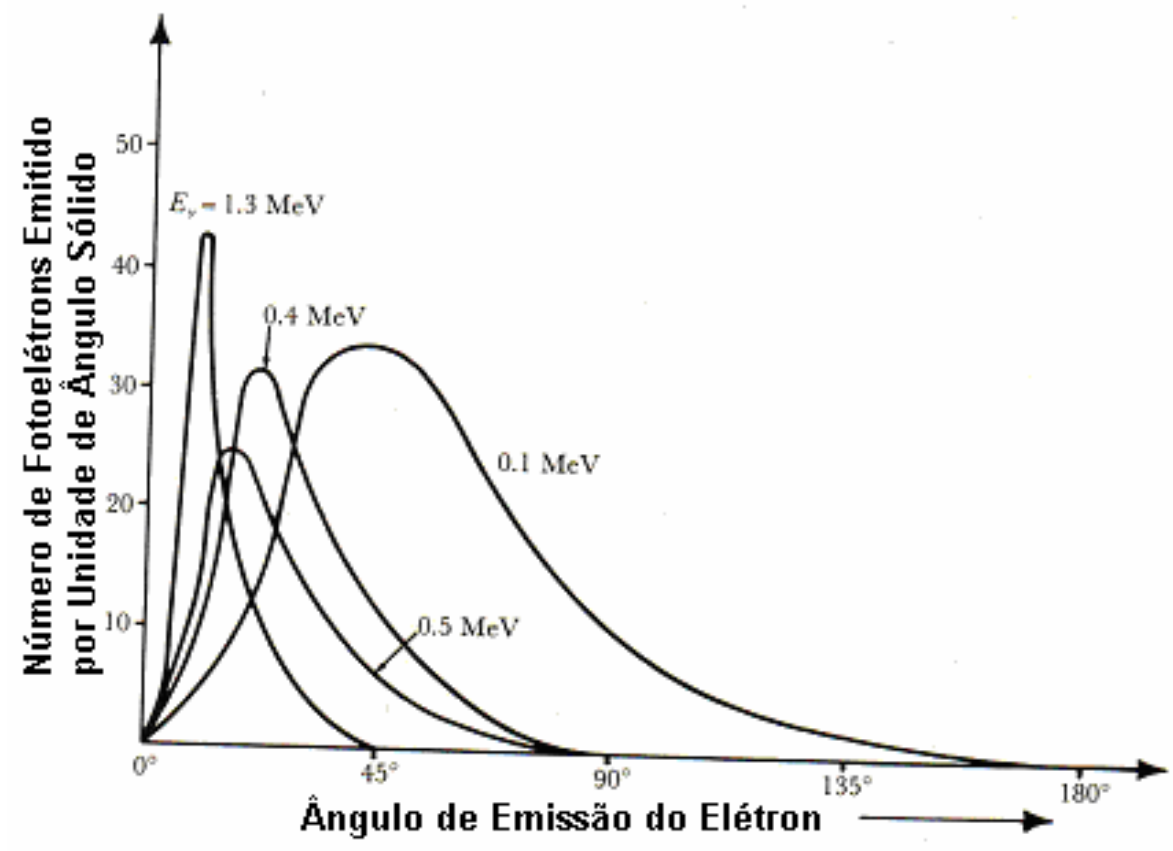

FIGURA 2.3: Secção de choques para o efeito fotoelétrico em função do ângulo e a distribuição de energia do feixe de radiação. Figura modificada (Sauter, 1931).

O Efeito Compton foi observado por Arthur Holly Compton (Compton, 1923), pelo qual ele recebeu o Prêmio Nobel de Física em 1927. O espalhamento de Compton ocorre em todos os materiais e predominantemente com fótons de média-energia (entre 0.5 e $3.5 \mathrm{MeV}$ ). Ele é também observado com fótons de alta-energia; fótons de luz visível ou de frequências mais altas, por exemplo, possuem energia suficiente para expelir os elétrons saltados do átomo.

No efeito Compton a radiação transfere parte de sua energia para o elétron e emerge com o restante da energia em direção diferente. A interação entre a alta energia dos fótons e elétrons resultam no elétron recebendo parte da energia, o qual recua, e um fóton contendo a energia restante sendo emitido numa direção diferente da original, sempre conservando o momentum total do sistema. Se o fóton emitido possuir ainda energia suficiente o processo pode se repetir (Christillin, 1986). 
Compton usou uma combinação de três fundamentais fórmulas representando os diversos aspectos da física clássica e moderna, combinando-os para descrever o procedimento quântico da luz como partícula: Dinâmica Relativística e Trigonometria.

Como resultado final se obtém a Equação do Espalhamento de Compton (EQ.2.5):

$$
\lambda_{2}=\frac{h}{m_{e} c}(1-\cos \theta)+\lambda_{1}
$$

Na qual: $\lambda_{1}$ é o comprimento de onda do fóton antes do espalhamento, $\lambda_{2}$ é o comprimento de onda do fóton depois do espalhamento, $\boldsymbol{m}_{\boldsymbol{e}}$ é a massa do elétron, $\boldsymbol{h} /\left(\boldsymbol{m}_{e} \boldsymbol{c}\right)$ é conhecido como o comprimento de onda de Compton, $\boldsymbol{\theta}$ é o ângulo pelo qual a direção do fóton muda, $\boldsymbol{h}$ é a constante de Planck, e $\boldsymbol{c}$ é a velocidade da luz. Coletivamente, o comprimento de onda de Compton é $2.43 \times 10^{-12} \mathrm{~m}$ (Christillin, 1986).

A dedução da equação do efeito Compton, apresentada no ANEXO B, parte da afirmação a seguir, EQ.2.6, a qual representa a conservação de energia do fóton antes e após a colisão (Chen, 2006).

$$
E_{\gamma}+E_{e}=E_{\gamma^{\prime}}+E_{e^{\prime}}
$$

Pela conservação de energia, se $E_{\gamma}$ é a energia do fóton antes da colisão e $E_{e}$ é a energia do elétron antes da colisão (sua massa em repouso), as variáveis com apóstrofe são usadas por estas respectivas energias depois da colisão, de forma que a equação a qual corresponde a conservação do momento (EQ.7) é:

$$
\overrightarrow{p_{\gamma}}+\overrightarrow{p_{e}}=\overrightarrow{p_{\gamma^{\prime}}}+\overrightarrow{p_{e^{\prime}}}
$$

Com o $p_{e}=0$, uma vez que se assume, que inicialmente o elétron em repouso. A FIG. 2.4 (a) mostra o espalhamento Compton. 


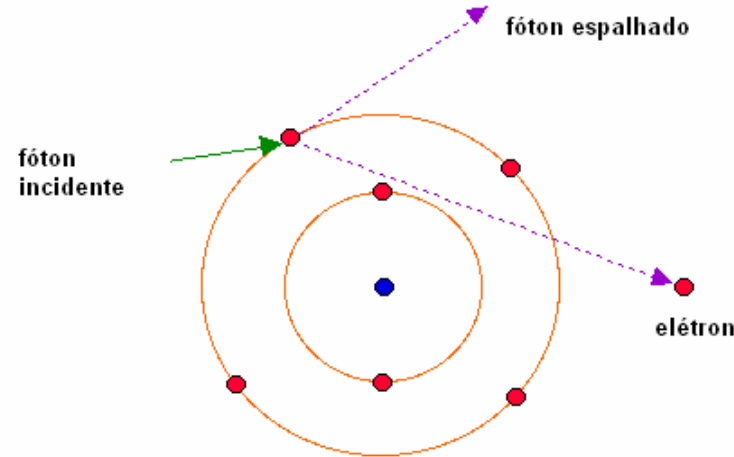

(a)

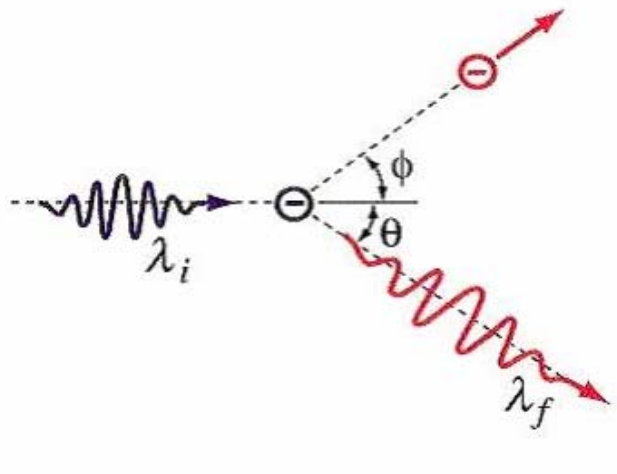

(b)

FIGURA 2.4: Ilustrações do espalhamento Compton. (a) fóton incidente e o elétron ejetado e (b) os ângulos de espalhamento $\theta$ e $\varphi$ e os comprimentos de onda $\lambda i_{\text {(incidente) }}$ e $\lambda f$. Adaptado de: <http://en.wikibooks.org/wiki/Basic.cph-theory. persiangig.com/1197> Acesso em: 20 ab. 2008.

A secção de choque diferencial do espalhamento Compton e as energias envolvidas neste efeito são mostradas no gráfico da FIG. 2.5:

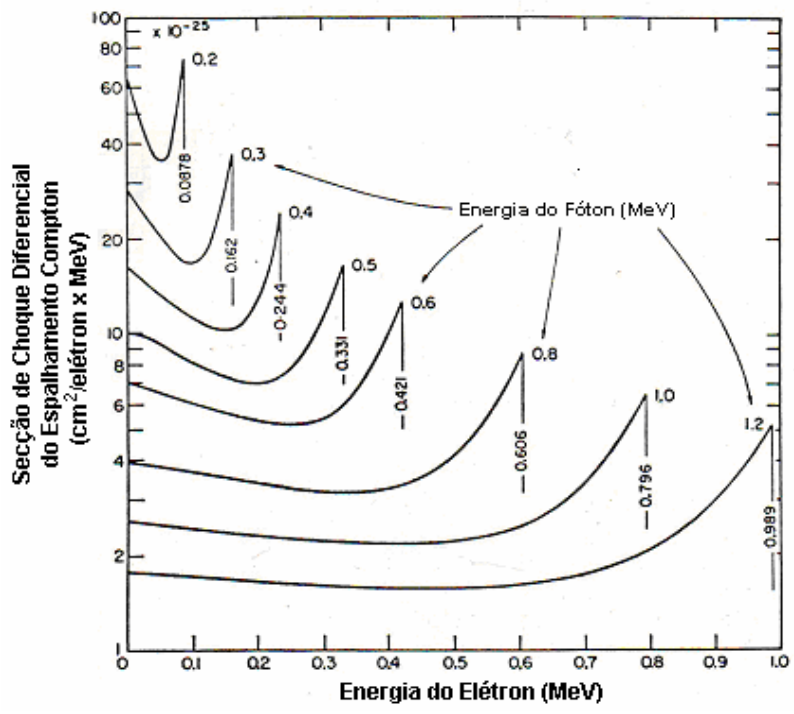

FIGURA 2.5: Gráficos representativos das diferentes energias dos fótons incidentes e os correspondentes valores da secção de choque diferencial de Compton. Figura modificada (John, 1983). 
Na produção de pares a radiação é absorvida gerando um par elétron-pósitron. A produção de pares ocorre quando fótons com energia maior ou igual a 1,02 MeV, no qual a massa de repouso de cada elétron é igual a $0,511 \mathrm{MeV}$, passam próximos a núcleos de número atômico elevado. A radiação incidente interage com o núcleo transformando-se em duas partículas, o par elétron-pósitron. A energia do fóton $\gamma$ incidente divide-se entre as partículas emitidas (Knoll, G. F., Wiley J. \& Sons, 1989), mostrados na EQ. 2.8:

$$
\gamma=\mathrm{e}^{-}+\mathrm{e}^{+}(+ \text {energia cinética })
$$

O pósitron, após ser criado, perde sua energia no meio interagindo com algum elétron, ocorre a aniquilação de ambos, originando radiação gama.

A criação de pares ocorre para altas energias e para elementos de grande número atômico. É proporcional ao quadrado do número atômico, $Z^{2}$ (Knoll, G. F., Wiley J. \& Sons, 1989).

Finalmente, o espalhamento Rayleigh é um processo em que os fótons são espalhados pelos elétrons sem arrancá-los de suas camadas de ligação e, portanto o átomo não é ionizado.

A dimensão do espalhamento da partícula é parametrizada pelo quociente $\mathbf{x}$, e é característica da sua dimensão $\boldsymbol{r}$ e comprimento de onda $\lambda$, apresentados na EQ.2.9:

$$
x=\frac{2 \pi r}{\lambda}
$$

O espalhamento Rayleigh pode ser definido como espalhamento em tamanho pequeno, com parâmetro em regime $\mathrm{x}<<1$. A quantidade de espalhamento Rayleigh em um feixe de luz é dependente do tamanho das partículas e do comprimento de onda da luz, em especial, o coeficiente de dispersão. Conseqüentemente, a intensidade da luz dispersa varia de tamanho, inversamente com a quarta potência do comprimento de onda (EQ. 2.10) . A intensidade da luz espalhada $\boldsymbol{I}$, por umas únicas pequenas partículas 
de um feixe de luz de comprimento de onda $\lambda$, não polarizada e intensidade $\boldsymbol{I}_{\mathbf{0}}$ é dada por:

$$
I=I_{0} \frac{1+\cos ^{2} \theta}{2 R^{2}}\left(\frac{2 \pi}{\lambda}\right)^{4}\left(\frac{n^{2}-1}{n^{2}+2}\right)^{2}\left(\frac{d}{2}\right)^{6}
$$

Em que $\boldsymbol{R}$ é a distância para a partícula, $\boldsymbol{\theta}$ é o ângulo de espalhamento ângulo, $\boldsymbol{n}$ é o índice de refração do meio onde a partícula está inserida e $\boldsymbol{d}$ é o diâmetro da partícula. A distribuição angular do espalhamento Rayleigh, que é regida pela função $(1+2 \cdot \cos \theta)$ é simétrica no plano normal à direção de incidência da luz. Por isso, pode ser integrada sobre a esfera em torno da partícula, o que fornece a secção transversal $\boldsymbol{\sigma}_{\mathbf{s}}$ do espalhamento Rayleigh:

$$
\sigma_{s}=\frac{2 \pi^{5}}{3} \frac{d^{6}}{\lambda^{4}}\left(\frac{n^{2}-1}{n^{2}+2}\right)^{2}
$$

O coeficiente de espalhamento Rayleigh $\boldsymbol{\sigma}_{\mathbf{s}}$, em função de um grupo de partículas é calculado pelo número de partículas por unidade de volume $N$, multiplicado pela área do corte transversal. Como acontece com todos os efeitos ondulatórios, o espalhamento é incoerente e a parcela espalhada pode ser adicionada, uma vez que as partículas estão muito perto uma das outras, os campos e adicionados referem-se às somas dos quadrados a fim de que se obtenha a potência total, com adição das partículas dispersas.

Este processo ocorre principalmente em baixas energias. Apesar do espalhamento Rayleigh praticamente não dissipar energia, o mesmo deve ser considerado no projeto do detector de radiação, pois o efeito Rayleigh é um importante fator de espalhamento dos fótons e, conseqüentemente, tem uma influência considerável na resolução da uma imagem tomográfica. 


\subsubsection{A probabilidade de ocorrência das interações}

A probabilidade de ocorrer uma dessas interações varia com o número atômico da matéria e a energia do fóton. O efeito fotoelétrico e Rayleigh predominam em baixas energias. $\mathrm{O}$ efeito Compton ocorre mais intensamente em energias próximas de $1 \mathrm{MeV}$, especialmente para material de baixo número atômico. Em energias próximas de $5 \mathrm{MeV}$ e para materiais de alto número atômico predomina o processo de produção de pares. (John, 1983; Knoll, 1989).

Quando um feixe de fótons incide em um meio absorvedor em geral, todos os processos de interação podem ocorrer simultaneamente, sendo que em cada interação ocorre um único processo (efeito fotoelétrico, espalhamento Compton e produção de pares).

O número de elétrons ejetados então deve ser calculado pela soma do número de efeitos fotoelétricos $(\tau)$, comptons $(\sigma)$ e produção de pares $(\pi)$ :

$$
\boldsymbol{\mu}=\boldsymbol{\tau}+\boldsymbol{\sigma}+\boldsymbol{\pi}
$$

A cada efeito pode-se atribuir uma porcentagem tal que:

Porcentagem de fotoelétricos $=\frac{100 \tau}{\tau+\sigma+\pi}=100\left(\frac{\tau}{\mu}\right)$

Porcentagem de elétrons Compton $=100\left(\frac{\sigma}{\mu}\right), \mathrm{e}$

Porcentagem de pósitrons ou elétrons em produção de pares $=100\left(\frac{\pi}{\mu}\right)$.

O coeficiente de absorção total de energia $\boldsymbol{\mu}_{\text {en }}$ deve ser:

$$
\mu_{\mathrm{en}}=\tau+\sigma_{\mathrm{en}}+\pi_{\mathrm{en}}
$$

Este coeficiente $\mu_{\text {en }}$ representa a fração de energia incidente por unidade de espessura do meio absorvedor por todos os processos, enquanto que o efeito tem sua própria fração de energia absorvida. Assim, a porcentagem de energia absorvida por cada efeito pode ser escrita como: 
Porcentagem de energia absorvida por fotoelétrons $=\frac{100 \tau}{\tau+\sigma_{e n}+\pi_{e n}}$

Porcentagem de energia absorvida por Comptons $=\frac{100 \sigma_{e n}}{\tau+\sigma_{e n}+\pi_{e n}}$

Porcentagem de energia absorvida por produção de pares $=\frac{100 \pi_{e n}}{\tau+\sigma_{e n}+\pi_{e n}}$

Esta razão, evoluída para a água, envolverá os dados apresentados na TAB. 2.1:

TABELA 2.1: Representação do número relativo de processos (efeito fotoelétrico, espalhamento Compton e produção de pares) e energia depositada por elétron em cada processo (\%) em função da energia do fóton incidente.

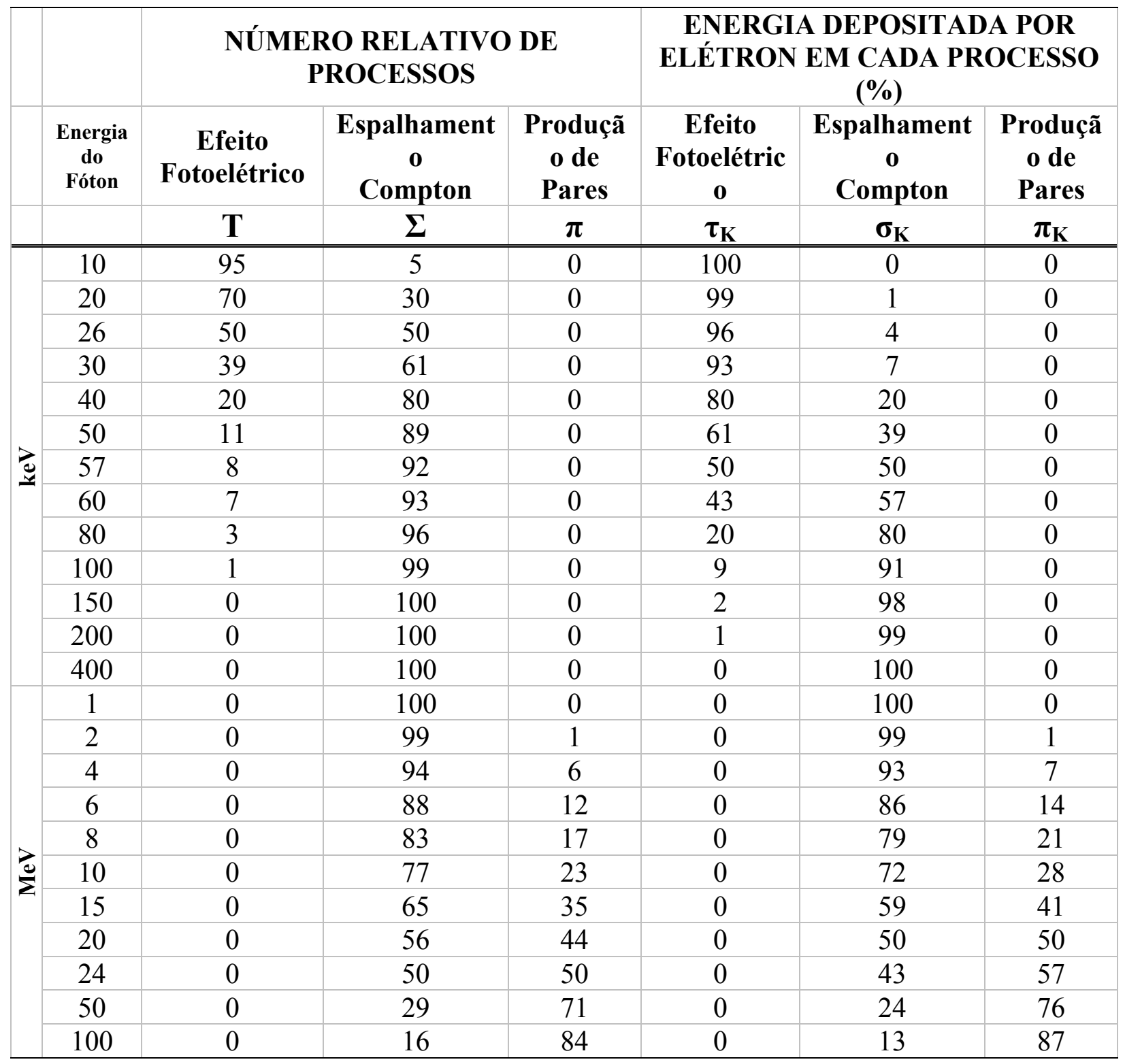




\subsubsection{Alcance e atenuação dos diferentes tipos de radiação na matéria}

Em virtude dos diferentes tipos de radiação interagir de diferentes modos com a matéria (secção 2.2.1), alguns tipos de radiação resultam mais penetrantes do que outros. Radiações eletromagnéticas são as mais penetrantes e quanto maior a sua energia, maior é o seu alcance na matéria. Partículas carregadas, devido à sua massa e carga, interagem muito intensamente com a matéria, tornando o seu alcance pequeno quando comparado ao da radiação eletromagnética. Entretanto, para partículas idênticas, quanto maior a energia maior o seu alcance.

Diferentemente do que o senso comum poderia levar a crer, a intensidade da interação com a matéria (e a interação/dano causado por ela) não cresce com a sua energia. Feixes de radiação com altíssima energia podem passar praticamente despercebidos pela matéria, enquanto radiações com energias mais baixas (da ordem das diferenças de energias dos níveis atômicos) são altamente absorvidas pela matéria. A FIG.2.6 e o ANEXO A mostram o coeficiente de atenuação de massa $\left(\mathrm{cm}^{2} / \mathrm{g}\right)$ em função da energia dos fótons incidentes para dois meios diferentes: ar e água.

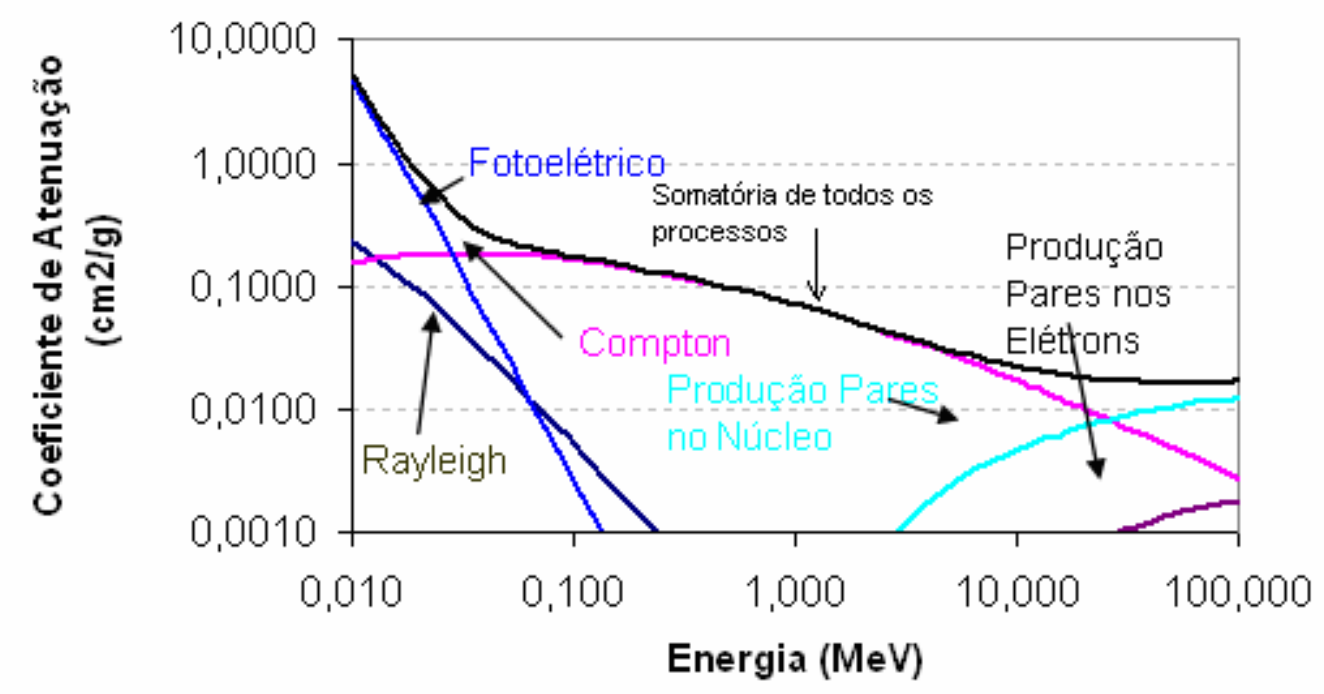

FIGURA 2.6: Coeficientes de atenuação parcial e total na água. Adaptado de:

$<$ http://physics.nist.gov/cgi-bin/Xcom/xcom> Acesso em: 14 set. 2008. 


\subsubsection{Considerações sobre a energia dos raios $X$ e radiação gama}

A radiação eletromagnética, dos tipos raios $\mathrm{X}$ e raios gama, carregam consigo energia e quantidade de movimento. Ao atravessar a matéria, a radiação interage de diversas formas, levando em consideração o tipo de radiação, a energia do feixe e as características do meio por onde se propaga. Além disso, os espalhamentos que ocorrem com a radiação resultam em interações secundárias que se acrescenta a estas interações.

Os feixes de raios X são provenientes da desaceleração de um feixe de elétrons, com uma determinada energia cinética inicial, que ao serem acelerados por uma diferença de potencial de alguns milhares de volts, atingem um alvo ocorrendo uma desaceleração muito rápida, causando a emissão dos fótons X.

Os elétrons do feixe incidente podem perder diferentes quantidades de energia nestas colisões, chegando geralmente ao repouso após várias colisões. O fóton de menor comprimento de onda seria emitido quando um elétron perdesse toda sua energia nas colisões. Desta forma o feixe de raios X não é totalmente mono energético. Dessa forma, os raios $\mathrm{X}$ emitidos por um determinado aparelho apresentam uma grande variedade de comprimento de onda, a partir do comprimento de onda mínimo.

$\mathrm{O}$ conceito de qualidade de radiação está ligado à energia do feixe de raios $\mathrm{X}$. Quando se aumenta a tensão elétrica do aparelho, aumenta-se a energia do feixe de radiação gerado, aumentando a qualidade da radiação, com conseqüente aumento do poder de penetração da mesma.

Os raios X de alta energia, geralmente produzidos com tensão superior a $120 \mathrm{kV}$ são também chamados de raios "duros". Os raios X gerados com tensão inferiores a 50 $\mathrm{kV}$ são chamados raios X "moles". O conceito de intensidade de radiação se refere à "quantidade" de raios X produzido, ou, de uma forma mais correta, ao número de "fótons" produzidos.

Quando se aumenta a corrente do filamento aumenta o aquecimento, liberando um número maior de elétrons. Isso fará com que ocorra um aumento na intensidade da 
radiação gerada, sem implicar em aumento na qualidade dessa mesma radiação. Em outras palavras pode-se aumentar a intensidade sem aumentar a energia do feixe de radiação. De uma forma prática pode-se dizer que a qualidade da radiação (energia) se relaciona com a capacidade de penetração nos materiais, enquanto que a intensidade está intimamente ligada com o tempo de exposição.

A radiação nuclear é um tipo de radiação originada no núcleo de determinados átomos de elementos químicos que não estão estáveis. Alguns núcleos são instáveis na sua composição de nuclídeos e podem decair para configurações mais estáveis. Os núcleos atômicos possuem níveis de energia discretos, análogos aos níveis dos orbitais atômicos. A transição entre estados de energia de um mesmo núcleo é acompanhada da emissão do fóton.

Em conseqüência da complexa estrutura de um átomo sobre a ação de forças elétricas, magnéticas e gravitacionais, a energia do fóton é muito grande. Os fótons emitidos pelo núcleo atômico são chamados radiação gama. Juntamente com os raios $\gamma$ as partículas alfa e beta são emitidas. As partículas $\alpha$ e $\beta$ são facilmente absorvidas, mas os raios gama são mais penetrantes, pois a sua energia é muito alta.

O Cobalto-60 $\left({ }^{60} \mathrm{Co}\right)$ é uns dos elementos radioativos artificiais, usados em ensaios industriais. Além do Cobalto-60 a indústria usa fontes seladas de outros radio nuclídeos com diferentes características físico-químicas. $\mathrm{O}{ }^{60} \mathrm{Co}$ é obtido por meio de bombardeamento por nêutrons do isótopo estável ${ }^{59} \mathrm{Co}$. Suas principais características são: meia-vida $T^{1} / 2=5,27$ anos e energia da radiação gama $=1,17$ e 1,33 MeV sendo, um radioisótopo de uso freqüente na indústria, pois na maioria das suas aplicações defronta-se com objetos densos e volumosos necessitando energias maiores do que rotineiramente se dispõem com as válvulas convencionais de raios $\mathrm{X}$.

Na FIG.2.7 mostram-se um esquema geral das regiões de predominância em termos da energia da radiação eletromagnética e do número atômico do absorvedor para as três interações: efeito fotoelétrico, espalhamento Compton e produção de pares. Para as baixas energias o efeito fotoelétrico é predominante, para as energias intermediárias o espalhamento Compton predomina e finalmente para as energias altas a produção de pares é dominante. 
Geralmente, os objetos analisados em tomografia industrial, têm grandes dimensões, como no caso das colunas de refino de petróleo. Nestes casos, para atravessar o material é necessária uma fonte de alta energia.

As partículas carregadas (alfa, elétrons, prótons, entre outros) interagem com a matéria principalmente através de forças coulumbianas com os elétrons orbitais do material. Algumas vezes podem ocorrer interações das partículas com o núcleo, como no espalhamento Rutherford, mas esses encontros são tão raros que não afetam a resposta dos detectores de radiação.

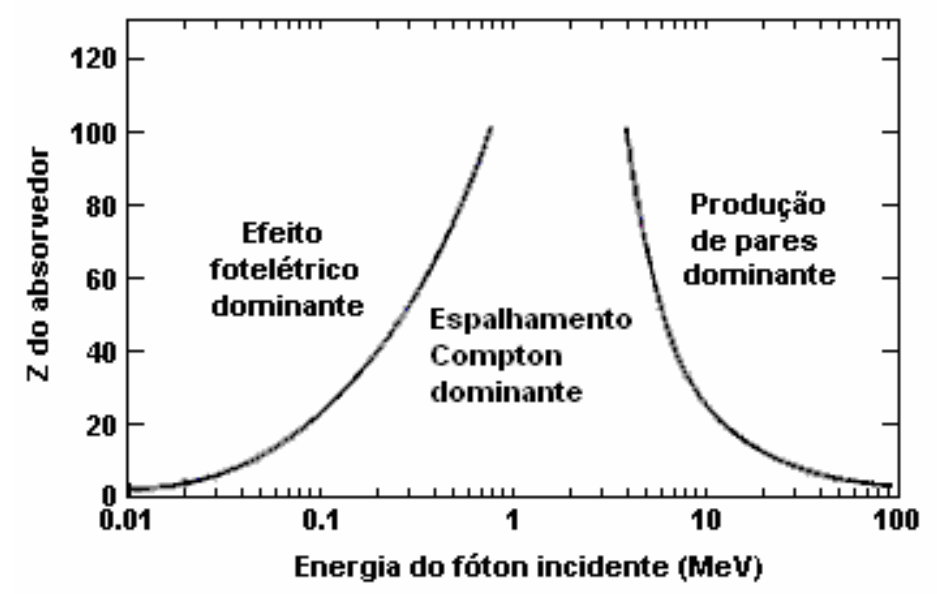

FIGURA 2.7: Probabilidade de ocorrência de efeito fotoelétrico, espalhamento Compton e produção de pares, em função da energia da radiação eletromagnética incidente $\mathrm{e}$ do número atômico $Z$ do absorvedor. Disponível em: $<$ http://www.fsc.ufsc.br/ canzian/intrort/fig-schoque $>$.Acesso em 03 jan. 2008.

Para fótons de baixa energia o efeito fotoelétrico é dominante. A produção de pares pode ocorrer apenas com fótons com energia superior a $1.02 \mathrm{MeV}$ (o dobro da massa de repouso do elétron).

\subsubsection{A deteç̧ão dos raios gama}

A detecção de raios gama com cristal de $\mathrm{NaI}(\mathrm{Tl})$, iodeto de sódio dopado com Tálio, foi descoberta por Robert Hofstadter em 1948, que lhe permitiu descobrir a espectroscopia gama mais tarde junto com seu aluno John McIntyre (Hofstader \& Mcntyre, 1950). 
Outros cristais podem ser usados como detectores de cintilação e tem sido utilizado em arranjos experimentais. Aí se incluem experimentos que descobriram o pósitron, espectroscopia Mossbauer (Dyar et al, 2006), tomografia de emissão de pósitron (PET), entre outros. A cintilação já era conhecida no século XIX e o cristal $\mathrm{ZnS}(\mathrm{Ag})$ foi usado por Rutherford em seu espalhamento de núcleos de He. Cintiladores são conhecidos nas formas gasosa, líquida e cristalina, e os cristais detectores de raios gama antraceno e naftalina foram desenvolvidos antes de Hofstadter descobrir o $\mathrm{NaI}(\mathrm{Tl})$. Um teste de comparação com vários cristais demonstra que o $\mathrm{NaI}(\mathrm{Tl})$ é o cristal mais eficiente. Com um pequeno cristal e uma fotomultiplicadora com diâmetro de 1,27 cm (1/2 polegada) Hofstadter observou sinais com altura de pulsos facilmente mensuráveis eletronicamente. Ademais, observou que os pulsos de cintilação poderiam ser classificados em termos de suas alturas e freqüência e assim poderia ser usado como uma ferramenta na espectroscopia de radiação gama. Seus resultados publicados mostraram que as grandezas dos pulsos estavam quase linearmente relacionadas com as energias dos raios gama. A divulgação desta forma de detecção evoluiu em outros importantes trabalhos de pesquisas expandindo-se a utilização do NAI (TI) (Attix, 1968; Burnham,1970, Mafra, 1970; Veglia, 1971; Burnham,1972; Bancroft, 1973, Peak, 1979, Montanheiro,1977; Robilotta, 2006).

O cristal NaI não é considerado condutor, o que significa que há uma grande diferença de energia (delta) entre a banda de valência cheia de elétrons e sua banda de condução vazia de elétrons.O fóton gama altamente energético dissipa sua energia na colisão com um elétron no cristal, que por sua vez produz pares de lacunas de elétrons nas sucessivas colisões na rede cristalina. Quando os elétrons deixam o estado excitado na banda de condução, e voltam a ocupar o respectivo estado fundamental na banda de valência. Nesta transição eletrônica há a emissão de luz ou a liberação de energia na forma de vibrações na rede cristalina (calor). A presença do Tálio como dopante diminui a possibilidade dos fótons de luz provocar nova excitação do elétron e um conseqüente salto para a banda de condução, criando novamente um par lacuna-elétron. Desta maneira a presença do Tálio numa fração molar de $10^{-3}$ aumenta de forma significativa a emissão de luz do cristal. Isto porque o decaimento do elétron é menor e o fóton resultante não irá estimular a excitação de um novo elétron, pois dificilmente irá encontrar outro Tálio no cristal. Isto faz com que o Tálio seja identificado como um 
ativador do cristal. Experimentos mostram que a luminescência do cristal $\mathrm{NaI}(\mathrm{Tl})$ é característico do decaimento do estado excitado nos íons de Tálio, sempre que a totalidade da energia gama é dissipada totalmente na rede do NaI. As diferentes taxas de difusão dos elétrons e das lacunas resultam no decaimento quase exponencial da emissão de Tálio depois de alguns poucos microssegundos. Em torno de $2 / 3$ de toda luminescência é emitida no primeiro $1 / 4$ de microssegundo (ms). Este tempo é importante porque, para se utilizar como um detector de fótons gama, as cintilações precisam ser distinguíveis no tempo. A produção de pares de buracos de elétrons da interação gama normalmente ocorre em menos de 1 (um) nanossegundo (1ns) e não afetam este resultado. A ativação do cristal de NaI pelo Tálio resulta numa conversão de aproximadamente $11 \%$ da energia incidente de raios gama em fótons com uma média de energia de 3,0 eV. A explosão de fótons, embora não seja exponencial, tem um tempo característico de $0,23 \mathrm{~ms}$ que tem uma emissão máxima num comprimento de onda de $415 \mathrm{~nm}$. A energia da radiação gama de $1.000 \mathrm{keV}$ produz, em média, 4,3×10 4 fótons. Variações estatísticas nesse número mostram que cada $1.000 \mathrm{keV}$ de energia gama, contribuem na largura dos picos de fótons observados e são chamadas de energia de resolução (Montanheiro, 1977).

\subsubsection{As fotomultiplicadoras}

Consistem de um tubo que converte luz em corrente elétrica, que pode ter sua magnitude amplificada em muitas ordens. Este tubo veio se transformar na câmara de televisão nos anos sessenta e nos anos setenta transformou-se na fotomultiplicadora para observar as cintilações do $\mathrm{NaI}(\mathrm{Tl})$ e detectar baixas intensidades de luz em geral ${ }^{8}$. As partículas carregadas (alfa, elétrons, prótons, entre outros) interagem com a matéria, principalmente através de forças coulumbianas com os elétrons orbitais do material. Algumas vezes podem ocorrer interações das partículas com o núcleo, como no espalhamento Rutherford, mas esses encontros são tão raros que não afetam a resposta dos detectores de radiação.

\footnotetext{
${ }^{8}$ Disponível em: <http://www.ifi.unicamp.br/ jmoreira/gama.html>. Acesso em 24 jul.2008.
} 


\section{PRINCÍPIOS DA TOMOGRAFIA}

\subsection{A construção da imagem de $\mathrm{TC}$}

\subsubsection{Considerações}

O princípio da tomografia computadorizada consiste na análise da atenuação sofrida por um feixe de radiação conhecido, o qual atravessa um objeto. A partir desta atenuação têm-se as medidas da integral na linha de distribuição da densidade de massa, através do caminho percorrido pelo feixe. A resposta de vários feixes com orientações diferentes, em relação ao volume estudado é que permite a reconstrução da imagem de acordo com a distribuição espacial de densidade (Aird,1988).

“Tomos" é a palavra grega para corte (cut) ou seção (section), e a tomografia pode ser compreendida como uma técnica digital onde o feixe de radiação "corta" um espécime para revelar seus detalhes interiores. Uma imagem de TC é chamada tipicamente "uma fatia", uma vez que corresponde a uma fatia de um corte axial do objeto. Entende-se que uma fatia corresponde a uma pequena espessura. Uma fatia de TC também corresponde a alguma espessura do objeto em que está sendo feita uma varredura. Conseqüentemente, visto que uma imagem digital típica é composta de elementos de retrato (pixels), e o número associado a cada elemento da imagem é denominado número de Hounsfield (HU) ou número de CT. Os elementos de volume (voxels) podem ser calculados pela multiplicação do pixel pela espessura do corte tomográfico. Na FIG.3.1, mostra-se a representação dos elementos de retrato e os elementos de volume.

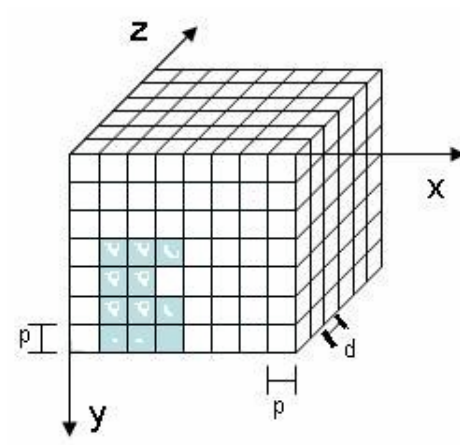

(a)

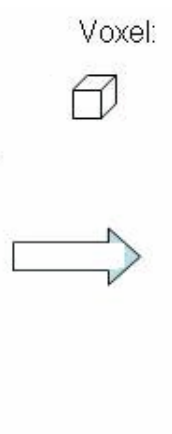

(b)

FIGURA 3.1: Representação dos elementos de volume e retrato: (a) voxels e (b) pixels. 
Uma comparação inicial entre o conceito de imagem radiográfica e imagem tomográfica é que enquanto a primeira vem de confusas informações tridimensionais indicadas em uma superfície bidimensional, a imagem tomográfica consiste em métodos de se obter uma imagem de um plano original dentro do paciente ou do objeto a ser estudado e com cada vez mais qualidade e nitidez (Aird, 1988).

Seja $\mathbf{f}(\mathbf{x})$ o coeficiente de atenuação do meio material em um ponto $\mathbf{x}$, isto é, fótons que atravessam uma pequena distância $\Delta \mathbf{x}$ a $\mathbf{x}$, sofrendo a relativa perda de intensidade:

$$
\frac{\Delta I}{I_{0}}=f(x) \Delta x
$$

$\mathrm{Na}$ qual $\mathbf{I}_{\mathbf{0}}$ é a intensidade do feixe inicial e $\mathbf{I}$ é a intensidade após o feixe passar pelo corpo. A direção por onde passa o feixe é $\mathbf{L}$ e desta forma:

$$
\frac{I}{I_{0}}=\exp \left\{-\int_{L} f(x) d x\right\}
$$

Com a integral de linha da função $\mathbf{f}$ ao longo de cada uma das linhas $\mathbf{L}$ pode-se reconstruir a função $\mathbf{f}(\mathbf{x})$. A transformação que traça uma função em $\mathrm{R}^{2} \mathrm{em}$ uma linha integral é a chamada transformada de Radon bidimensional. Assim, o problema da reconstrução de CT é a chamada inversão da transformada de Radon em $\mathrm{R}^{2}$ (Radon 1917).

A função $\mathbf{f}$ não depende apenas de $\mathbf{x}$, mas também da energia $\mathbf{E}$ dos raios $\mathrm{X}$ Assumindo T(E) a energia do feixe.

$$
\frac{I}{I_{0}}=\int T(E) \exp \left\{-\int_{L} f(x, E) d x\right\} d E
$$

A EQ. 3.4 fornece a função $\mathbf{f}(\mathbf{x}, \mathbf{E})$ com a correspondente aproximação da função de Klein-Nishina: 


$$
f(x, E)=E^{-3} f_{1}(x)+C(E) f_{2}(x)
$$

O termo $\mathbf{C}(\mathbf{E})$, que é a da função de Klein-Nishina, tem uma pequena variação para feixes de baixa energia de forma que o endurecimento do feixe é mais pronunciado em altas energias.

\subsection{A obtenção da imagem}

\subsubsection{A transformada de Radon}

Se $\mathbf{P}(\mathbf{u}, \boldsymbol{\theta})$ representar um grupo de projeções (conhecidas também como a raio soma), como mostrado na FIG. 3.2:

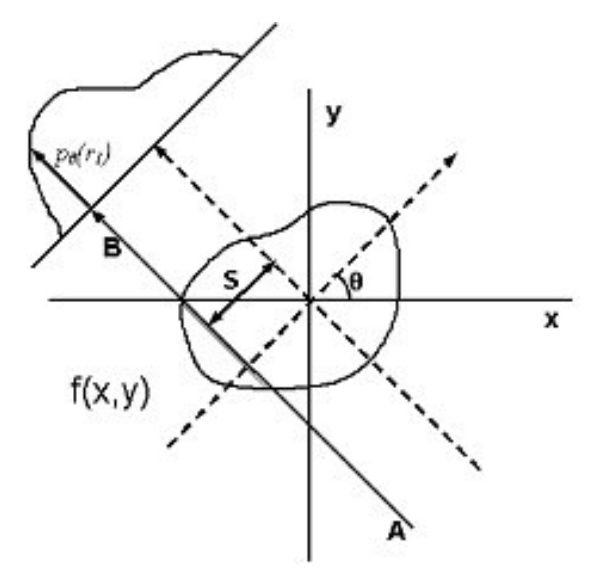

FIGURA 3.2: As projeções $\mathrm{P}(\mu, \theta)$ são compostas das somas das contagens de radioatividade do volume ao longo de linhas perpendiculares ao detector, em um determinado ângulo $\theta$.

Define-se $\mathbf{f}(\mathbf{x}, \mathbf{y})$ ao longo de um feixe de ângulo $\boldsymbol{\theta}(0<\theta<\pi)$, e desta forma $\mathbf{u}$ representa a distância desde a origem( $-\mathrm{r} \leq \mathrm{u} \leq \mathrm{r}=$ dimensão da seção estudada), a relação entre estes será dada pela integral mostrada na EQ. 3.5 (Natterer, 1986):

$$
P(u, \theta)=\int_{L} f(x, y) \cdot d v
$$


Quando o ângulo $\boldsymbol{\theta}$ é conhecido para um grupo de projeções sendo $\theta=[0, \pi]$; a equação denomina-se Transformada de Radon de $\mathbf{f}(\mathbf{x}, \mathbf{y})$, sendo representada por :

$$
p(u, \theta)=\int_{0}^{\pi} f(x, y) d v
$$

Basicamente, o problema da reconstrução tomográfica está em inverter a transformada de Radon para poder estimar $\mathbf{f}(\mathbf{x}, \mathbf{y})$ a partir de $\mathbf{p}(\mathbf{u}, \boldsymbol{\theta})$ :

$$
R[f(x, y)]=\int p(u, \theta) d \theta
$$

\subsubsection{A reconstrução da imagem}

A reconstrução da imagem tomográfica pode ser obtida por meio de uma matriz discreta, por meio de um sistema de equações de grande tamanho. Assim, a idéia fundamental deste método é inverter o sistema de equações de uma forma iterativa.

A fim de exemplificar, a seguir é utilizado um sistema matricial 4x4, representativo de quatro projeções. Os valores de $\mathbf{p}$ representam as medidas experimentais, $\mathbf{r}_{\mathbf{i j}}$ são parâmetros de regressão e $\mathbf{f}$ as funções de $\mathbf{x}$ e $\mathbf{y}$, as quais serão determinadas pela resolução da equação matricial:

$$
\begin{aligned}
& P_{1}=r_{11} f_{1}+r_{12} f_{2}+r_{13} f_{3}+r_{14} f_{4} \\
& P_{2}=r_{21} f_{1}+r_{22} f_{2}+r_{23} f_{3}+r_{24} f_{4} \\
& P_{3}=r_{31} f_{1}+r_{32} f_{2}+r_{33} f_{3}+r_{34} f_{4}
\end{aligned}
$$




$$
P_{4}=r_{41} f_{1}+r_{42} f_{2}+r_{43} f_{3}+r_{44} f_{4}
$$

Matricialmente este sistema é reescrito como abaixo:

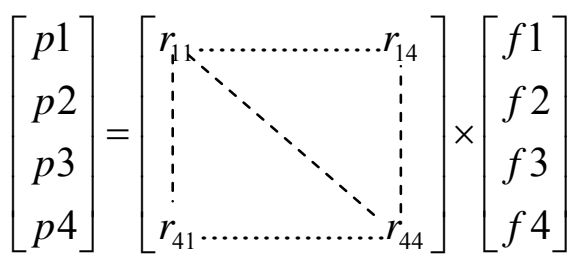

E o vetor $\mathbf{f}(\mathbf{x}, \mathbf{y})$ representativo da imagem procurada igual a:

$$
\left[\begin{array}{c}
f 1 \\
f 2 \\
f 3 \\
f 4
\end{array}\right]=\left[\begin{array}{cccc}
r_{11} & \ldots \ldots \ldots \ldots \ldots . . r_{14} \\
\vdots & \ddots & & \vdots \\
\vdots & \ddots & & \vdots \\
\vdots & \ddots & \ddots & \vdots \\
r_{41} \ldots \ldots \ldots \ldots \ldots . . & r_{44}
\end{array}\right]^{-1} \times\left[\begin{array}{c}
p 1 \\
p 2 \\
p 3 \\
p 4
\end{array}\right]
$$

O coeficiente de atenuação linear média $\boldsymbol{\mu}_{\mathrm{t}}$ de cada pixel é comparado com o coeficiente da água, $\boldsymbol{\mu}_{\mathrm{a}}$, definindo o número $\mathbf{C T}$ :

$$
C T=1000\left(\mu_{t}-\mu_{a}\right) / \mu_{a}
$$

A água é utilizada como referência, uma vez que seu coeficiente de atenuação é similar ao dos tecidos moles, e é um material fácil de obter-se para calibrar os aparelhos. O coeficiente 1000 é utilizado para obter-se números inteiros.

O número CT, ou coeficiente de Hounsfield é definido como -1000 para o ar e 0 para a água. Para os tecidos em geral, ele depende da energia do feixe empregado. Por exemplo, para $80 \mathrm{keV}$, se o coeficiente de atenuação linear típico dos ossos é de 0,38 $\mathrm{cm}^{-1}$, e da água $0,19 \mathrm{~cm}^{-1}$, o número CT dos ossos é de +1000 . Pode ser ainda maior para ossos corticais. Estes valores também variam de aparelho para aparelho, já que os coeficientes dependem da distribuição de energia do feixe. 
A radiação observada $\mathbf{I}$, como foi mencionado na seção 2.2, EQ.2.1, relaciona-se com a intensidade da radiação na fonte, $\mathbf{I}_{\mathbf{0}}$, por $\mathbf{I}=\mathbf{I}_{\mathbf{0}} \mathrm{e}^{-\boldsymbol{\mu x}}$ e o número do CT será relacionado ao coeficiente de atenuação. A TAB. 3.1 apresenta os número de CT relacionados com os tecidos importantes do corpo humano.

Para se calibrar um tomógrafo e obterem-se imagens compatíveis com um determinado equipamento, utiliza-se a determinação do valor médio do número de CT por meio da matriz de valores de CT selecionados. No ANEXO C é mostrado um exemplo de calibração (Jenkins \& Gedcke,1981). Por convenção, altos valores de CT são imageados como branco, e baixos como preto.

TABELA 3.1: Relação entre o tecido do corpo humano com densidade conhecida e os respectivos números de CT, para fins de calibração de tomógrafos. Disponível em: $<$ http://www.if.ufrgs.br/ast/med/imagens/node4.htm $>$. Acesso em 20 jul. 2008 .

\begin{tabular}{lc}
\hline \multicolumn{1}{c}{ TECIDO } & NÚMERO CT \\
\hline Ar & -1000 \\
Pulmão & -900 a -400 \\
Gordura & -110 a -65 \\
Água & 0 \\
Rim & 30 \\
Sangue normal & 35 a 55 \\
Sangue coagulado & 80 \\
Músculo & 40 a 60 \\
Fígado & 50 a 85 \\
Ossos & 130 a 250 \\
\hline
\end{tabular}




\subsubsection{Digitalização da Imagem}

Os valores numéricos de todas as projeções tomográficas p (secção 3.2.2) determinam uma função de distribuição bidimensional dos coeficientes lineares de atenuação. O número de projeções é finito e o número de valores dos coeficientes da seção estudada será finito. A seção estudada pode ser decomposta em um número de unidades de volume com a forma de um prisma, voxel. Cada voxel tem dimensão aproximadamente igual ao diâmetro do feixe de radiação, sendo caracterizado por um valor simples de coeficientes $\mathbf{r}_{\mathbf{i}, \mathbf{j}}$ de atenuação linear. Para cada voxel pode ser atribuído um pixel de imagem, cuja sombra (cor) será proporcional ao valor numérico dos coeficientes de atenuação. Este mapa contendo os resultados bidimensionais representará a distribuição dos coeficientes lineares de atenuação sobre a ação inteira, cuja resolução espacial será igual ao tamanho do voxel.

Este gráfico que representa a reconstrução da função de distribuição dos coeficientes $\boldsymbol{\mu}$ por médio de projeções, será a imagem final da tomografia. Ou ainda, expandindo-se a EQ. 3.11 pode-se por meio do algoritmo matemático calcular, a partir das medidas dos detectores, o coeficiente de atenuação de cada pixel e daí converterem estes valores ao número do CT utilizando-se a EQ. 3.11.

\subsubsection{Tratamento matemático das imagens: a Transformada de Fourier.}

A transformada de Fourier pode ser utilizada na reconstrução bi-dimensional de imagens, em função da facilidade e rapidez de cálculos, comparado com a resolução das equações de projeção algebrica, que consistem na montagem de uma matriz e sua resolução (Kak \& Slaney, 1999).

A transformada de Fourier de uma função $\boldsymbol{f}(\boldsymbol{x})$ é definida como:

$$
\mathcal{F}[f(x)] \equiv F\left(w_{x}\right)=\int_{-\infty}^{\infty} f(x) e^{-2 i \pi w_{s} x} d x
$$


A Transformada de Fourier Inversa, $\mathrm{F}^{-1}$ que recupera a função original é definida por:

$\mathcal{F}^{-1}\left[F\left(w_{x}\right)\right] \equiv f(x)=\frac{1}{2 \pi} \int_{-\infty}^{\infty} F\left(w_{x}\right) e^{2 i \pi w_{s} x} d w_{x}$

Na qual $\omega_{x}$ é a freqüência angular, e $i \equiv \sqrt{-1}$.

Pode-se ainda definir também:

$$
\mathcal{F}[f(x)] \equiv F(\nu)=\int_{-\infty}^{\infty} f(x) e^{-i \nu x} d x
$$

A Transformada de Fourier Inversa, que recupera a função original é definida como:

$$
\mathcal{F}^{-1}[F(\nu)] \equiv f(x)=\frac{1}{2 \pi} \int_{-\infty}^{\infty} F(\nu) e^{i \nu x} d \nu
$$

Sendo que o termo $v=\mathbf{2} \pi \omega_{\mathrm{x}}$ significa a freqüência linear.

Nota-se que:

$$
e^{-i \nu x} \equiv \cos (-i \nu x)+i \operatorname{sen}(-i \nu x)
$$

A condição suficiente para e existência da transformada de Fourier de uma função $f(x)$ qualquer é que a função seja integrável, e finita, isto é:

$$
\int_{-\infty}^{\infty}|f(x)| d x<\infty
$$


As imagens que se está interessado são sempre integráveis e finitas. Um pulso retangular, FIG. 3.3 (a) pode ser integrado de forma a se obter uma amplitude de sinal compatível com o pulso, como é mostrado na FIG. 3.3 (b) (Kak \& Slaney, 1999):

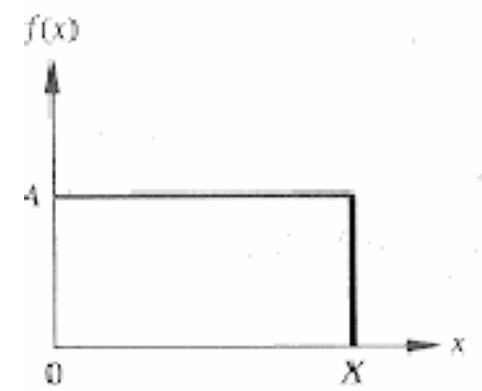

(a)

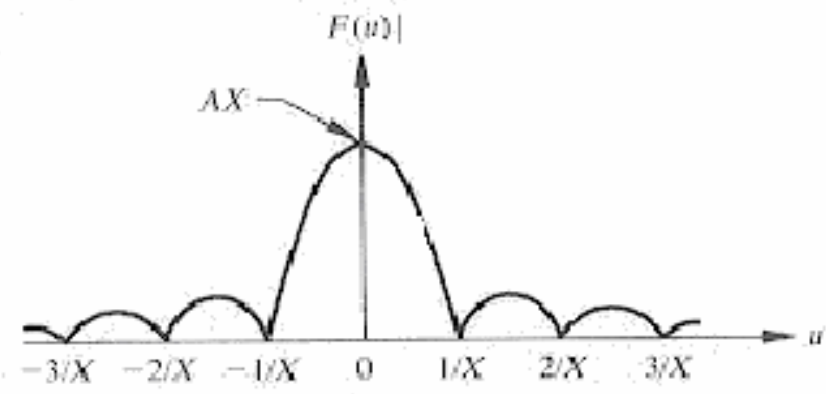

(b)

FIGURA 3.3: Representação de um pulso retangular (a) que pode ser integrado de forma a se obter uma amplitude de sinal compatível com o pulso (b).

Embora a imagem seja real, a transformada de Fourier é uma função complexa, com coeficientes reais e imaginários:

$$
F\left(w_{x}\right)=\Re\left[F\left(w_{x}\right)\right]+i \Im\left[F\left(w_{x}\right)\right]
$$

O espectro de potências $\boldsymbol{P}\left(\boldsymbol{\omega}_{x}\right)$ é definido como:

$$
P\left(w_{x}\right)=\Re\left[F\left(w_{x}\right)\right]^{2}+\Im\left[F\left(w_{x}\right)\right]^{2}
$$

O ângulo de fase é dado por:

$$
\phi\left(w_{x}\right)=\tan ^{-1} \frac{\Im\left[F\left(w_{x}\right)\right]}{\Re\left[F\left(w_{x}\right)\right]}
$$


Por exemplo, pode-se calcular a Transformada de Fourier de um pulso retangular, definido por:

$$
f(x)= \begin{cases}1 & \text { se }|x|<T \\ 0 & \text { se }|x|>T\end{cases}
$$

A transformada de Fourier $\boldsymbol{F}(\boldsymbol{\omega})$ de $\boldsymbol{f}(\boldsymbol{x})$ é dada por:

$$
\begin{aligned}
\mathcal{F}[f(x)] \equiv F(w) & =\int_{-\infty}^{\infty} f(x) e^{-i w x} d w \\
& =\int_{-T}^{T} 1 \cdot e^{-i w x} d w \\
& =\left.\frac{e^{-i w x}}{-i w}\right|_{-T} ^{T} \\
& =\frac{1}{-i w}\left(e^{-i w T}-e^{i w T}\right) \\
& =2 T \frac{\operatorname{sen}(w t)}{w T} \\
& =2 T \operatorname{sinc}(w T)
\end{aligned}
$$

E,

$$
\operatorname{sen}(w t)=\frac{e^{-i w d}-e^{i w t}}{2 i}
$$




\subsection{Desenvolvimento}

Em função da importância social da medicina os aprimoramentos da tecnologia dos tomógrafos advêm dos equipamentos projetados para a diagnose médica. Considerando que as dimensões do corpo humano são razoavelmente padronizadas tornou-se possível a produção de aparelhos tomográficos em escala industrial e, em função dos aspectos de globalização da macroeconomia, esses equipamentos são produzidos atualmente por poucas empresas que dominam o mercado globalizado (Siemems, Phillips, GE, Toshiba e Hitachi).

Cinco gerações de tomógrafos foram desenvolvidas de acordo com as necessidades operacionais. Os tomógrafos, de acordo com a varredura são classificados em $1^{\mathrm{a}}, 2^{\mathrm{a}}, 3^{\mathrm{a}}$ e $4^{\mathrm{a}}$ geração. A $5^{\mathrm{a}}$ geração de tomógrafos está agora se difundido e é fruto de muito investimento em pesquisas, recorrente da importância de sua utilização na medicina.

\subsubsection{A Tomografia Computadorizada de $1^{\mathrm{a}}$ e $2^{\mathrm{a}}$ geração}

Os primeiros aparelhos, chamados de $1^{\mathrm{a}}$ geração mostrados na FIG. 3.4 (a) surgiram no início dos anos 70 e se constituíam de um feixe em forma de lápis e um detector do lado oposto ao objeto a ser estudado.
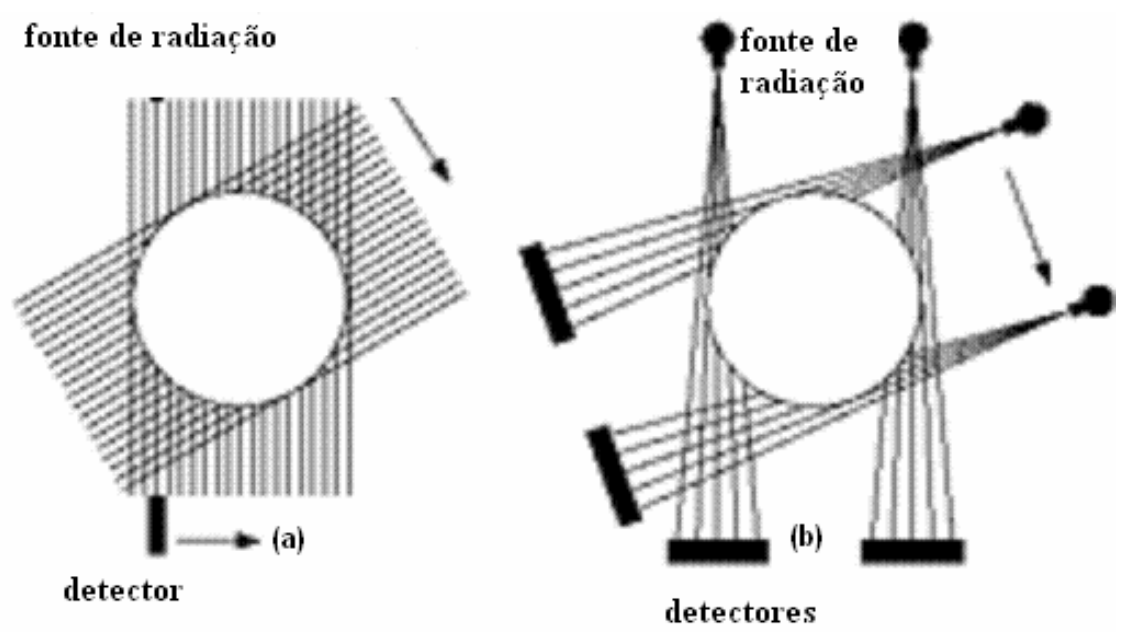

FIGURA 3.4: Representação dos tomógrafos: (a) $1^{\mathrm{a}}$ geração e (b) $2^{\mathrm{a}}$ geração. 
O tubo de raios $\mathrm{X}$ e o detector de radiação possuem, nos tomógrafos de $1^{\text {a }}$ geração, movimento de rotação e translação, que demoram aproximadamente 5 minutos. Os aparelhos de $2^{\mathrm{a}}$ geração introduziram mais detectores e as fontes em forma de leques também com movimentos de rotação e translação mostrados na FIG. 3.4 (b). Entretanto, diminuiu o tempo de cada $\operatorname{scan}^{9}$ em aproximadamente 1 minuto e meio.

\subsubsection{Tomografia de $3^{\mathrm{a}}$ geração}

A terceira geração de tomógrafos apareceu entre 1975 e 1977 e consta de um feixe de radiação também em forma de leque mais largo e com um sistema de múltiplos detectores mostrados na FIG.3.5. A fonte e os detectores giram simultaneamente $360^{\circ}$. Consequentemente, a imagem é obtida mais rapidamente do que os aparelhos de $2^{\mathrm{a}}$ geração.

\subsubsection{Tomografia de $4^{\mathrm{a}}$ geração}

Os tomógrafos de $4^{\mathrm{a}}$ geração mantêm o feixe em leque e possuem um anel de detectores, mostrados na FIG.3.6. O giro de $360^{\circ}$ é ainda mais rápido do que nos de $3^{\mathrm{a}}$ geração. Os pontos de cada projeção são obtidos simultaneamente, reduzindo-se ainda mais o tempo de varredura, graças ao simples movimento de rotação e ao feixe em leque cobrindo todo o objeto. Entretanto, o tamanho do corpo em estudo é limitado pelo feixe em leque produzido pela fonte de raios $\mathrm{X}$.

\footnotetext{
${ }^{9} \mathrm{O}$ termo scan é significa uma rotação completa do sistema de tomada de dados em TC de forma a constituir uma varredura completa.
} 


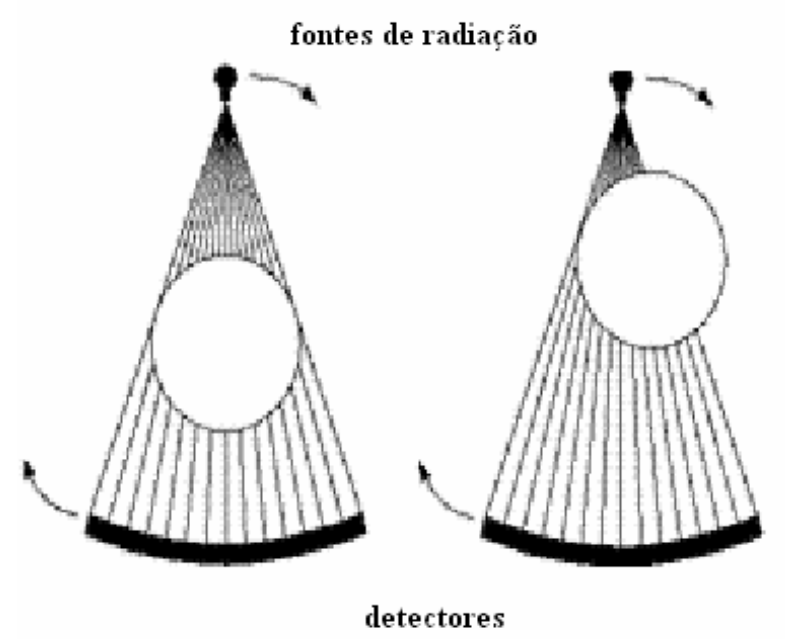

(a)

(b)

FIGURA 3.5: Representação do sistema de tomografia de $3^{\text {a }}$ geração, (a) objeto centralizado em relação ao sistema fonte/detectores e (b) objeto descentralizado. Nesta geração utiliza-se um sistema de múltiplos detectores.

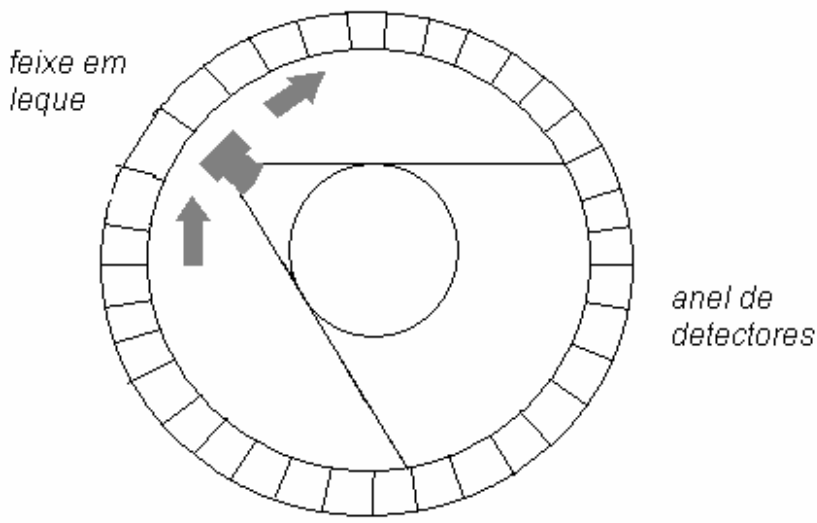

FIGURA 3.6: Representação da tomografia de $4^{\mathrm{a}}$ geração mostrando a fonte de radiação, o objeto centralizado e o anel de detectores (Quoirin, 2004). 


\subsubsection{Tomografia de $5^{\text {a }}$ geração}

Este tomógrafo possue um tubo de raios $\mathrm{X}$ cuja emissão é feita em diversas direções sem que a mesa do paciente ou o sistema fonte-detector se mova. O paciente não precisa se movimentar, uma vez que um solenóide é colocado entre os elétrons acelerados e o alvo, de forma a conseguir diferentes ângulos de deflexão do feixe e, consequentemente, diferentes direções de emissão, mostrados na FIG.3.7. O sistema de detectores é em forma de anel e o tempo de exposição bastante reduzido. Os tomógrafos de quinta geração são os únicos que possibilitam medidas em tempos bastante pequenos. No tomógrafo de quinta geração, o canhão de elétrons gera raios $\mathrm{X}$ em várias direções fazendo uma varredura sobre um alvo côncavo, o que possibilita tempos de aquisição da ordem de milissegundos.

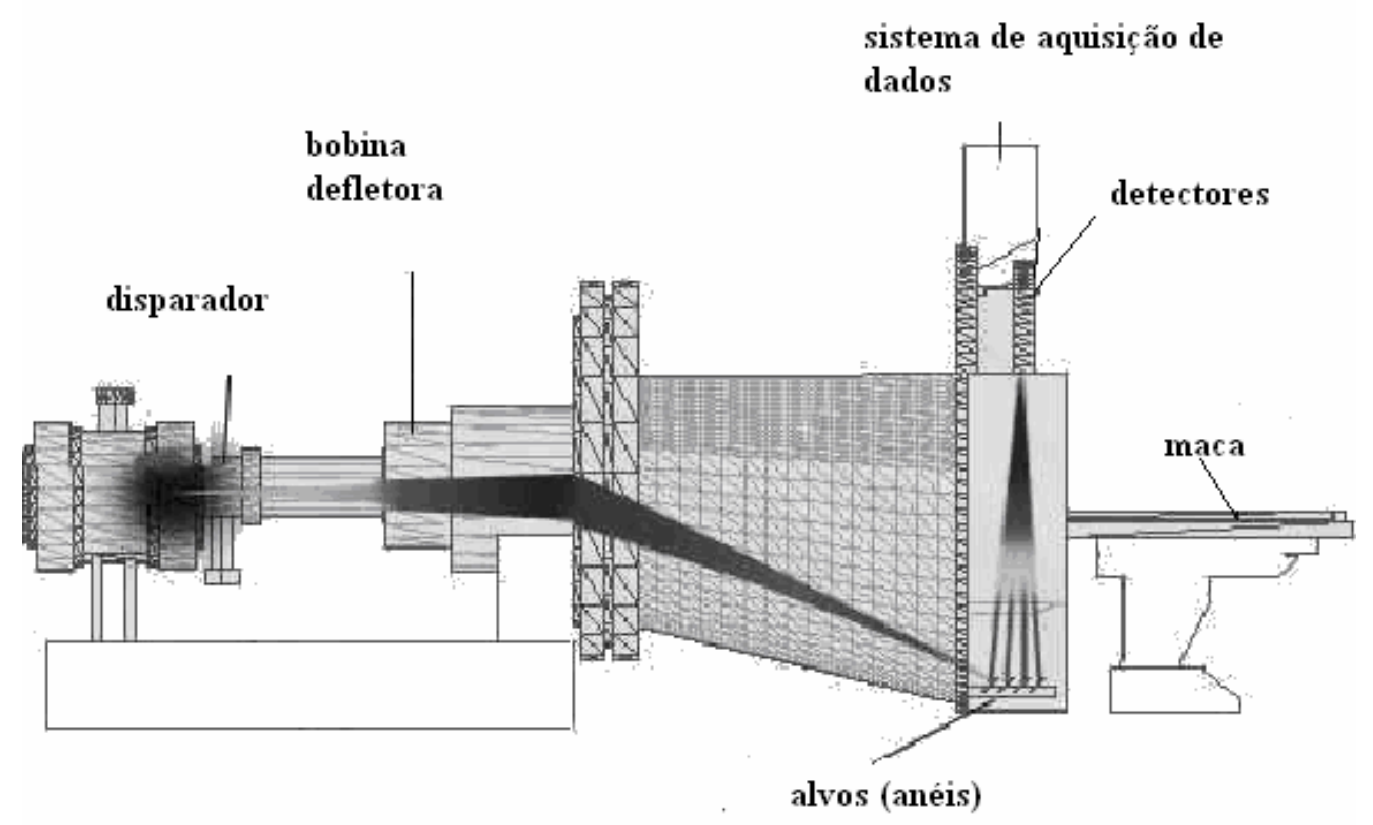

FIGURA 3.7: Representação esquemática de tomografia de $5^{\text {a }}$ geração. Adaptado de: < http://www.prorad.com.br/pro/Tomo.pdf > Acesso em: 24 jul. 2008. 


\subsubsection{Aplicações científicas e industriais}

Para ensaios industriais as técnicas de tomografia mais utilizadas são as de $\mathbf{1}^{\mathrm{a}} \mathbf{a}$ $3^{a}$ geração. O sistema tomográfico proposto é um sistema de tomografia por transmissão e utiliza uma fonte radioativa $\left({ }^{60} \mathrm{Co}\right)$ e os detectores são posicionados diametralmente do lado oposto, mostrados na FIG. 3.8. A escolha do tipo e geometria da fonte radioativa (planar ou em forma de leque), assim como a dos detectores de radiação é fundamental para as medidas de atenuação.

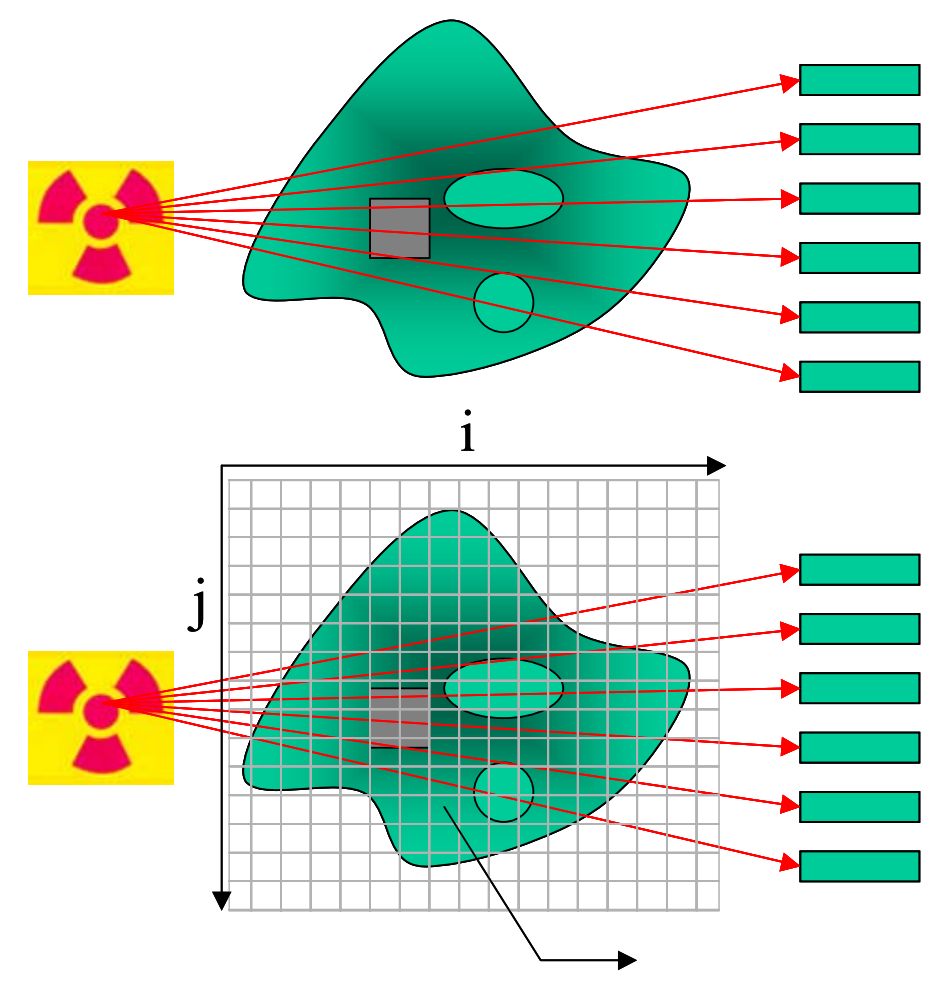

FIGURA 3.8: Sistema tomográfico constituído (a) fonte radioativa, objeto a ser tomografado e conjunto de detectores, (b) Sistema tomográfico considerando a matriz reticulada ("pixelizada").

Os equipamentos em desenvolvimento no CTR-IPEN-CNEN/SP constituem-se de um sistema multi-detectores de radiação e do sistema de detector de radiação único (plástico cintilador), mostrados, respectivamente, na FIG. 3.9 (a) e (b). 


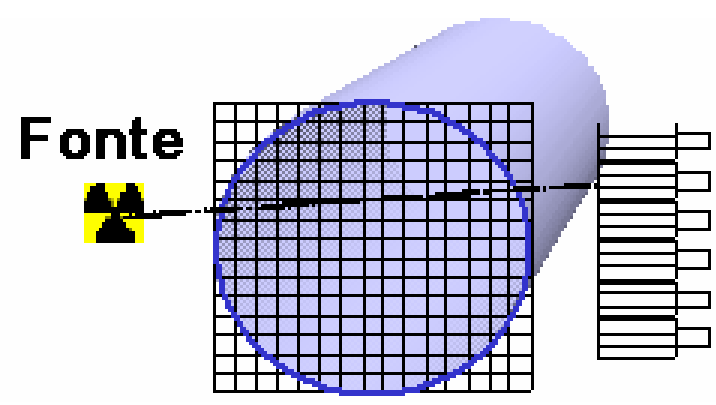

(a)

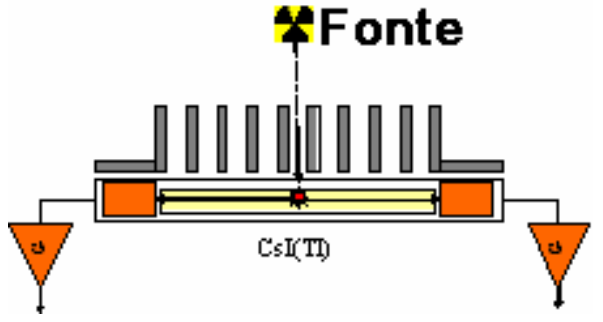

(b)

FIGURA 3.9: Equipamento em desenvolvimento no CTR-IPEN-CNEN/SP:

(a) Sistema de múltiplos detectores de radiação e (b) sistema de detector de radiação único, de plástico cintilador, sensível à posição.

Quando a radiação interage com o detector cintilador, mostrado na FIG. 3.9 (b), os fótons de luz se espalham dentro de detector e alcançam suas extremidades gerando dois diferentes sinais (exceto para a posição do meio do detector, a qual gera sinais idênticos). Conseqüentemente, muitos eventos ocorrem mais próximos de uma ou outra fotomultiplicadora (RCA, mod. HV, alimentado por Ortec mod.556), gerando sinais cujas alturas (volts) será função da distância de cada fotomultiplicadora. Subsequentemente, o sinal é pré-amplificado (Ortec mod.276) e amplificado (Ortec mod.460). Para cada sinal os seus valores picos e altura precisam permanecer constantes ao menos durante 1 a $2 \mu \mathrm{s}$, em função da limitação do tempo de conversão do ADC usado (ADC0820).

$\mathrm{Na}$ seqüência o sinal percorre três caminhos: o primeiro será usado para a medida do espectral, o segundo para segurar o sinal coincidente em duas fotomultiplicadoras e o terceiro que será usado para controle de limiar (threshold). Desta forma, o ruído em cada fotomultiplicadora pode ser eliminado. No terceiro caminho o sinal é processado pelo computador. Nesta fase, os sinais são somados e avaliados pelos critérios de limiar (threshold). Em seguida, todos os três sinais são convertidos em níveis TTL (sinais de 5V). Quando esses três sinais alcançam, simultaneamente, a porta AND "signal gate" o sinal é finalmente recebido e processado pelo computador PC. O sinal analógico é convertido em um sinal digital de 8 bit (ADC0820) e captado em uma memória RAM até ser alcançado pelo computador PC. 


\section{MATERIAL E MÉTODOS}

\subsection{O material}

O material de análise deste trabalho consistiu de uma pedra proveniente de uma rocha ígnea ${ }^{10}$, que foi submetida a dois diferentes ensaios tomográficos. Este tipo de pedra pode ter considerável valor comercial desde que sua formação interna seja cristalina. Isto ocorre quando o resfriamento durante a formação destas pedras for rápido permitindo a formação deste material interno vítreo.

Em alguns casos as pedras podem ter esta formação, mas como prever sua constituição interna sem seccioná-la? O estudo tomográfico foi uma possibilidade interessante de confirmar ou não a previsão de que a pedra submetida ao exame possuía internamente a estrutura cristalina. Na FIG.4.1 (a) mostra-se uma pedra ígnea com formação interna cristalina, após ser seccionada e polida.

A pedra ígnea que foi objeto de estudo dos dois diferentes ensaios tomográficos é a pedra "in natura" mostrada no lado direito da FIG. 4.1 (b), embora qualquer uma das duas pudesse ter ou não cristal em seu interior o que diferencia o valor comercial das mesmas.

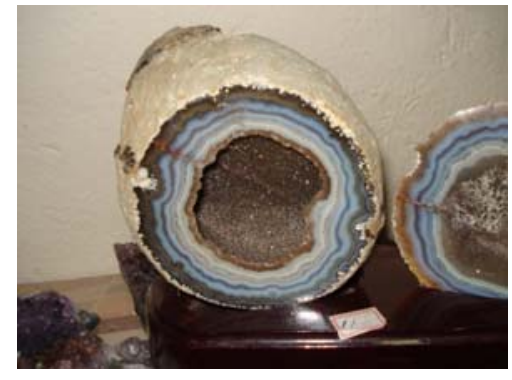

(a)

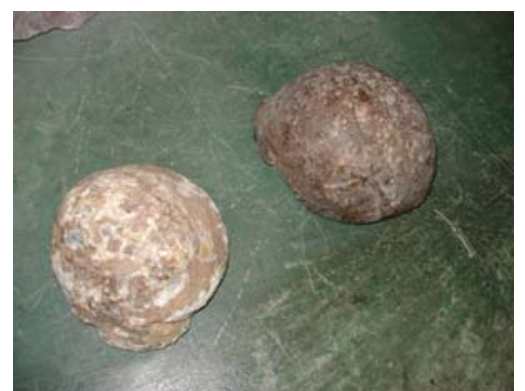

(b)

FIGURA 4.1: Rochas ígneas brasileiras (a) com texturas microlíticas, aberta e polida, de considerável beleza em sua estrutura interna cristalina e (b) amostras "in natura”.

\footnotetext{
${ }^{10}$ Rocha ígnea resultante da consolidação do resfriamento de magma derretido ou parcialmente derretido
} 


\subsection{O tomógrafo que utiliza raios $\mathrm{X}$ da CTUT}

A escolha de se utilizar um tomógrafo já reconhecido pela comunidade científica foi possível em função da receptividade e colaboração da equipe do Instituto de Geociências da Universidade do Texas (CTUT). A FIG. 4.2 mostra uma fotografia deste laboratório, no qual o equipamento tem sido utilizado em estudos de objetos de diferentes dimensões, diferentes densidades e formas geométricas há mais de dez anos e serviu de referência neste trabalho.

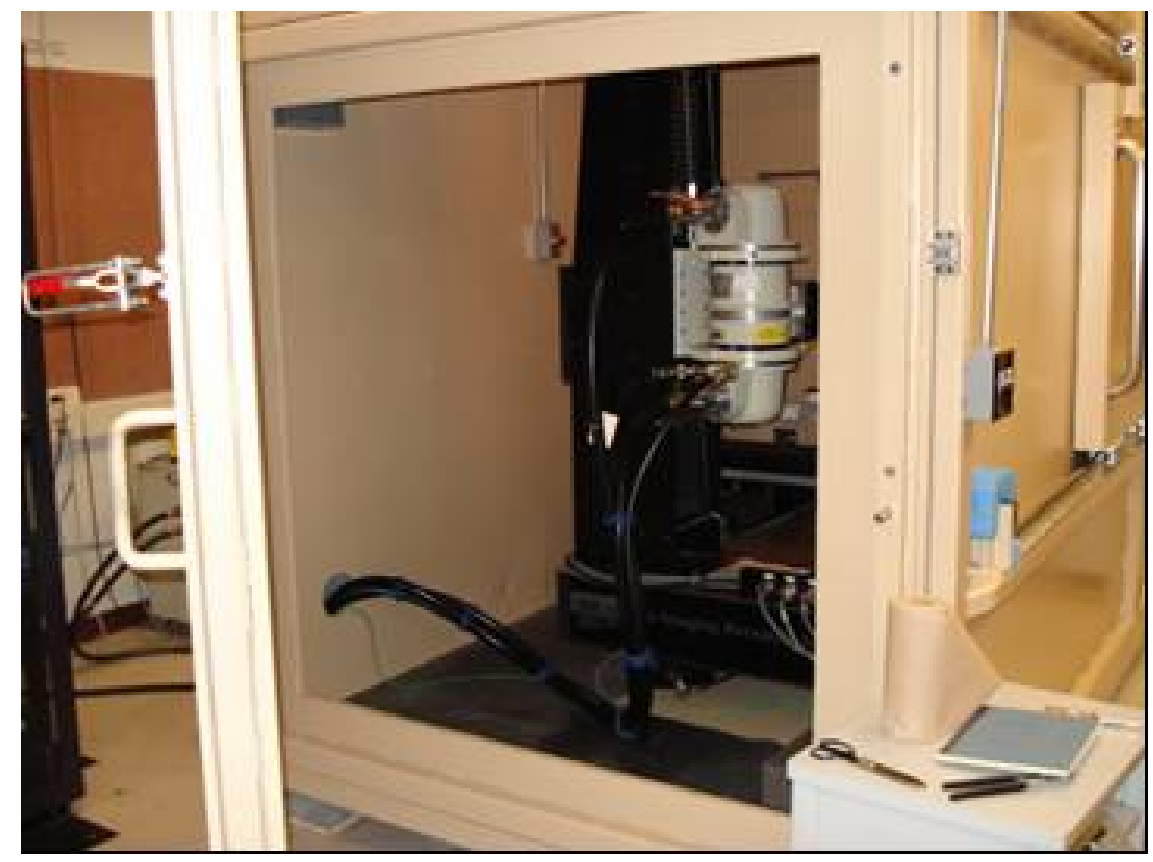

FIGURA 4.2: Fotografia do tomógrafo do CTUT.

O laboratório de pesquisas tomográficas da CTUT possui uma sala de controle, ao lado da cabine que abriga o tubo de raios $\mathrm{X}$ e os sistemas de detectores de radiação. Na FIG. 4.3 (a) é mostrada uma vista lateral do equipamento e o tubo de raios $\mathrm{X}$. Na FIG. 4.3 (b) são mostrados o tubo de raios X e os detectores de radiação e na FIG. 4.3 (c) são mostrados os sistemas de detectores de radiação e a esteira que se movimenta durante o exame do objeto. É mostrada ainda, na FIG. 4.3 (d), a rocha ígnea sendo posicionada no início do exame tomográfico.

Após a rocha ser devidamente posicionada, como mostrada na FIG 4.3 (e) e os parâmetros de compatibilidade do equipamento devidamente especificados, como 
mostrado na FIG. 4.3 (f) iniciou-se o exame tomográfico da mesma. Foram feitos oitenta cortes axiais tomográficos na região central da pedra.

As imagens foram processadas no laboratório do CTUT utilizando-se uma fonte de raios X com $415 \mathrm{kV}$ de tensão, corrente elétrica 3,2 $\mathrm{mA}$ e filtro de folha de bronze + ar. O tempo de integração foi de $32 \mathrm{~ms}$. As espessuras dos cortes foram de 0,5 mm, estendendo-se a $752 \mathrm{~mm}$ com um total de 1000 varreduras e um campo de reconstrução de $134 \mathrm{~mm}$. As oitenta imagens do interior da pedra foram obtidas em um intervalo de tempo de aproximadamente 50 minutos.

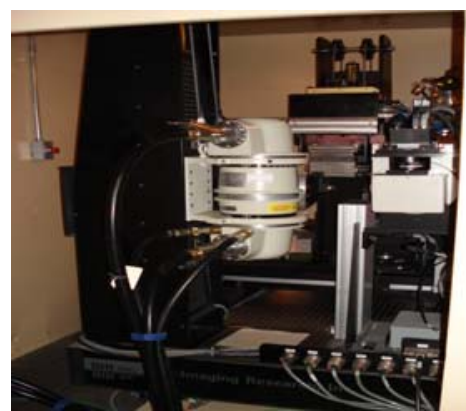

(a)

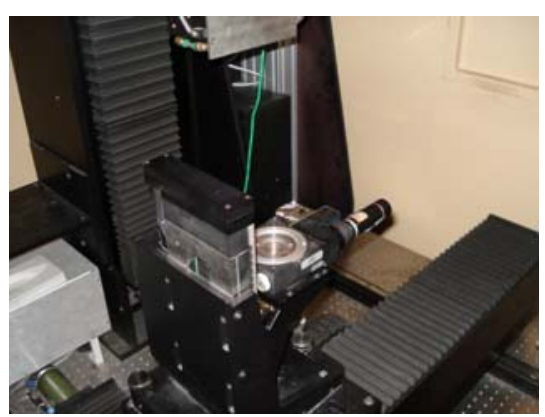

(c)

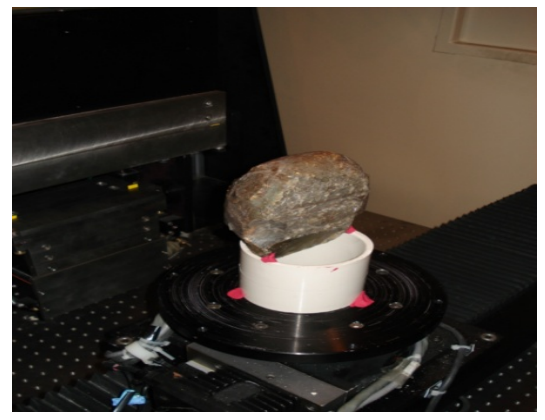

(e)

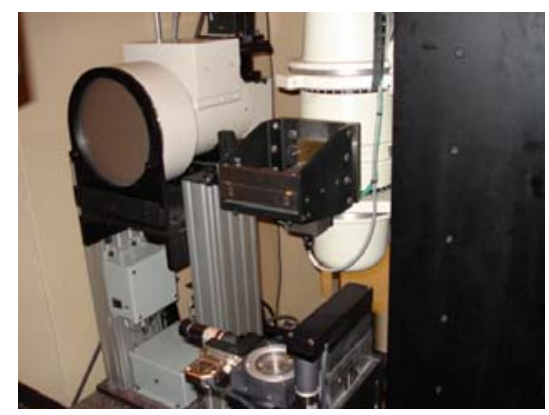

(b)

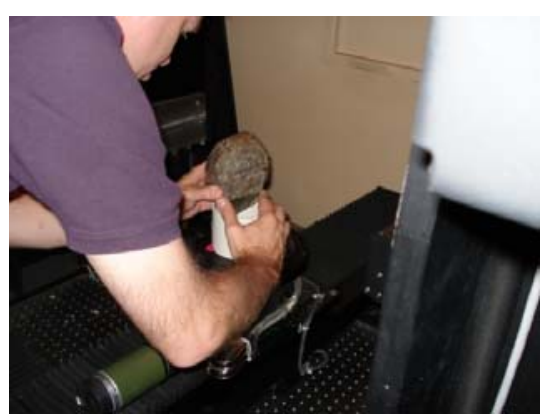

(d)

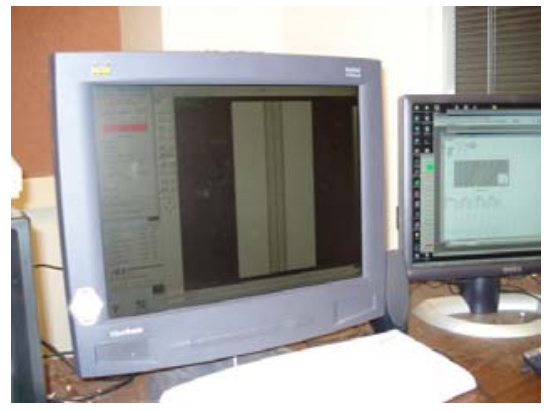

(f)

FIGURA 4.3: Fotografias do equipamento utilizado no exame tomográfico computadorizado da rocha ígnea no CTUT. 


\subsection{O tomógrafo do CTR-IPEN-CNEN/SP.}

O equipamento desenvolvido no laboratório de tomografia do CTR - IPENCNEN/SP, utiliza tecnologia nacional de software e hardware. No presente trabalho o tomógrafo utilizado é do tipo transmissão, no qual o objeto é posicionado entre a fonte e o detector de radiação. Utilizou-se uma fonte de ${ }^{60} \mathrm{Co}$ com atividade de 3,7 GBq (100mCi) cujas energias predominantes são de $1,173 \mathrm{MeV}$ e 1,332 MeV. A fonte foi disposta em frente ao sistema mecânico de movimentação (translação e rotação). $\mathrm{O}$ detector foi colimado e possuía uma fenda de $2,38 \mathrm{~mm}$ de largura e 4,76 $\mathrm{mm}$ de altura. O detector de $\mathrm{NaI}(\mathrm{Tl})$ com dimensões de 5,08 cm (2") de diâmetro por 5,08 cm (2") de comprimento, acoplado a fotomultiplicadora foi colocado opostamente à fonte e ao objeto. O tomógrafo dispõe de uma placa eletrônica para o controle dos motores responsáveis pelos movimentos de rotação e translação e para o tratamento e aquisição dos sinais eletrônicos provenientes do detector de radiação, conforme mostra a FIG. 4.4.

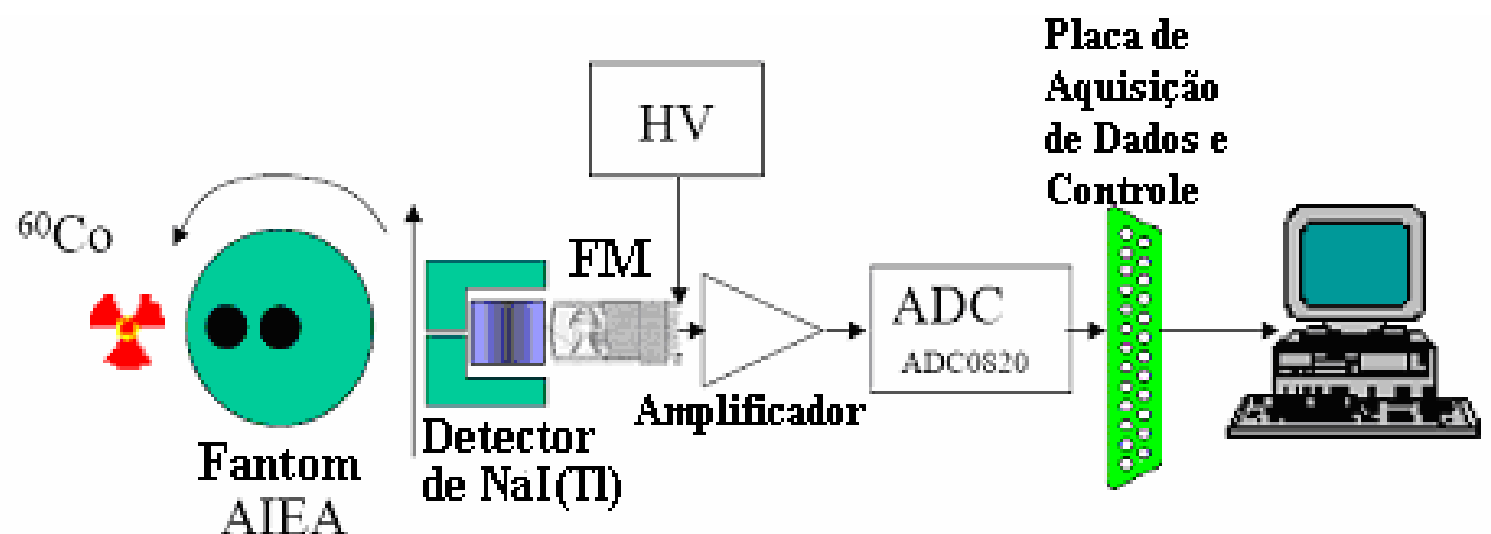

FIGURA 4.4: Reprodução do equipamento tomográfico computadorizado desenvolvido no CTR-IPEN-CNEN/SP.

Uma visão lateral do tomógrafo construído no CTR-IPEN-CNEN/SP é mostrada na FIG. 4.5: 


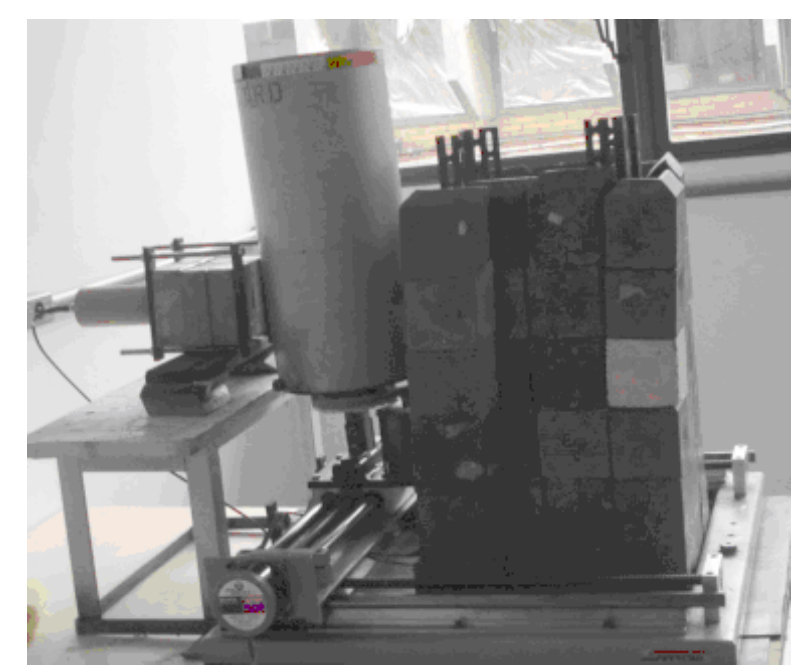

FIGURA 4.5: Fotografia da vista lateral do tomógrafo computadorizado experimental desenvolvido no CTR-IPEN-CNEN/SP.

Antes de iniciar as medidas do objeto de interesse deste trabalho (pedra proveniente de uma rocha ígnea) efetuaram-se alguns testes padrão para se assegurar da qualidade do sistema tomográfico desenvolvido no instituto. Para isto, utilizou-se um phantom cilíndrico especialmente preparado e construído na Universidade de Bergen, Noruega, uma vez que este trabalho está inserido no projeto: “Desenvolvimento de Um Sistema Tomográfico Computadorizado para Análise de Processos Multifase em Torres de Refino" ${ }^{1}$, o qual faz parte de um projeto de cooperação internacional apoiado pela Agência Internacional de Energia Atômica (AIEA).

Este phantom possui $40 \mathrm{~cm}$ de diâmetro e $25 \mathrm{~cm}$ de altura, com dois orifícios de $5,0 \mathrm{~cm}$ de diâmetro, inseridos na parte superior circular do corpo do phantom, conforme é mostrado na FIG. 4.6.

O phantom foi primeiramente tomografado com os dois orifícios vazios (FIG. 4.8(a)) e posteriormente um dos orifícios foi preenchido com óleo de canola ${ }^{11}$ cujo coeficiente de atenuação, $0,0572 \mathrm{~cm}^{-1}$, é igual ao do material do phantom (propileno) e assim, desaparece na figura tomografada (Mesquita et al, 2005).

\footnotetext{
${ }^{1}$ Variedade genética da colza (Brassica napus), do grupo Pabularia, extraído do óleo das sementes, cuja característica principal é possuir níveis reduzidos de ácidos graxos saturados.
} 


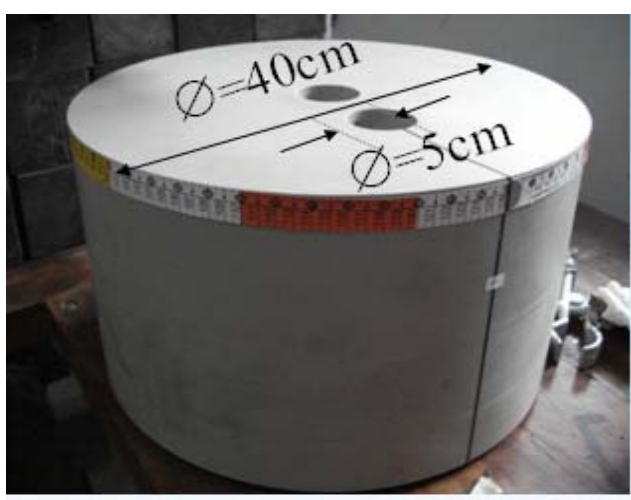

(a)

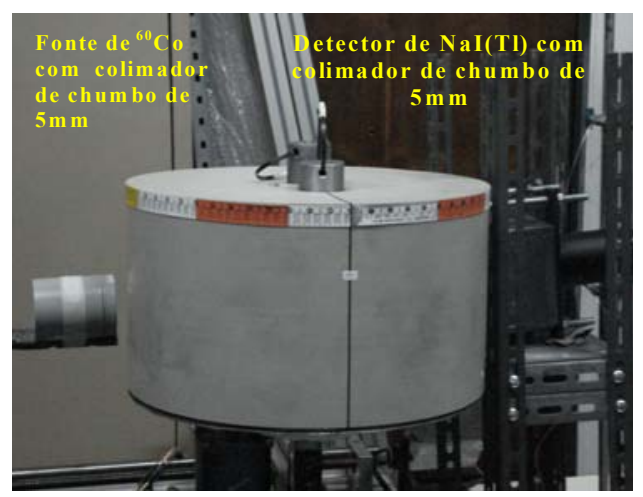

(b)

FIGURA 4.6: Phantom construído com polipropileno contendo dois orifícios de $5 \mathrm{~cm}$ de diâmetro. Este phantom foi especialmente preparado e construído na Universidade de Bergen, Noruega para servir como controle de qualidade em laboratórios participantes do projeto internacional de desenvolvimento de tomografia computadorizada financiado pela Agência Internacional de Energia Atômica (AIEA).

Após a conclusão dos testes padrão com o phantom, iniciou-se o exame tomográfico da mesma pedra ígnea, que foi tomografada no CTUT, no equipamento do CTR-IPEN-CNEN/SP. As mesmas condições iniciais de exame tomográfico foram repetidas. A pedra foi posicionada na esteira móvel do tomógrafo e o exame tomográfico foi iniciado, obtendo-se 12 matrizes de dados seus respectivos sinogramas, os quais analisados utilizando-se o programa MATLAB, versão 7.1 (Gonzáles \& Woods, 2005). O APÊNDICE B mostra alguns destes sinogramas.

Na FIG.4.7 é mostrado o início do exame tomográfico, com a pedra sendo posicionada em (a) e já na posição de exame em (b).

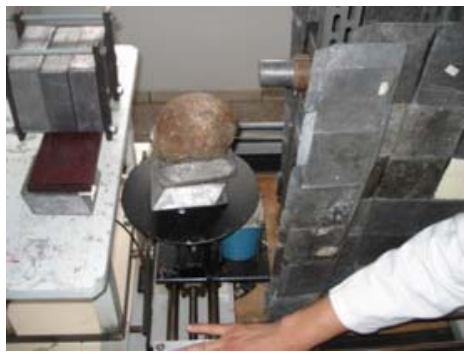

(a)

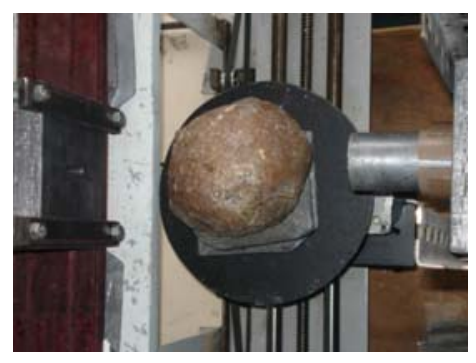

(b)

FIGURA 4.7: (a) Posicionamento da rocha no tomógrafo do CTR-IPEN-CNEN/SP e (b) a rocha na posição inicial para ser submetida ao exame tomográfico. 


\section{RESULTADOS E DISCUSSÕES}

Ao contrário do aspecto padronizado na aplicação da tomografia médica os objetos industriais a serem tomografados possuem entre si muitas diferenças geométricas, principalmente no tocante ao tamanho desses objetos. Daí há necessidade de serem desenvolvidos equipamentos diferenciados para estas aplicações. Este aspecto inibe a produção em larga escala desses tomógrafos, mas constitui um nicho de amplo interesse científico.

Nos tomógrafos industriais o tipo de fonte de radiação (gama ou raios X) e sua intensidade mudam de objeto para objeto.

A análise de qualidade utilizando um phantom padrão fornecido pela AIEA aplicado ao tomógrafo desenvolvido no CTR, do IPEN-CNEN/SP demonstrou que seus resultados estão compatíveis com os valores esperados para os dois materiais estudados, a saber: óleo de canola e polipropileno, conforme se infere da TAB 5.1.

TABELA 5.1: Relação entre valores experimentais e teóricos dos coeficientes de atenuação de materiais inseridos colocados nos orifícios do phantom.

\begin{tabular}{lcc}
\hline Material & \multicolumn{2}{c}{ Coeficiente de atenuação } \\
& $\begin{array}{c}\text { Valores experimentais } \\
\left(\mathrm{cm}^{-1}\right)\end{array}$ & $\begin{array}{c}\text { Valores esperados } \\
\left(\mathrm{cm}^{-1}\right)\end{array}$ \\
\hline Óleo de canola & 0,055 & 0,0572 \\
Polipropileno & 0.055 & 0,0572 \\
\hline
\end{tabular}

As imagens obtidas com o phantom nestes testes serviram como calibração inicial do tomógrafo computadorizado e estão mostradas na FIG. 5.1. 


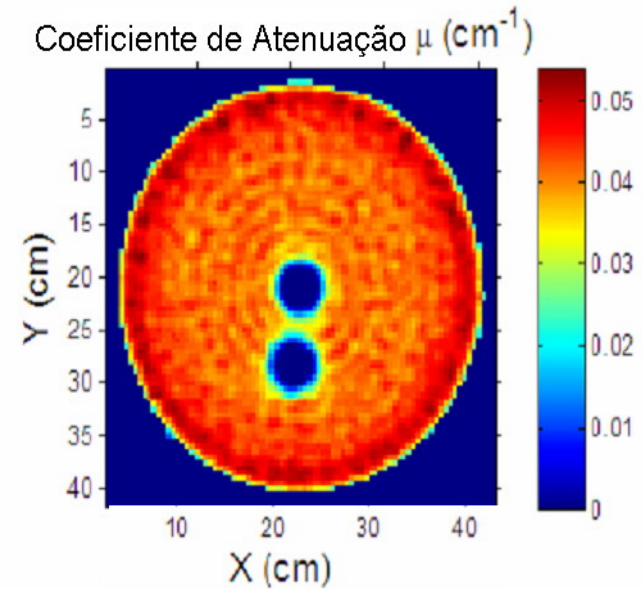

(a)

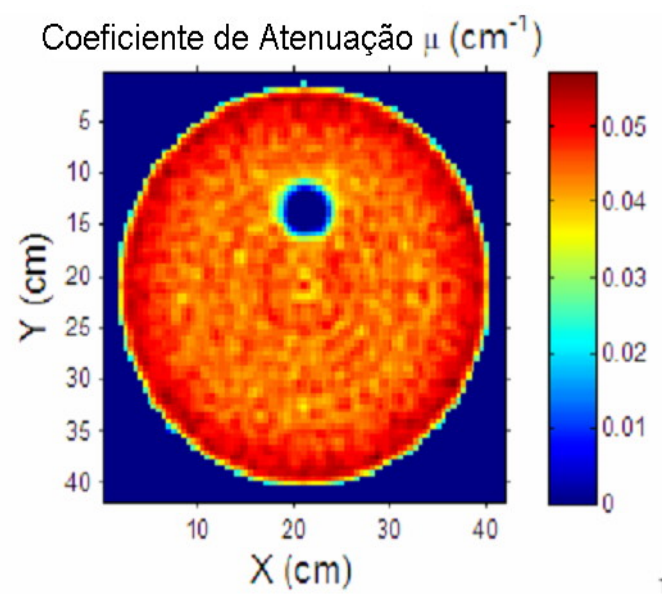

(b)

FIGURA 5.1: Imagens tomográficas do phantom: (a) figura tomográfica utilizando o tomógrafo computadorizado do CTR-IPEN-CNEN/SP, com os dois orifícios contendo apenas ar e (b) um dos orifícios preenchido com óleo de canola.

O objeto de estudo escolhido foi uma pedra brasileira (rocha ígnea), a qual passou por dois estudos tomográficos diferentes. Primeiramente foi analisada tomograficamente no laboratório de Tomografia Computadorizada da Universidade do Texas (CTUT), considerado como laboratório padrão nesta área. No CTUT foram obtidas oitenta imagens tomográficas do interior da pedra, utilizando-se a fonte de raios $\mathrm{X}$ como um exame de rotina daquele laboratório. O CTUT foi construído há mais de dez anos no Instituto de Geociências da Universidade do Texas e serviu como laboratório padrão neste tipo de aplicação.

O segundo estudo tomográfico focado na mesma pedra foi realizado no equipamento desenvolvido pela equipe de pesquisadores e colaboradores do CTRIPEN-CNEN/SP. Este equipamento, que está em fase experimental, utiliza fonte de ${ }^{60} \mathrm{Co}$ e um sistema de detectores de cintilação de Iodeto de Sódio dopado com Tálio, NaI(TI). Dada a complexidade e a extensão do assunto ressalta-se a importância de se desenvolver uma pesquisa com tecnologia totalmente nacional.

A tomografia computadorizada neste equipamento teve, além do caráter comparativo, a finalidade de contribuir com o conhecimento das escolhas dos componentes do equipamento e ainda conhecer melhor o campo de aplicação das técnicas tomográficas com potencial de interesse da comunidade. 
Comparar e discutir as semelhanças e diferenças entre os resultados obtidos pelas duas técnicas foi uma das formas possíveis de estudar a eficiência dos métodos tomográficos desenvolvidos no CTR-IPEN-CNEN/SP. A partir dos resultados buscar os possíveis usuários interessados nesses equipamentos.

A avaliação das imagens obtidas primeiramente com raios $X$, mostrou que a constituição interna da pedra é praticamente homogênea, com pequenos espaços vazios e ausência de formação de cristais conforme é mostrado na FIG.5.2.

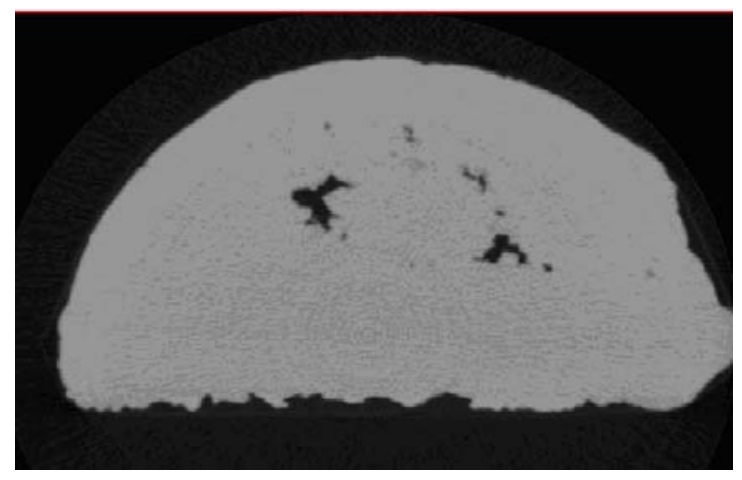

(a)

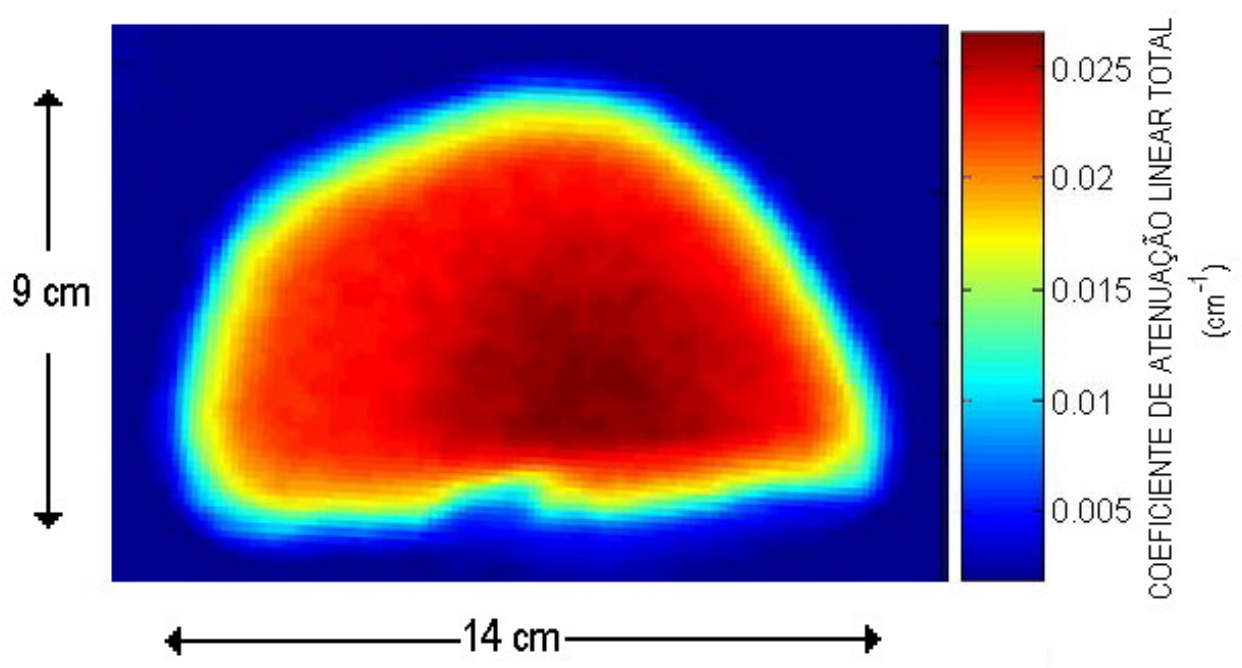

(b)

FIGURA 5.2: Imagens tomográficas obtidas: (a) tomógrafo CTUT (Texas-USA) e (b) tomógrafo do CTR-IPEN-CNEN/SP. Cortes longitudinais na região central do interior da rocha. A imagem obtida com a radiação gama $\left({ }^{60} \mathrm{Co}, \mathrm{E} \approx 1250 \mathrm{keV}\right)$ observa-se melhor diferenciação de densidade comparativamente à imagem obtida com raios $\mathrm{X}$ $(415 \mathrm{kV}, \mathrm{E} \approx 140 \mathrm{keV})$. 
Encontram-se no APÊNDICE A, as demais imagens tomográficas obtidas no tomógrafo do CTUT e no APÊNDICE B, os sinogramas obtidos no CTR-IPENCNEN/SP. Infere-se desses sinogramas a confirmação da ausência de cristais no interior da pedra utilizada neste estudo.

Observa-se que a resolução obtida é suficiente para o reconhecimento da homogeneidade interna. Na FIG 5.3 é mostrada a pedra, após ser seccionada na sua região central. E na FIG 5.4 é mostrada uma imagem tomográfica obtida no CTR-IPENCNEN/SP correspondente a secção do corte que aparece na fotografia da FIG. 5.3.

regióes que se destacam no interior da célula por apresentarem menor atenuação

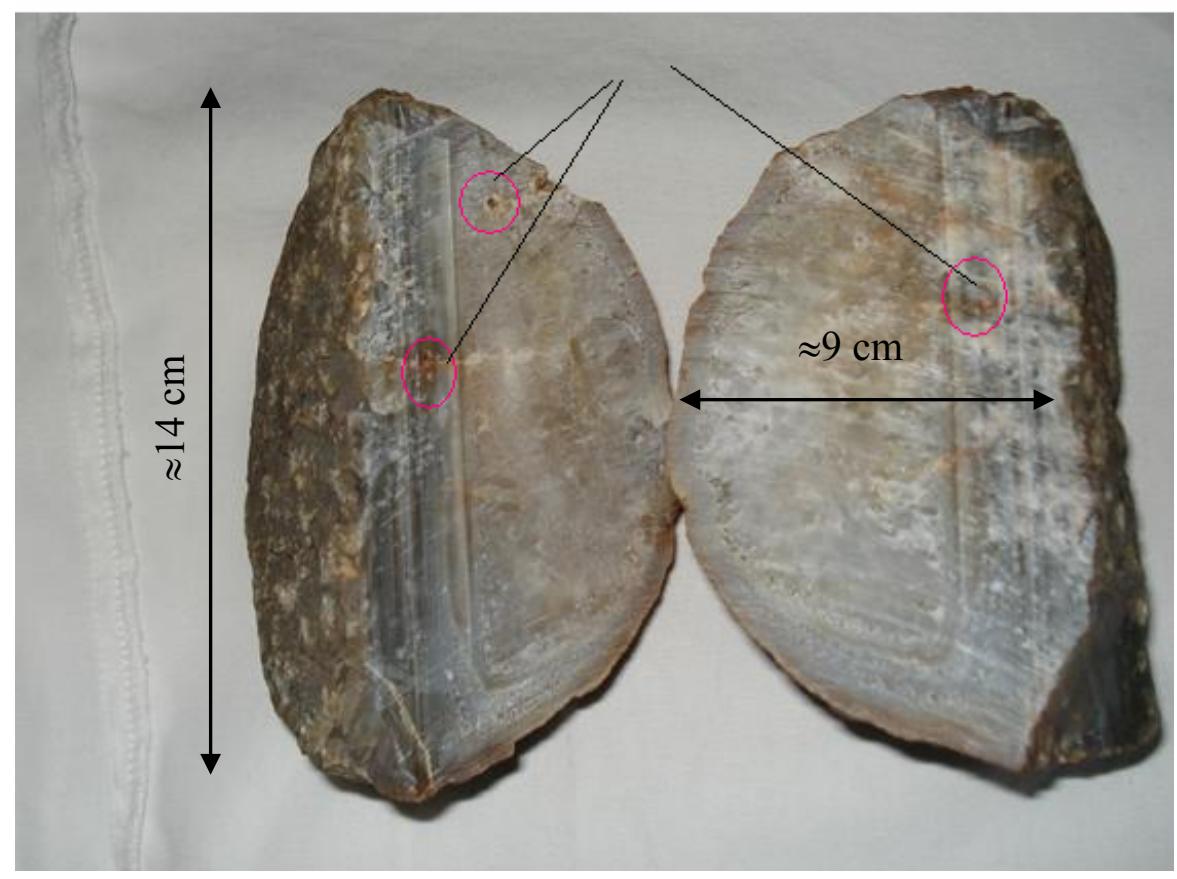

FIGURA 5.3: Na fotografia é mostrada a rocha ígnea seccionada ao meio.

A tomografia industrial abre espaço para um amplo campo de pesquisa na área tecnológica, assim como ocorreu com o desenvolvimento das técnicas tomográficas na área médica. Dentre as aplicações industriais dessa tecnologia poder-se-ia citar a sua aplicação para a orientação otimizada do corte de pedras com perspectivas de conter gemas preciosas em seu interior e também na análise prévia do interior de rochas provenientes de meteoritos. 

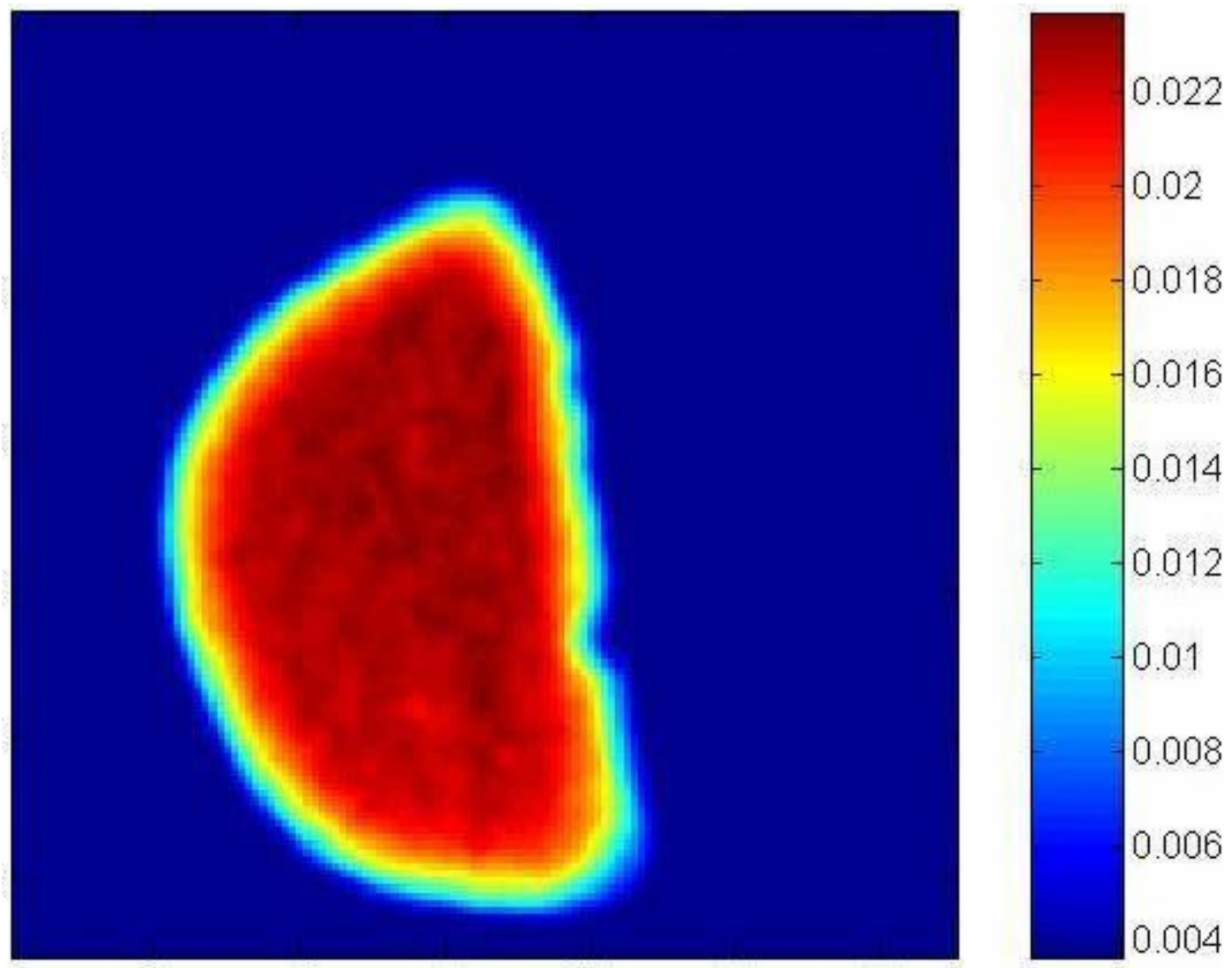

FIGURA 5.4: Imagem tomográfica da região onde a rocha foi seccionada obtida no CTR-IPEN-CNEN/SP. Os valores da coluna esquerda da figura referem-se ao coeficiente de atenuação do material interno da rocha $\left(\mathrm{cm}^{-1}\right)$.

Os resultados comparativos entre a utilização da tomografia com raios $\mathrm{X}$ e raios gama mostraram ser relativamente semelhantes. A pedra escolhida contrariou a expectativa de possuir uma formação interna vítrea. Por esta razão sugerem-se outros trabalhos utilizando-se rochas de diferentes composições internas. 


\section{CONCLUSÕES}

Neste trabalho verificou-se que é possível estudar o interior de uma rocha aplicando-se técnicas de TC. A resolução obtida foi suficiente para o reconhecimento da homogeneidade interna e a localização dos espaços vazios da mesma.

Os testes realizados nos dois laboratórios de tomografia computadorizada permitem as seguintes conclusões:

o As imagens tomográficas reconhecem o conteúdo interno de uma pedra, desde que se utilize um equipamento com fonte e detectores de radiação adequados;

o A TC é indicada para estudar a morfologia interna de pedras e rochas, sendo que a TC com raios $\mathrm{X}$ ou com radiação gama são compatíveis para este tipo de material. O tomógrafo estudado se presta para analisar rochas com valor comercial ou de interesse científico como a análise de meteoritos;

o O uso da tomografia computadorizada poderá ser útil na análise do corte otimizado de rochas com considerável valor econômico;

o O tomógrafo desenvolvido no CTR-IPEN-CNEN/SP apresentou resultados satisfatórios nos testes padrão realizados com o phantom fornecido pela AIEA (projetado e construído na Universidade de Bergen, Noruega);

o As comparações entre as imagens produzidas pelo tomógrafo do departamento de Tomografia Computadorizada da Universidade do Texas (CTUT) e do presente trabalho mostraram-se semelhantes, apesar da diferença tecnológica entre ambos tomógrafos (fonte de raios $\mathrm{X}$ versus fonte de raios gama do ${ }^{60} \mathrm{Co}$, tempos de medidas e tamanhos das fendas utilizadas); e

o O tomógrafo do CTR-IPEN-CNEN/SP pode ser utilizado em diversos ensaios industriais. 


\section{ANEXO A}

Coeficientes de atenuação de massa $\left(\mathrm{cm}^{2} / \mathrm{g}\right)$, decorrentes do efeito fotoelétrico, Compton, Rayleigh e produção de pares, em função da energia dos fótons incidentes para dois meios diferentes: ar e água.

\begin{tabular}{|c|c|c|c|c|c|c|}
\hline $\begin{array}{l}\text { Energia do } \\
\text { Fóton } \\
\text { (Mev) }\end{array}$ & Compton & Rayleigh & Fotoelétrico & $\begin{array}{l}\text { Produção } \\
\text { Pares no Núcleo } \\
(\mathrm{cm} 2 / \mathrm{g})\end{array}$ & $\begin{array}{c}\text { Produção } \\
\text { Pares Elétrons }\end{array}$ & Total \\
\hline $1.000 \mathrm{E}-03$ & $1.37 \mathrm{E}+00$ & $1.32 \mathrm{E}-02$ & $4.08 \mathrm{E}+03$ & $\odot \odot . \odot \odot E+\odot \odot$ & $0 . \odot \odot E+\odot \odot$ & $4.08 \mathrm{E}+03$ \\
\hline $1.500 \mathrm{E}-03$ & $1.27 \mathrm{E}+\odot \odot$ & $2.67 \mathrm{E}-02$ & $1.37 \mathrm{E}+03$ & $\odot . \odot \odot E+\odot \odot$ & $\odot . \odot \odot E+\odot \odot$ & $1.38 \mathrm{E}+03$ \\
\hline $2.0 \odot \odot E-\odot 3$ & $1.15 \mathrm{E}+\odot \odot$ & $4.18 \mathrm{E}-02$ & $6.16 \mathrm{E}+02$ & $\odot . \odot \odot \mathrm{E}+\odot \odot$ & $\odot . \odot \odot \mathrm{E}+\odot \odot$ & $6.17 \mathrm{E}+02$ \\
\hline $3.000 \mathrm{E}-03$ & $9.09 \mathrm{E}-01$ & $7.07 \mathrm{E}-02$ & $1.92 \mathrm{E}+02$ & $0.00 \mathrm{E}+00$ & $0.00 \mathrm{E}+00$ & $1.93 \mathrm{E}+02$ \\
\hline $4.000 \mathrm{E}-03$ & $7.08 \mathrm{E}-01$ & $9.43 \mathrm{E}-02$ & $8.20 \mathrm{E}+01$ & $0.0 \odot \mathrm{E}+\odot \odot$ & $\odot .0 \odot \mathrm{E}+\odot \odot$ & $8.28 \mathrm{E}+01$ \\
\hline $5.000 \mathrm{E}-03$ & $5.58 \mathrm{E}-01$ & $1.12 \mathrm{E}-01$ & $4.19 \mathrm{E}+01$ & $0.00 \mathrm{E}+0 \odot$ & $0.00 \mathrm{E}+0 \odot$ & $4.26 \mathrm{E}+01$ \\
\hline $6.000 \mathrm{E}-03$ & $4.49 \mathrm{E}-01$ & $1.26 \mathrm{E}-01$ & $2.41 \mathrm{E}+01$ & $\odot . \odot \odot \mathrm{E}+\odot \odot$ & $\odot .0 \odot \mathrm{E}+\odot \odot$ & $2.46 \mathrm{E}+01$ \\
\hline $8.000 \mathrm{E}-03$ & $3.10 \mathrm{E}-01$ & $1.44 \mathrm{E}-01$ & $9.92 \mathrm{E}+0 \odot$ & $\odot .0 \odot \mathrm{E}+\odot \odot$ & $\odot .0 \odot \mathrm{E}+\odot \odot$ & $1.04 \mathrm{E}+01$ \\
\hline $1.000 \mathrm{E}-02$ & $2.31 \mathrm{E}-01$ & $1.55 \mathrm{E}-01$ & $4.94 \mathrm{E}+00$ & $\odot .00 \mathrm{E}+0 \odot$ & $\odot .0 \odot \mathrm{E}+\odot \odot$ & $5.33 \mathrm{E}+00$ \\
\hline $1.500 \mathrm{E}-02$ & $1.33 \mathrm{E}-01$ & $1.70 \mathrm{E}-01$ & $1.37 \mathrm{E}+0 \odot$ & $0.00 \mathrm{E}+\odot \odot$ & $\odot .0 \odot \mathrm{E}+\odot \odot$ & $1.67 \mathrm{E}+00$ \\
\hline $2.0 \odot \odot E-\odot 2$ & $8.86 \mathrm{E}-02$ & $1.77 \mathrm{E}-01$ & $5.44 \mathrm{E}-01$ & $\odot . \odot \odot \mathrm{E}+\odot \odot$ & $\odot . \odot \odot \mathrm{E}+\odot \odot$ & $8.10 \mathrm{E}-01$ \\
\hline $3.000 \mathrm{E}-02$ & $4.69 \mathrm{E}-02$ & $1.83 \mathrm{E}-01$ & $1.46 \mathrm{E}-01$ & $\odot . \odot \odot E+\odot \odot$ & $\odot . \odot \odot \mathrm{E}+\odot \odot$ & $3.76 \mathrm{E}-01$ \\
\hline $4.000 \mathrm{E}-02$ & $2.87 \mathrm{E}-02$ & $1.83 \mathrm{E}-01$ & $5.68 \mathrm{E}-02$ & $0.00 \mathrm{E}+\odot \odot$ & $\odot .0 \odot \mathrm{E}+\odot \odot$ & $2.68 \mathrm{E}-01$ \\
\hline $5.000 \mathrm{E}-02$ & $1.94 \mathrm{E}-02$ & $1.80 \mathrm{E}-01$ & $2.72 \mathrm{E}-02$ & $0.00 \mathrm{E}+00$ & $0.00 \mathrm{E}+00$ & $2.27 \mathrm{E}-01$ \\
\hline $6.000 \mathrm{E}-02$ & $1.39 \mathrm{E}-02$ & $1.77 \mathrm{E}-01$ & $1.49 \mathrm{E}-02$ & $0.00 \mathrm{E}+00$ & $0.00 \mathrm{E}+0 \odot$ & $2.06 \mathrm{E}-01$ \\
\hline $8.000 \mathrm{E}-\odot 2$ & $8.16 \mathrm{E}-03$ & $1.70 \mathrm{E}-01$ & $5.77 \mathrm{E}-03$ & $\odot . \odot \odot \mathrm{E}+\odot \odot$ & $\odot . \odot \odot \mathrm{E}+\odot \odot$ & $1.84 \mathrm{E}-01$ \\
\hline $1.000 \mathrm{E}-01$ & $5.35 \mathrm{E}-03$ & $1.63 \mathrm{E}-01$ & $2.76 \mathrm{E}-03$ & $0.0 \odot \mathrm{E}+\odot \odot$ & $\odot .0 \odot \mathrm{E}+\odot \odot$ & $1.71 \mathrm{E}-01$ \\
\hline $1.500 \mathrm{E}-01$ & $2.44 \mathrm{E}-03$ & $1.47 \mathrm{E}-01$ & $7.31 \mathrm{E}-04$ & $\odot . \odot \odot \mathrm{E}+\odot \odot$ & $\odot . \odot \odot \mathrm{E}+\odot \odot$ & $1.51 \mathrm{E}-01$ \\
\hline $2.000 \mathrm{E}-01$ & $1.39 \mathrm{E}-03$ & $1.35 \mathrm{E}-01$ & $2.89 \mathrm{E}-04$ & $\odot . \odot \odot \mathrm{E}+\odot \odot$ & $\odot . \odot \odot E+\odot \odot$ & $1.37 \mathrm{E}-01$ \\
\hline $3.000 \mathrm{E}-01$ & $6.22 \mathrm{E}-04$ & $1.18 \mathrm{E}-01$ & $8.16 \mathrm{E}-05$ & $\odot .0 \odot \mathrm{E}+\odot \odot$ & $0.0 \odot \mathrm{E}+\Theta \odot$ & $1.19 \mathrm{E}-01$ \\
\hline $4.000 \mathrm{E}-01$ & $3.51 \mathrm{E}-\odot 4$ & $1.06 \mathrm{E}-01$ & $3.49 \mathrm{E}-05$ & $0.0 \odot \mathrm{E}+\odot \odot$ & $\odot . \odot \odot \mathrm{E}+\odot \odot$ & $1.06 \mathrm{E}-01$ \\
\hline $5.000 \mathrm{E}-01$ & $2.25 \mathrm{E}-04$ & $9.66 \mathrm{E}-02$ & $1.88 \mathrm{E}-05$ & $\odot . \odot \odot E+\odot \odot$ & $\odot . \odot \odot E+\odot \odot$ & $9.69 \mathrm{E}-02$ \\
\hline $6.000 \mathrm{E}-01$ & $1.56 \mathrm{E}-04$ & $8.94 \mathrm{E}-02$ & $1.17 \mathrm{E}-05$ & $0.00 \mathrm{E}+0 \odot$ & $0.00 \mathrm{E}+\Theta \odot$ & $8.96 \mathrm{E}-02$ \\
\hline $8.00 \odot \mathrm{E}-01$ & $8.79 \mathrm{E}-05$ & $7.86 \mathrm{E}-02$ & $5.92 \mathrm{E}-06$ & $\odot . \odot \odot \mathrm{E}+\odot \odot$ & $\odot . \odot \odot \mathrm{E}+\odot \odot$ & $7.87 \mathrm{E}-02$ \\
\hline $1.000 \mathrm{E}+00$ & $5.63 \mathrm{E}-05$ & $7.07 \mathrm{E}-02$ & $3.68 \mathrm{E}-06$ & $0.00 \mathrm{E}+00$ & $0.00 \mathrm{E}+00$ & $7.07 \mathrm{E}-02$ \\
\hline $1.022 \mathrm{E}+0 \odot$ & $5.39 \mathrm{E}-05$ & $6.99 \mathrm{E}-02$ & $3.43 E-06$ & $0.00 \mathrm{E}+0 \odot$ & $0.00 \mathrm{E}+0 \odot$ & $7.00 \mathrm{E}-02$ \\
\hline $1.25 \odot \mathrm{E}+\odot \odot$ & $3.60 \mathrm{E}-05$ & $6.32 \mathrm{E}-02$ & $2.33 \mathrm{E}-06$ & $1.78 \mathrm{E}-05$ & $\odot . \odot \odot E+\odot \odot$ & $6.32 \mathrm{E}-02$ \\
\hline $1.500 \mathrm{E}+00$ & $2.50 \mathrm{E}-05$ & $5.74 \mathrm{E}-02$ & $1.69 \mathrm{E}-06$ & $9.82 \mathrm{E}-05$ & $0.00 \mathrm{E}+\odot \odot$ & $5.75 \mathrm{E}-02$ \\
\hline $2.000 \mathrm{E}+0 \odot$ & $1.41 \mathrm{E}-05$ & $4.90 \mathrm{E}-02$ & $1.06 \mathrm{E}-06$ & $3.91 \mathrm{E}-04$ & $\odot . \odot \odot \mathrm{E}+\odot \odot$ & $4.94 \mathrm{E}-02$ \\
\hline $2.044 \mathrm{E}+00$ & $1.35 \mathrm{E}-05$ & $4.84 \mathrm{E}-02$ & $1.03 \mathrm{E}-06$ & $4.21 \mathrm{E}-04$ & $0.00 \mathrm{E}+00$ & $4.88 \mathrm{E}-02$ \\
\hline $3.000 \mathrm{E}+\Theta \odot$ & $6.26 \mathrm{E}-06$ & $3.85 \mathrm{E}-02$ & $5.94 \mathrm{E}-07$ & $1.12 \mathrm{E}-03$ & $1.35 \mathrm{E}-05$ & $3.97 \mathrm{E}-02$ \\
\hline $4.0 \odot \odot E+\odot \odot$ & $3.52 \mathrm{E}-06$ & $3.22 \mathrm{E}-02$ & $4.08 \mathrm{E}-07$ & $1.81 \mathrm{E}-03$ & $5.51 \mathrm{E}-05$ & $3.40 \mathrm{E}-02$ \\
\hline $5.000 \mathrm{E}+00$ & $2.25 \mathrm{E}-06$ & $2.78 \mathrm{E}-02$ & $3.09 \mathrm{E}-07$ & $2.43 \mathrm{E}-03$ & $1.10 \mathrm{E}-04$ & $3.03 \mathrm{E}-02$ \\
\hline $6.000 \mathrm{E}+0 \odot$ & $1.56 \mathrm{E}-06$ & $2.45 \mathrm{E}-02$ & $2.48 \mathrm{E}-07$ & $2.99 \mathrm{E}-03$ & $1.69 \mathrm{E}-04$ & $2.77 \mathrm{E}-02$ \\
\hline $7.000 \mathrm{E}+0 \odot$ & $1.15 \mathrm{E}-06$ & $2.21 \mathrm{E}-02$ & $2.07 \mathrm{E}-07$ & $3.48 \mathrm{E}-03$ & $2.27 \mathrm{E}-04$ & $2.58 \mathrm{E}-02$ \\
\hline $8.000 \mathrm{E}+00$ & $8.80 \mathrm{E}-07$ & $2.01 \mathrm{E}-02$ & $1.78 \mathrm{E}-07$ & $3.93 \mathrm{E}-03$ & $2.84 \mathrm{E}-04$ & $2.43 \mathrm{E}-02$ \\
\hline $9.0 \odot \odot E+\odot \odot$ & $6.95 \mathrm{E}-07$ & $1.85 \mathrm{E}-02$ & $1.56 \mathrm{E}-07$ & $4.33 \mathrm{E}-03$ & $3.39 \mathrm{E}-04$ & $2.31 \mathrm{E}-02$ \\
\hline $1.000 \mathrm{E}+01$ & $5.63 \mathrm{E}-07$ & $1.71 \mathrm{E}-02$ & $1.39 \mathrm{E}-07$ & $4.70 \mathrm{E}-03$ & $3.91 \mathrm{E}-04$ & $2.22 \mathrm{E}-02$ \\
\hline $1.100 \mathrm{E}+01$ & $4.65 \mathrm{E}-07$ & $1.59 \mathrm{E}-02$ & $1.25 \mathrm{E}-07$ & $5.03 \mathrm{E}-03$ & $4.40 \mathrm{E}-04$ & $2.14 \mathrm{E}-02$ \\
\hline $1.200 \mathrm{E}+01$ & $3.91 \mathrm{E}-07$ & $1.50 \mathrm{E}-02$ & $1.13 \mathrm{E}-07$ & $5.34 \mathrm{E}-03$ & $4.87 \mathrm{E}-04$ & $2.08 \mathrm{E}-02$ \\
\hline $1.300 \mathrm{E}+01$ & $3.33 \mathrm{E}-07$ & $1.41 \mathrm{E}-02$ & $1.04 \mathrm{E}-07$ & $5.63 \mathrm{E}-03$ & $5.32 \mathrm{E}-04$ & $2.02 \mathrm{E}-02$ \\
\hline $1.400 \mathrm{E}+01$ & $2.87 \mathrm{E}-07$ & $1.33 E-02$ & $9.59 \mathrm{E}-08$ & $5.89 \mathrm{E}-03$ & $5.74 \mathrm{E}-04$ & $1.98 \mathrm{E}-02$ \\
\hline $1.500 \mathrm{E}+01$ & $2.50 \mathrm{E}-07$ & $1.27 \mathrm{E}-02$ & $8.91 \mathrm{E}-08$ & $6.14 \mathrm{E}-03$ & $6.13 \mathrm{E}-04$ & $1.94 \mathrm{E}-02$ \\
\hline $1.600 \mathrm{E}+01$ & $2.20 \mathrm{E}-07$ & $1.21 \mathrm{E}-02$ & $8.31 \mathrm{E}-08$ & $6.38 \mathrm{E}-03$ & $6.52 \mathrm{E}-04$ & $1.91 \mathrm{E}-02$ \\
\hline $1.800 \mathrm{E}+01$ & $1.74 \mathrm{E}-07$ & $1.10 \mathrm{E}-02$ & $7.33 \mathrm{E}-08$ & $6.80 \mathrm{E}-03$ & $7.23 \mathrm{E}-04$ & $1.85 \mathrm{E}-02$ \\
\hline $2.000 \mathrm{E}+01$ & $1.41 \mathrm{E}-07$ & $1.02 \mathrm{E}-02$ & $6.56 \mathrm{E}-08$ & $7.19 \mathrm{E}-03$ & $7.88 \mathrm{E}-04$ & $1.81 \mathrm{E}-02$ \\
\hline $2.200 \mathrm{E}+01$ & $1.16 \mathrm{E}-07$ & $9.44 \mathrm{E}-03$ & $5.93 \mathrm{E}-08$ & $7.54 \mathrm{E}-03$ & $8.48 \mathrm{E}-04$ & $1.78 \mathrm{E}-02$ \\
\hline $2.40 \odot \mathrm{E}+01$ & $9.77 \mathrm{E}-08$ & $8.82 \mathrm{E}-03$ & $5.41 \mathrm{E}-08$ & $7.85 \mathrm{E}-03$ & $9.03 \mathrm{E}-04$ & $1.76 \mathrm{E}-02$ \\
\hline $2.600 \mathrm{E}+01$ & $8.33 \mathrm{E}-08$ & $8.28 \mathrm{E}-03$ & $4.98 \mathrm{E}-08$ & $8.14 \mathrm{E}-03$ & $9.55 \mathrm{E}-04$ & $1.74 \mathrm{E}-02$ \\
\hline $2.800 \mathrm{E}+01$ & $7.18 \mathrm{E}-08$ & $7.81 \mathrm{E}-03$ & $4.61 \mathrm{E}-08$ & $8.41 \mathrm{E}-03$ & $1.00 \mathrm{E}-03$ & $1.72 \mathrm{E}-02$ \\
\hline $3.000 \mathrm{E}+01$ & $6.26 \mathrm{E}-08$ & $7.40 \mathrm{E}-03$ & $4.29 \mathrm{E}-08$ & $8.66 \mathrm{E}-03$ & $1.05 \mathrm{E}-03$ & $1.71 \mathrm{E}-02$ \\
\hline $4.000 \mathrm{E}+01$ & $3.52 \mathrm{E}-08$ & $5.88 \mathrm{E}-03$ & $3.19 \mathrm{E}-08$ & $9.67 \mathrm{E}-03$ & $1.24 \mathrm{E}-03$ & $1.68 \mathrm{E}-02$ \\
\hline $5.000 \mathrm{E}+01$ & $2.25 \mathrm{E}-08$ & $4.91 \mathrm{E}-03$ & $2.53 \mathrm{E}-08$ & $1.04 \mathrm{E}-02$ & $1.39 \mathrm{E}-03$ & $1.67 \mathrm{E}-02$ \\
\hline $6.000 \mathrm{E}+01$ & $1.56 \mathrm{E}-08$ & $4.22 \mathrm{E}-03$ & $2.10 \mathrm{E}-08$ & $1.11 \mathrm{E}-02$ & $1.51 \mathrm{E}-03$ & $1.68 \mathrm{E}-02$ \\
\hline $8.000 \mathrm{E}+01$ & $8.80 \mathrm{E}-09$ & $3.33 \mathrm{E}-03$ & $1.57 \mathrm{E}-08$ & $1.20 \mathrm{E}-02$ & $1.69 \mathrm{E}-03$ & $1.70 \mathrm{E}-02$ \\
\hline $1.000 \mathrm{E}+02$ & $5.63 \mathrm{E}-09$ & $2.77 \mathrm{E}-03$ & $1.25 \mathrm{E}-08$ & $1.27 \mathrm{E}-02$ & $1.83 \mathrm{E}-03$ & $1.73 \mathrm{E}-02$ \\
\hline
\end{tabular}




\begin{abstract}
ANEXO B
Dedução da equação do efeito Compton parte da afirmação a seguir,
\end{abstract} EQ.2.6, a qual representa a conservação de energia do fóton antes e após a colisão (Chen, 2006).

$$
E_{\gamma}+E_{e}=E_{\gamma^{\prime}}+E_{e^{\prime}}
$$

Pela conservação de energia, se $E_{\gamma}$ é a energia do fóton antes da colisão e $E_{e}$ é a energia do elétron antes da colisão (sua massa de repouso), as variáveis com apóstrofe são usadas por estas respectivas energias depois da colisão de forma que a equação que corresponde a conservação do momento (EQ. 2.7):

$$
\overrightarrow{p_{\gamma}}+\overrightarrow{p_{e}}=\overrightarrow{p_{\gamma^{\prime}}}+\overrightarrow{p_{e^{\prime}}}
$$

Com $p_{e}=0$, uma vez que se assume, inicialmente, o elétron em repouso. Obtem-se a energia envolvida no espalhamento Compton, através das relações apresentadas a seguir:

$$
\begin{gathered}
\boldsymbol{E}=\boldsymbol{h \boldsymbol { f }}=\boldsymbol{p \boldsymbol { c }} \\
\overrightarrow{p_{e^{\prime}}}=\overrightarrow{p_{\gamma}}-\overrightarrow{p_{\gamma^{\prime}}} \\
\overrightarrow{p_{e^{\prime}}}{ }^{2}=\left(\overrightarrow{p_{\gamma}}-\overrightarrow{p_{\gamma^{\prime}}}\right)^{2} \\
\overrightarrow{p_{e^{\prime}}}=\overrightarrow{p_{\gamma}^{2}}-2 \cdot \overrightarrow{p_{\gamma}} \cdot \overrightarrow{p_{\gamma^{\prime}}}+\overrightarrow{p_{\gamma^{\prime}}} \\
\overrightarrow{p_{e^{\prime}}} \cdot \overrightarrow{p_{e^{\prime}}}=\overrightarrow{p_{\gamma}} \cdot \overrightarrow{p_{\gamma}}-2 \cdot \overrightarrow{p_{\gamma}} \cdot \overrightarrow{p_{\gamma^{\prime}}}+\overrightarrow{p_{\gamma^{\prime}}} \cdot \overrightarrow{p_{\gamma^{\prime}}} \\
p_{e^{\prime}}^{2} \cdot \cos (0)=p_{\gamma}^{2} \cdot \cos (0)-2 \cdot p_{\gamma} \cdot p_{\gamma^{\prime}} \cdot \cos (\theta)+\vec{p}_{\gamma^{\prime}}^{2} \cdot \cos (0)
\end{gathered}
$$

O termo $\cos (\theta)$ aparece porque o momentum está em vetores espaciais, no qual todos estão em um plano singular 2D. Portanto, seu produto escalar é o produto de suas normas multiplicado pelo cosseno do ângulo entre eles. 
Substituindo $p_{\gamma}$ por h.f $/ \mathbf{c}$ e $p_{\gamma^{\prime}}$ por h.f'/c, obtem-se:

$$
p_{e^{\prime}}^{2}=\frac{h^{2} f^{2}}{c^{2}}+\frac{h^{2} f^{\prime 2}}{c^{2}}-\frac{2 h^{2} f f^{\prime} \cos \theta}{c^{2}}
$$

Completando a parte da energia:

$$
\begin{gathered}
E_{\gamma}+E_{e}=E_{\gamma^{\prime}}+E_{e^{\prime}} \\
h f+m c^{2}=h f^{\prime}+\sqrt{\left(p_{e^{\prime}} c\right)^{2}+\left(m c^{2}\right)^{2}}
\end{gathered}
$$

Que se resolve por $\mathrm{p}_{\mathrm{e}}$ :

$$
\begin{gathered}
\left(h f+m c^{2}-h f^{\prime}\right)^{2}=\left(p_{e^{\prime}} c\right)^{2}+\left(m c^{2}\right)^{2} \\
\frac{\left(h f+m c^{2}-h f^{\prime}\right)^{2}-m^{2} c^{4}}{c^{2}}=p_{e^{\prime}}^{2} \\
\frac{\left(h f+m c^{2}-h f^{\prime}\right)^{2}-m^{2} c^{4}}{c^{2}}=\frac{h^{2} f^{2}}{c^{2}}+\frac{h^{2} f^{\prime 2}}{c^{2}}-\frac{2 h^{2} f f^{\prime} \cos \theta}{c^{2}}
\end{gathered}
$$

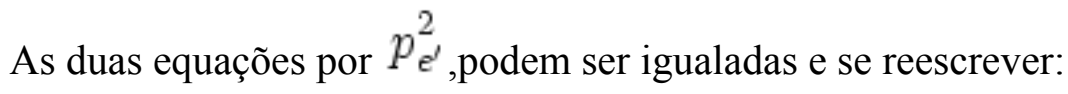

$$
\begin{gathered}
h^{2} f^{2}+h^{2} f^{\prime 2}-2 h^{2} f f^{\prime}+2 h\left(f-f^{\prime}\right) m c^{2}=h^{2} f^{2}+h^{2} f^{2}-2 h^{2} f f^{\prime} \cos \theta \\
-2 h^{2} f f^{\prime}+2 h\left(f-f^{\prime}\right) m c^{2}=-2 h^{2} f f^{\prime} \cos \theta \\
h f f^{\prime}-\left(f-f^{\prime}\right) m c^{2}=h f f^{\prime} \cos \theta
\end{gathered}
$$




$$
\begin{gathered}
h \frac{c}{\lambda^{\prime}} \frac{c}{\lambda}(1-\cos \theta)=\left(\frac{c}{\lambda}-\frac{c}{\lambda^{\prime}}\right) m c^{2} \\
h \frac{c}{\lambda^{\prime}} \frac{c}{\lambda}(1-\cos \theta)=\left(\frac{c \lambda^{\prime}}{\lambda \lambda^{\prime}}-\frac{c \lambda}{\lambda^{\prime} \lambda}\right) m c^{2} \\
h(1-\cos \theta)=\frac{\lambda^{\prime}}{c} \frac{\lambda}{c}\left(\frac{c \lambda^{\prime}}{\lambda^{\prime} \lambda}-\frac{c \lambda}{\lambda \lambda^{\prime}}\right) m c^{2} \\
h(1-\cos \theta)=\left(\frac{\lambda^{\prime}}{c}-\frac{\lambda}{c}\right) m c^{2} \\
\frac{h}{m c}(1-\cos \theta)=\lambda^{\prime}-\lambda
\end{gathered}
$$




\section{ANEXO C}

\section{Exemplo de calibração do sistema tomográfico}

A calibração do sistema tomográfico consiste, basicamente, em se encontrar a relação existente entre as unidades tomográficas e os coeficientes de atenuação linear para alguns materiais "homogêneos".

Os materiais selecionados para a calibração devem ser bastante homogêneos a fim de garantir um bom ajuste linear entre o coeficiente de atenuação do material $\mu$ e o número de CT. O coeficiente de atenuação linear de cada material geralmente é determinado várias vezes em diferentes posições para se obter um valor médio de $\mu$. As unidades tomográficas são obtidas através das matrizes de dados que deverão gerar as imagens tomográficas de cada um dos materiais que tiveram os valores de $\mu$ determinados. O procedimento para a determinação de $C T$, para um determinado material, consiste na seleção de uma matriz de dados que esteja contida na matriz original. $\mathrm{O}$ valor médio de todos os pontos da matriz selecionada é adotado como o valor de $C T$ para o material usado na calibração. Após a obtenção de todos os coeficientes de atenuação linear e unidades tomográficas para cada um dos materiais plota-se o gráfico de $C T$ versus $\mu$. Possíveis materiais que podem ser usados na calibração de sistemas tomográficos são: água, álcool, nylon, acrílico, alumínio e latão.

Na realização da calibração é possível se encontrar uma relação linear entre a unidade tomográfica e o coeficiente de atenuação linear do material que está sendo submetido à tomografia. A TAB. C.1 representa um exemplo de valores obtidos na calibração de um sistema tomográfico. Os números em vermelho na área central representam a matriz selecionada para a determinação do valor médio de $C T$ dos materiais usados na calibração do tomógrafo.

TABELA C.1: Esquema de uma matriz de unidades tomográficas ou número de CT. Os números em vermelho na área central representam a matriz selecionada para a determinação do valor médio de $C T$ dos materiais usados na calibração do tomógrafo.

$\begin{array}{cccccccccc}\mathbf{0} & \mathbf{0} & \mathbf{0} & \mathbf{0} & \mathbf{0} & \mathbf{0} & \mathbf{0} & \mathbf{0} & \mathbf{0} & \mathbf{0} \\ \mathbf{0} & \mathbf{8 0} & \mathbf{8 0} & \mathbf{8 0} & \mathbf{8 0} & \mathbf{8 0} & \mathbf{8 0} & \mathbf{8 0} & \mathbf{8 0} & \mathbf{0} \\ \mathbf{0} & \mathbf{8 0} & \mathbf{5 0} & \mathbf{5 0} & \mathbf{5 0} & \mathbf{5 0} & \mathbf{5 0} & \mathbf{5 0} & \mathbf{8 0} & \mathbf{0} \\ \mathbf{0} & \mathbf{8 0} & \mathbf{5 0} & \mathbf{5 0} & \mathbf{5 0} & \mathbf{5 0} & \mathbf{5 0} & \mathbf{5 0} & \mathbf{8 0} & \mathbf{0} \\ \mathbf{0} & \mathbf{8 0} & \mathbf{5 0} & \mathbf{5 0} & \mathbf{5 0} & \mathbf{5 0} & \mathbf{5 0} & \mathbf{5 0} & \mathbf{8 0} & \mathbf{0} \\ \mathbf{0} & \mathbf{8 0} & \mathbf{5 0} & \mathbf{5 0} & \mathbf{5 0} & \mathbf{5 0} & \mathbf{5 0} & \mathbf{5 0} & \mathbf{8 0} & \mathbf{0} \\ \mathbf{0} & \mathbf{8 0} & \mathbf{5 0} & \mathbf{5 0} & \mathbf{5 0} & \mathbf{5 0} & \mathbf{5 0} & \mathbf{5 0} & \mathbf{8 0} & \mathbf{0} \\ \mathbf{0} & \mathbf{8 0} & \mathbf{5 0} & \mathbf{5 0} & \mathbf{5 0} & \mathbf{5 0} & \mathbf{5 0} & \mathbf{5 0} & \mathbf{8 0} & \mathbf{0} \\ \mathbf{0} & \mathbf{8 0} & \mathbf{8 0} & \mathbf{8 0} & \mathbf{8 0} & \mathbf{8 0} & \mathbf{8 0} & \mathbf{8 0} & \mathbf{8 0} & \mathbf{0} \\ \mathbf{0} & \mathbf{0} & \mathbf{0} & \mathbf{0} & \mathbf{0} & \mathbf{0} & \mathbf{0} & \mathbf{0} & \mathbf{0} & \mathbf{0}\end{array}$

Os números " 0 " representam a atenuação somente pelo ar e os números "80" a atenuação pelas bordas do recipiente que contém amostras líquidas. 


\section{APÊNDICE A}

Imagens obtidas no CTUT, as quais confirmam os resultados e ainda acrescentam ao estudo uma avaliação da extensão dos espaços vazios internos detectados.

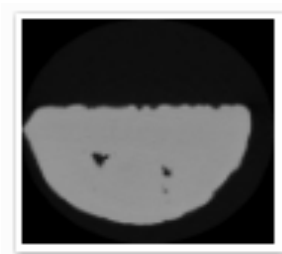

rockCT0001

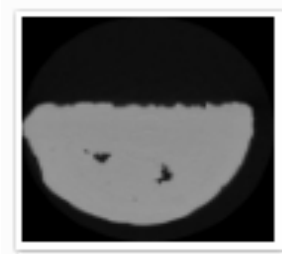

rockCT0011

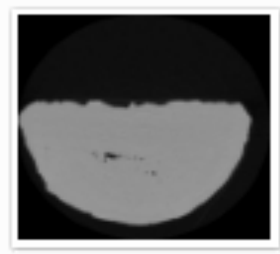

rockCT0021

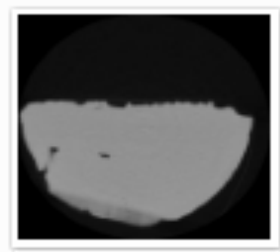

rockCT0031

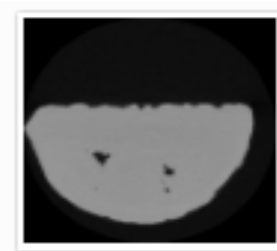

rockCT0002

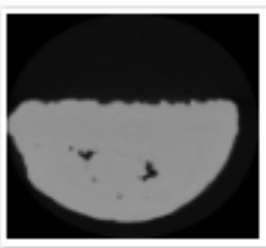

rockCT0012

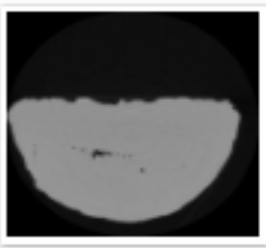

rockCT0022

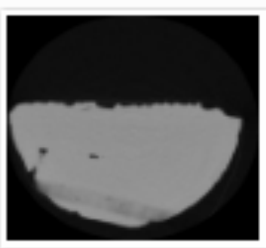

rockCT0032

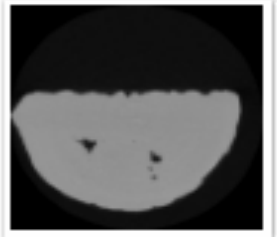

rockCT0003

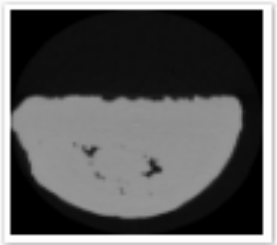

rockCT0013

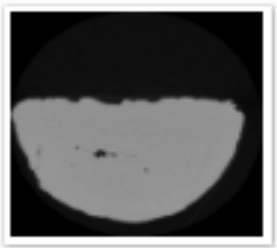

rockCT0023

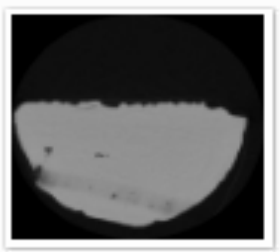

rockCT0033

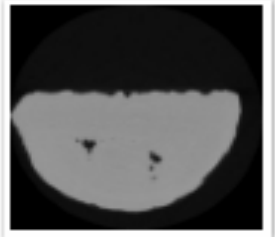

rockCT0004

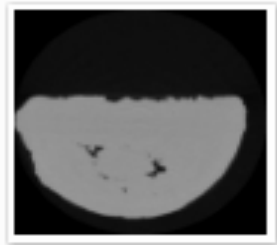

rockCT0014

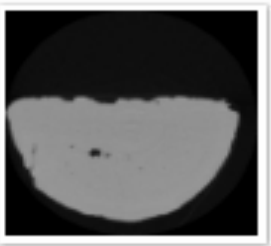

rockCT0024

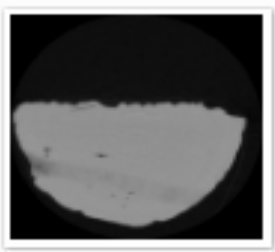

rockCT0034

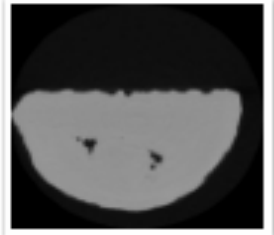

rockCT0005

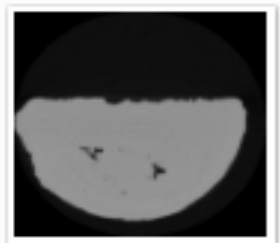

rockCT0015

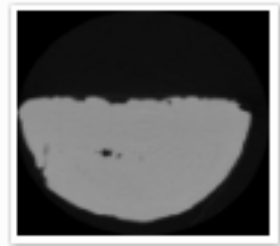

rockCT0025

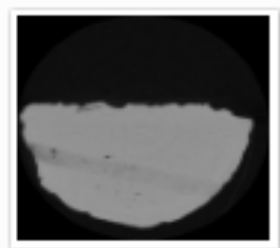

rockCT0035

rock: Scans of rock sample for Guaraciaba Tetzner of the University of Sao Paolo. All scanning and image processing by Richard Ketcham, 10 July 2007.

rockCT $\backslash$ 16bitTIF : $512 x 512$ 16-bit TIFF images. P250D, [images 1-9: 419 kV, 4.7 mA; images 10-29: $415 \mathrm{kV}, 4.0 \mathrm{~mA}$; images 30-80: $415 \mathrm{kV}, 3.2 \mathrm{~mA}$, 1 brass filter, air wedge, no offset, $32 \mathrm{~ms}$ integration time, slice thickness $=0.5 \mathrm{~mm}$, S.O.D. $752 \mathrm{~mm}$, 1000 views, 1 ray averaged per view, 1 sample per view, inter-slice spacing $0.5 \mathrm{~mm}$, field of reconstruction $134 \mathrm{~mm}$ (maximum field of view $134.67 \mathrm{~mm}$ ), reconstruction offset 4000, reconstruction scale 5000. Total final slices $=80$. 


\section{APÊNDICE B}

Inferem-se um exemplo de tomograma, sinograma e a imagem tomográfica obtida no tomógrafo do CTR-IPEN-CNEN/SP. Ressaltando-se que:

(1) Tomogramas referem-se à matriz de dados obtidos com o exame tomográfico da rocha ígnea, no tomógrafo do CTR-IPEN-CNEN/SP. No eixo horizontal representam-se as varreduras obtidas em rotações de $2.7481^{\circ}$, num total de $360^{\circ}$, ou seja, 131 varreduras. No eixo vertical representa-se o número de contagens por segundo.

(2) O sinograma é uma forma gráfica bidimensional (2D) de representar o conjunto de projeções obtidas aplicando-se a transformação $-\log _{\mathrm{e}}\left(\mathrm{I} / \mathrm{I}_{0}\right)$, sendo $\mathrm{I}_{\text {e }} \mathrm{I}_{0}$ valores amostrais geralmente expressos em contagens por segundo, ao longo das tomadas angulares.

(3) As respectivas imagens tomográficas obtidas com o algoritmo da retroprojeção filtrada aplicado aos dados da projeção. Essas imagens foram geradas pelo programa computacional Matlab $^{\circledR}$ versão 7.1 (produto da MathWorks Inc.).

R1

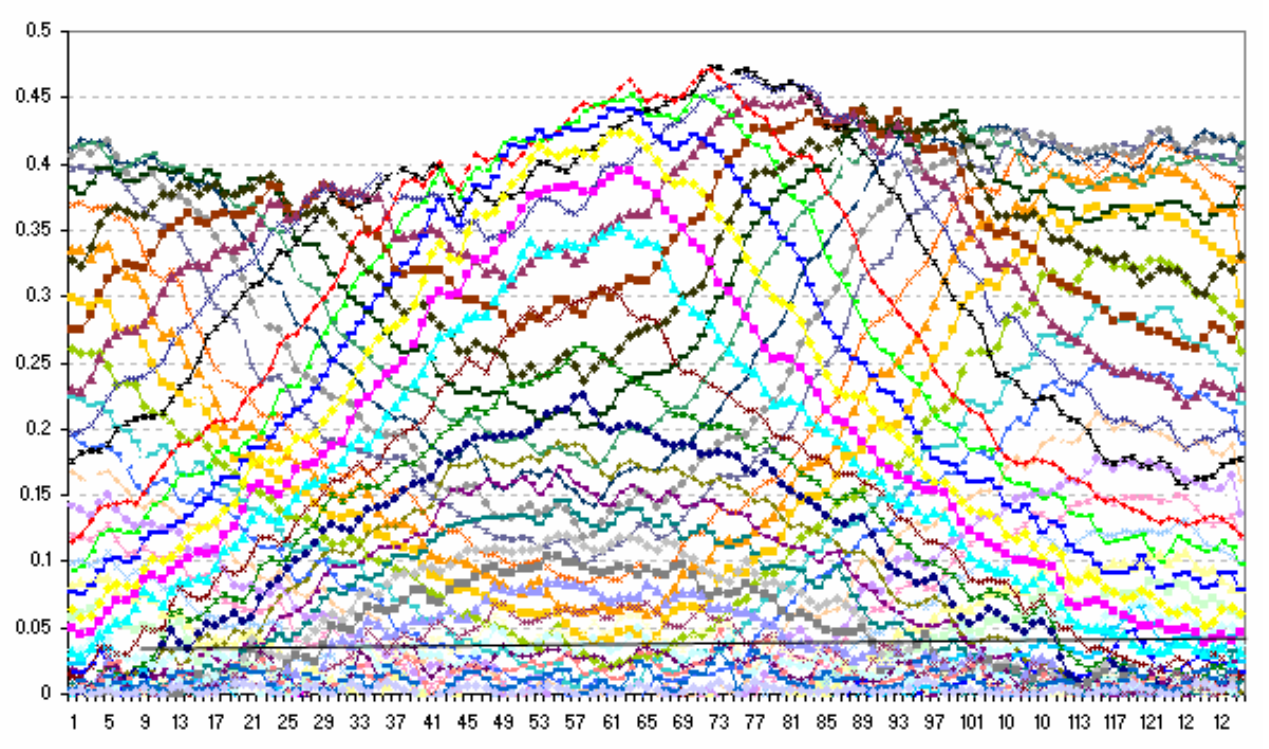

(1) 


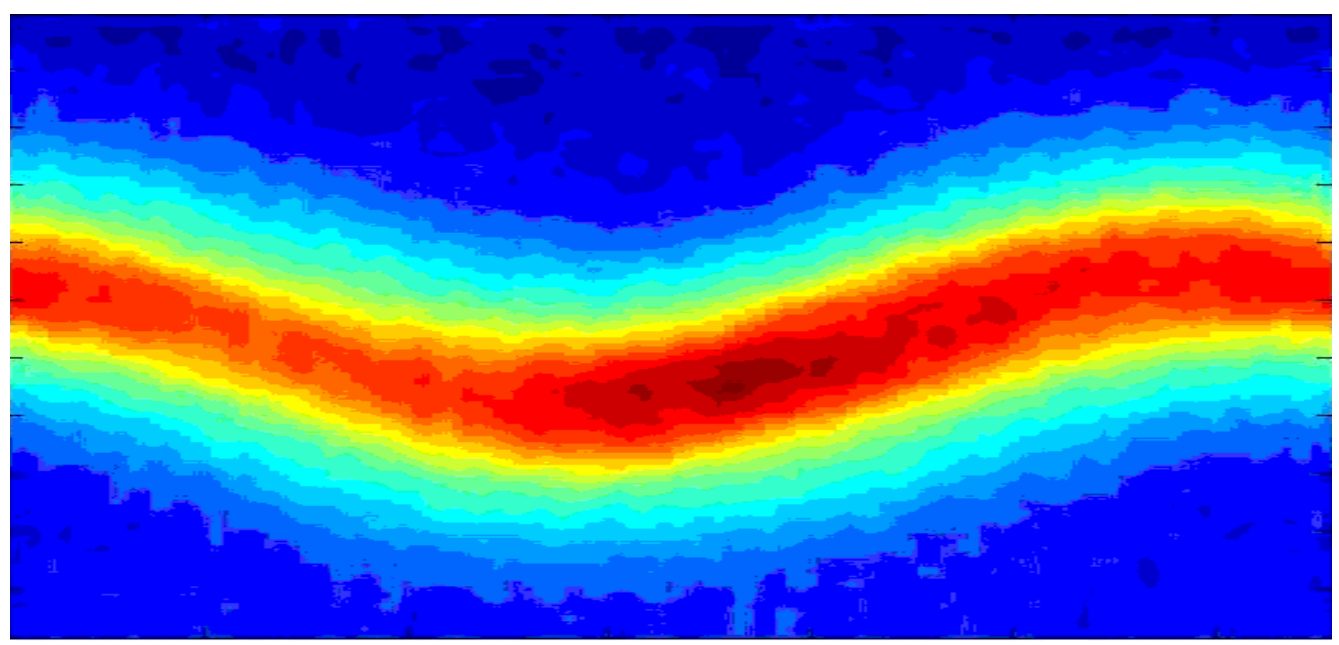

(2)

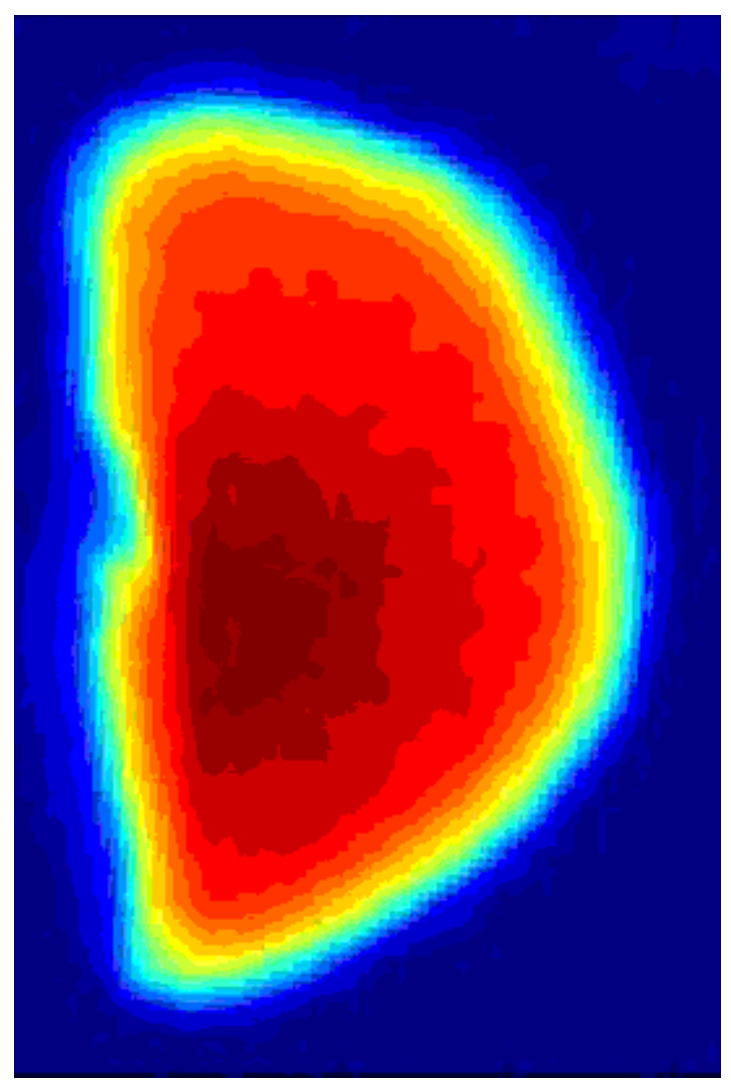

(3) 


\section{APÊNDICE C}

Inferem-se dos tomogramas e respectivas imagens tomográficas axiais obtidas da em um estudo inicial da rocha ígnea no CTR-IPEN-CNEN/SP.

1.
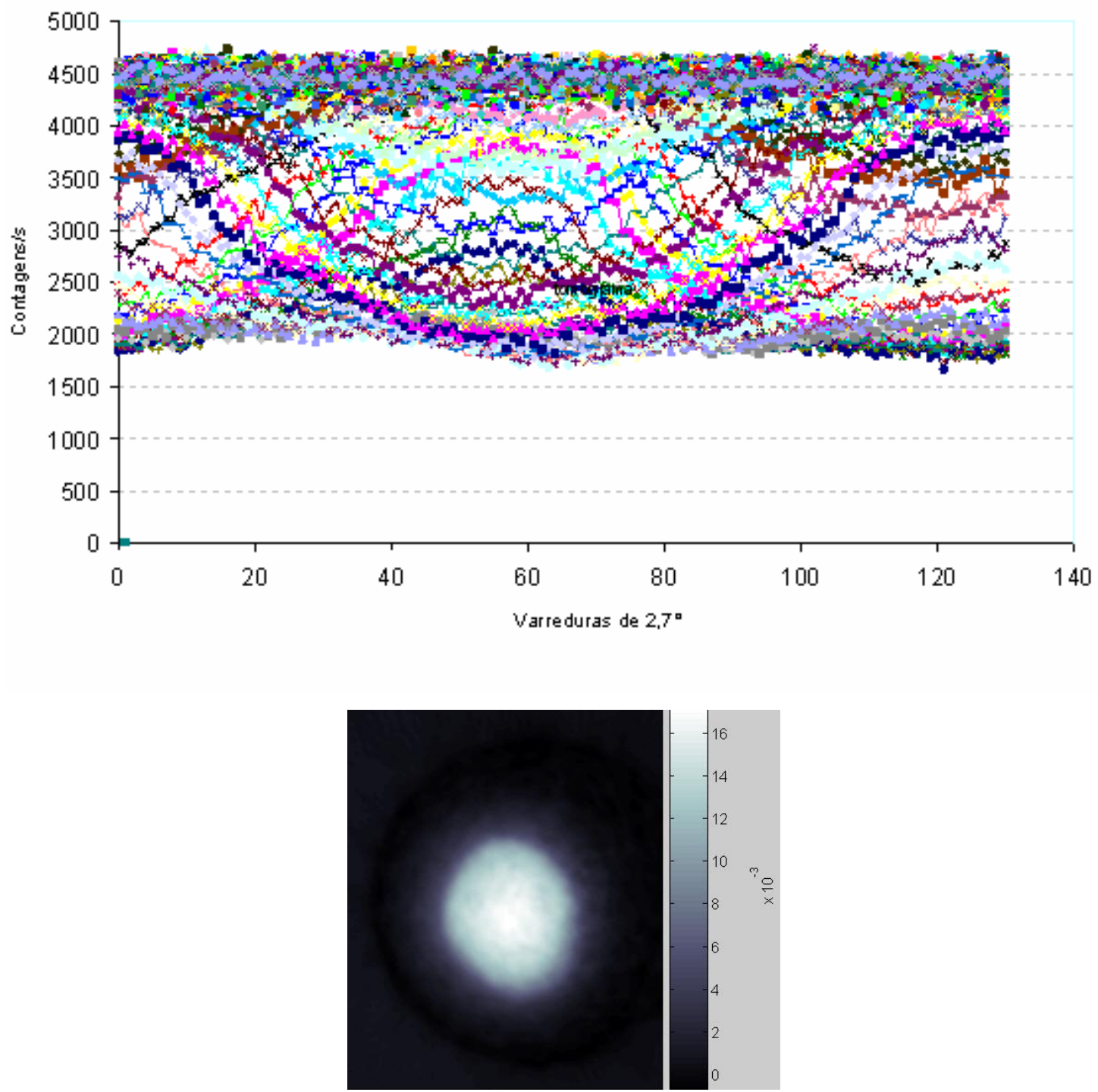
2.
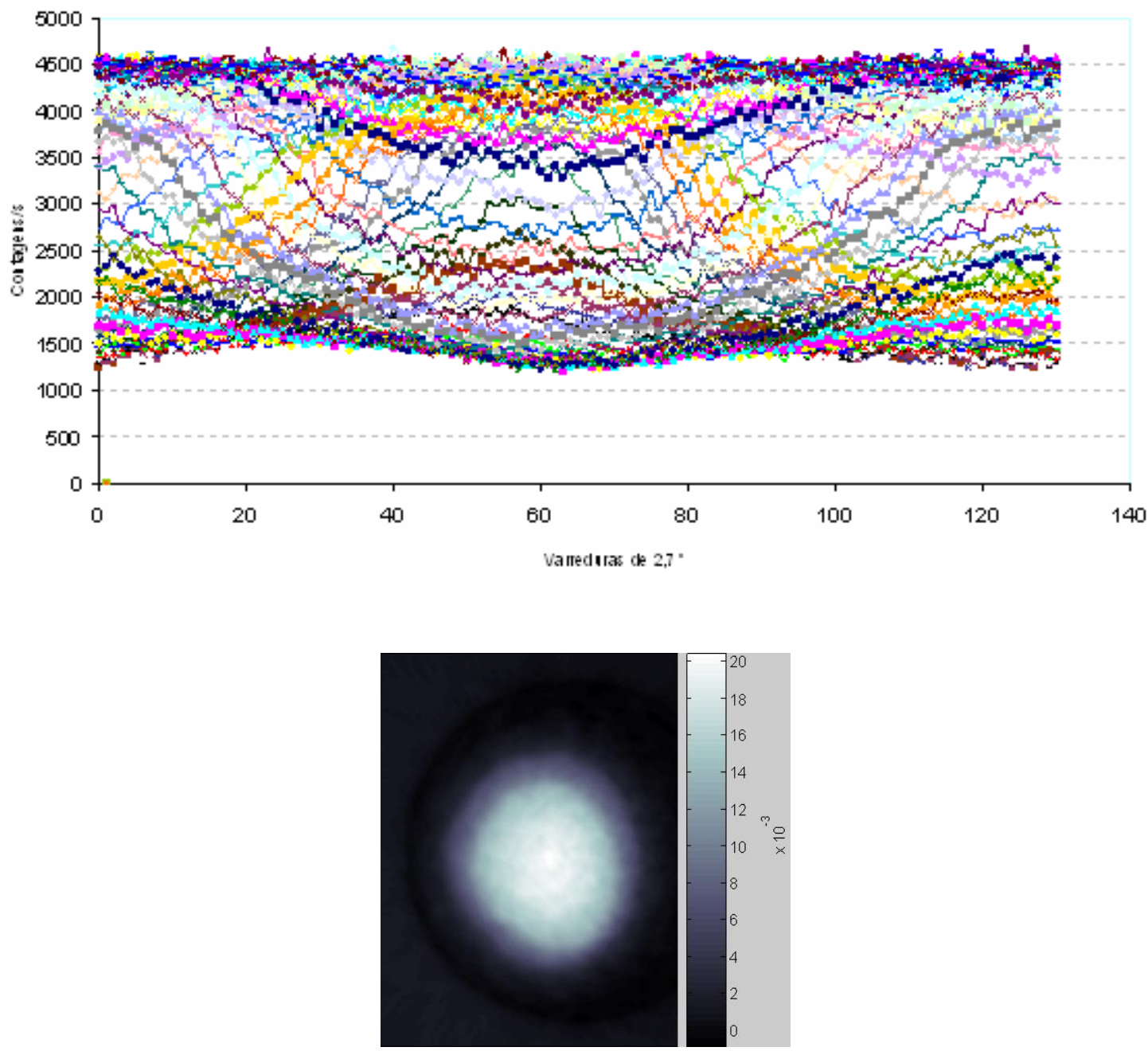
3.
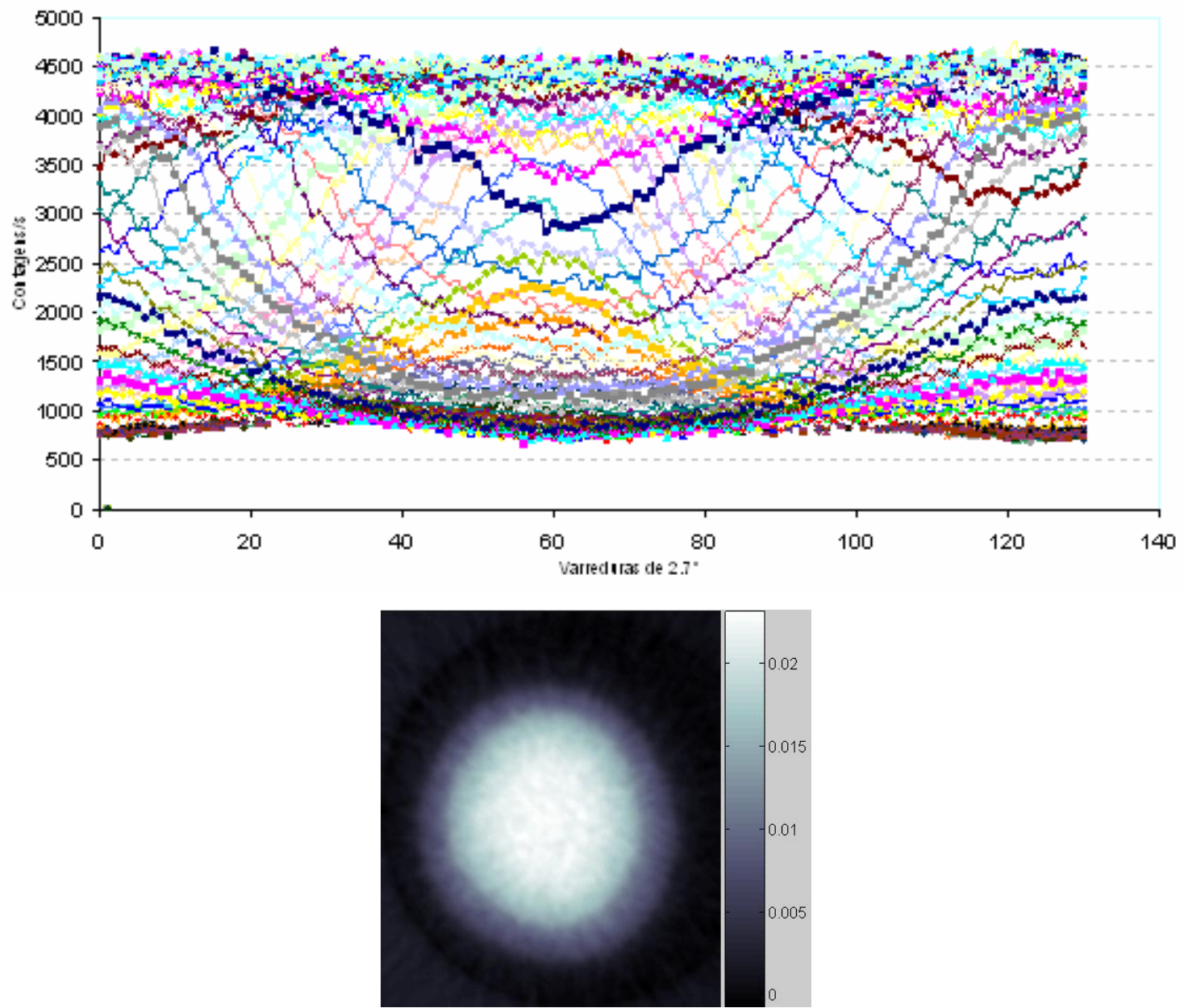
4.
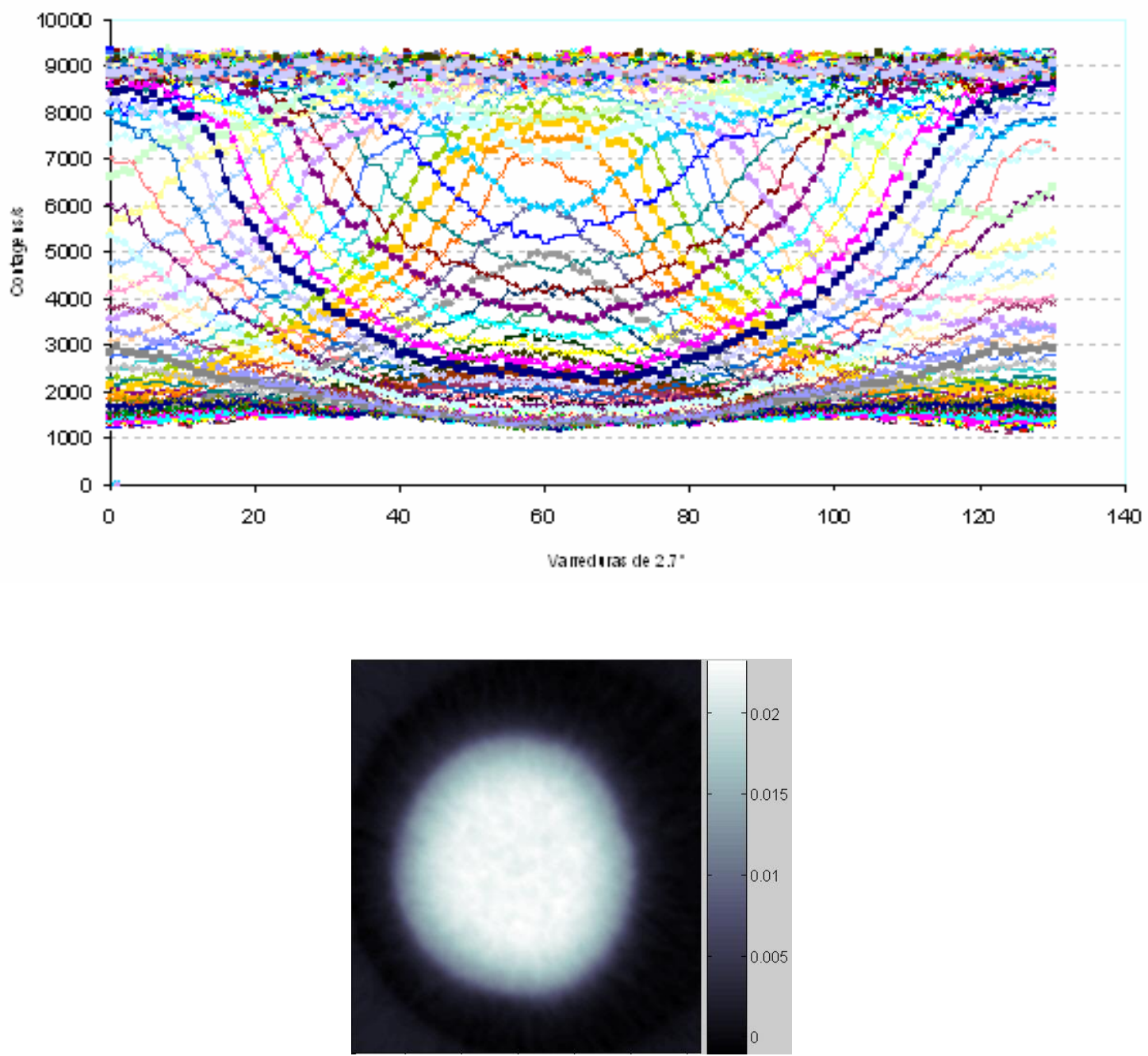
5.
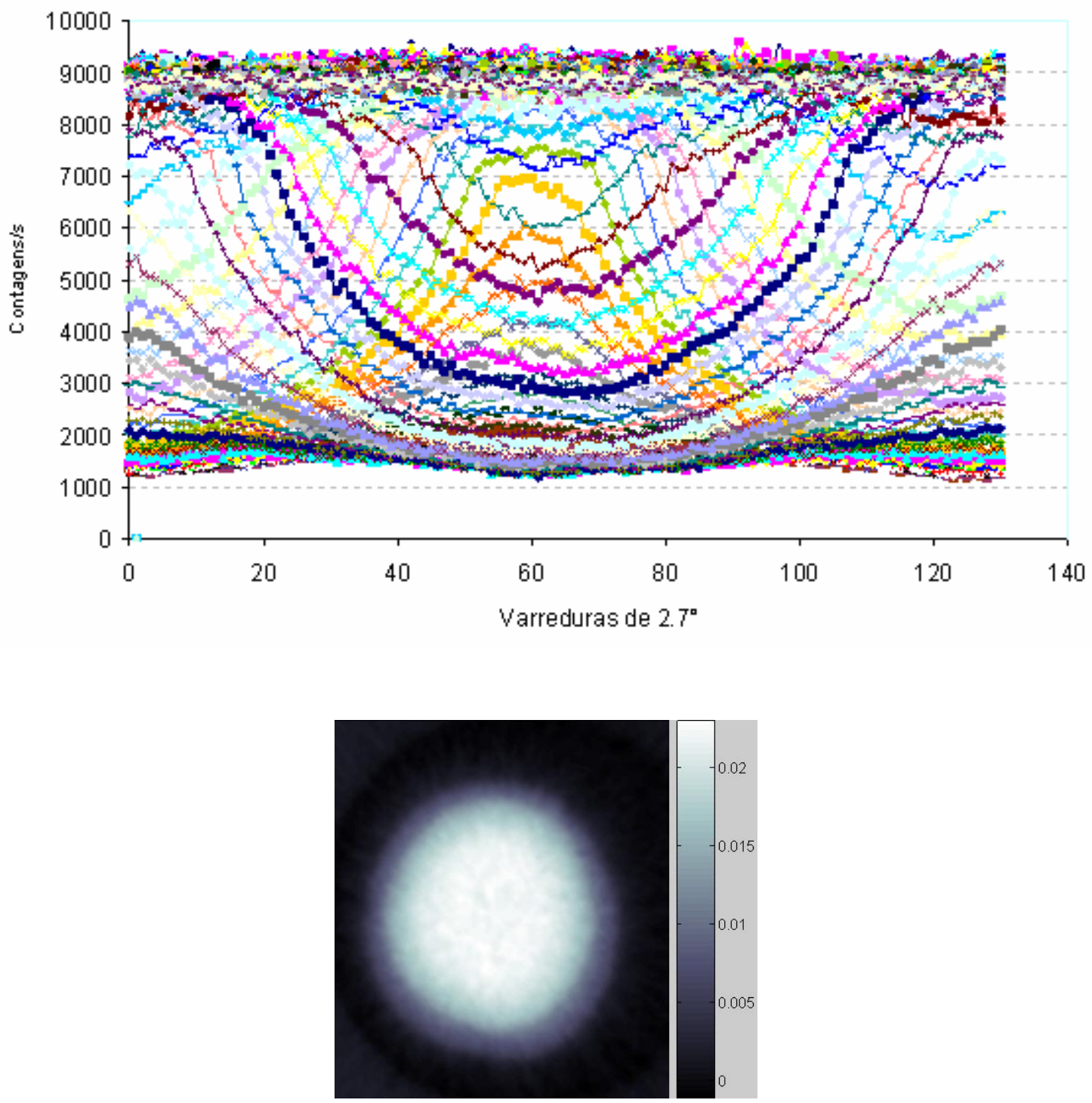
6.
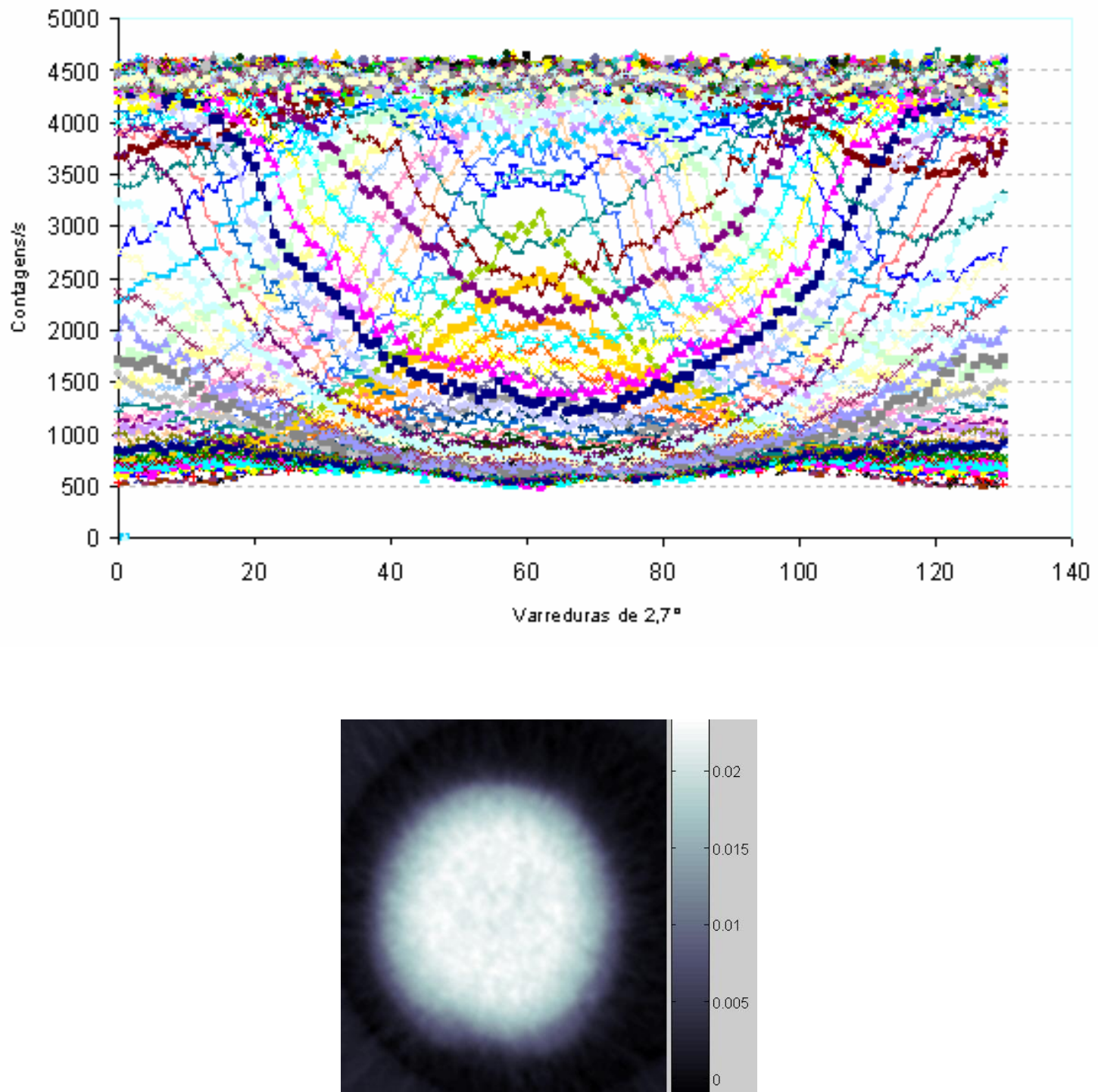
7.
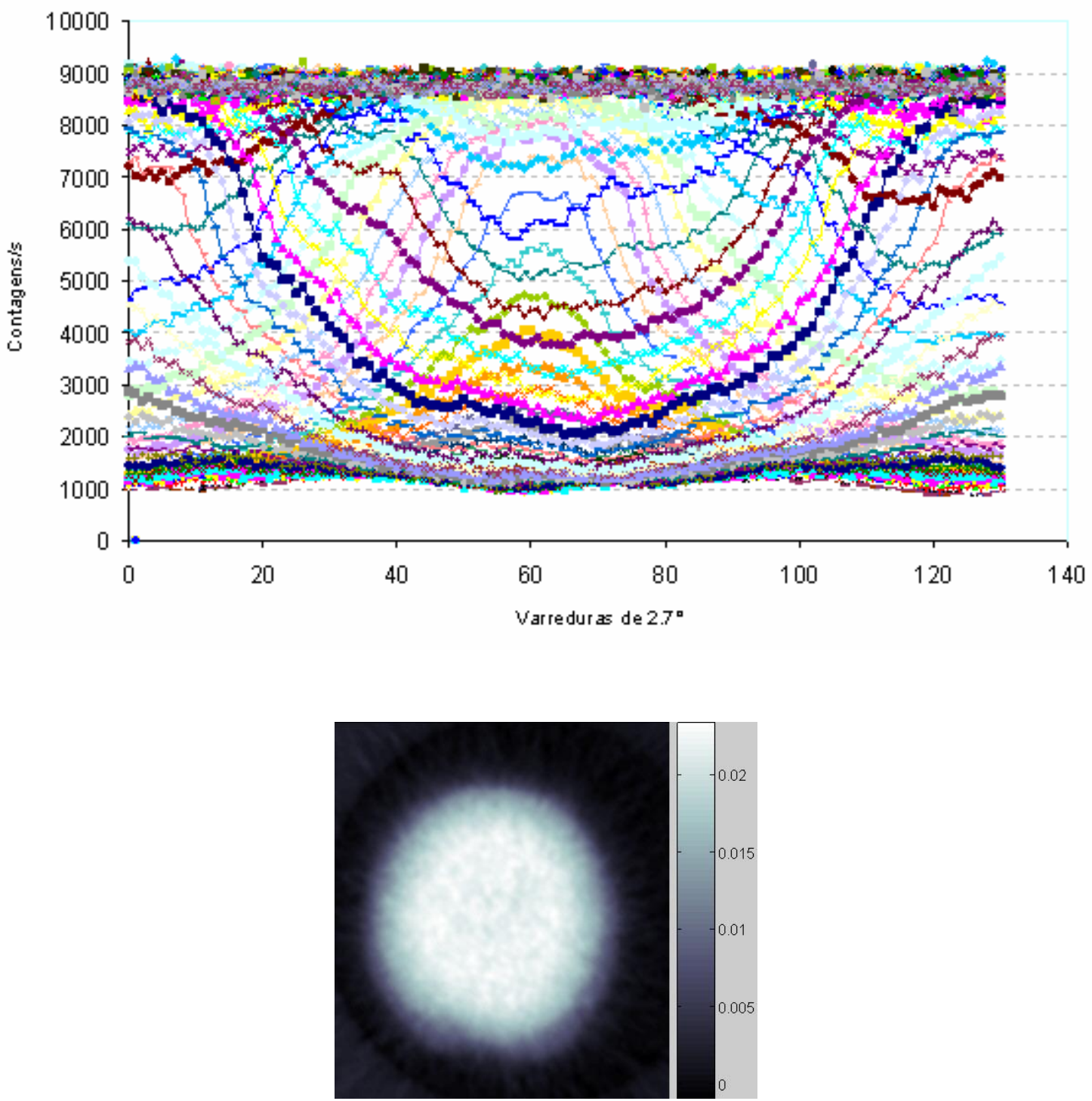
8.
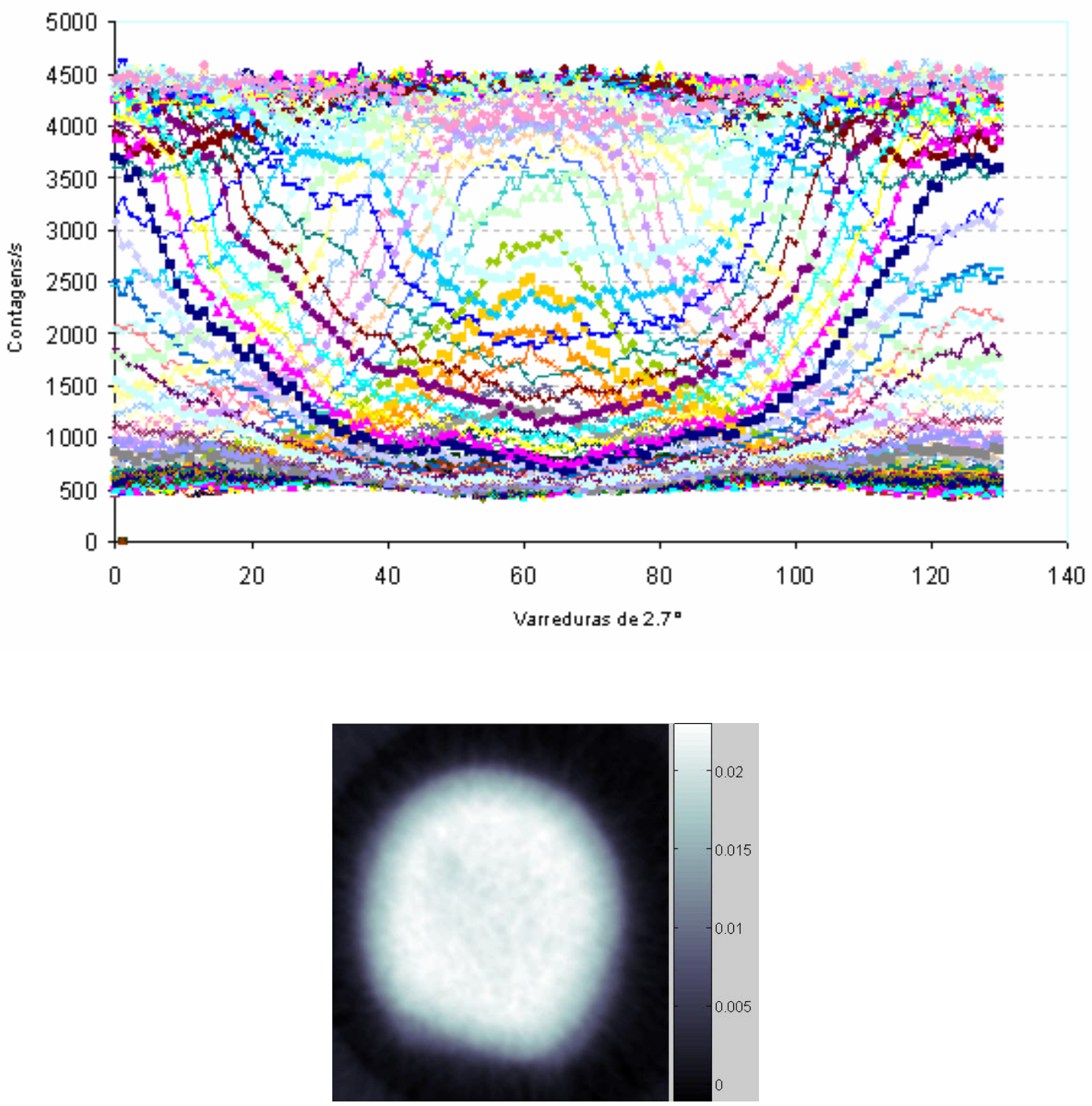


\section{REFERÊNCIAS BIBLIOGRÁFICAS}

1. AIRD, Edwin G.A.,Basic physics for medical imaging, ButterworthHeinemann, 1998.

2. ATTIX, F. H., \& ROESCH, W. C., ed. - Radiation Dosimetry. $2^{\underline{a}}$ ed., New York, Academic Press, 1968, v.1.

3. BANCROFT, G.M. 1973. Mössbauer spectroscopy: an introduction for inorganic chemists and geochemists. Wiley and Sons, New York, $251 \mathrm{pp}$.

4. BEALL, J.L., GORDON, I.T., GOURNAY, J.P., KIRKLAND, B.L., WHITE, J.V., 1996. Analysis of porosity in lower Ismay phylloid algal packstone using high-resolution computed X-ray tomography. American Association of Petroleum Geologists Annual Meeting Abstracts 5, 13.

5. BURNHAM, C A, Aronow S, Brownell G L, A hybrid positron scanner 1970 Phys. Med. Biol. 15 517-528.

6. BURNHAM, C A, Brownell G L. A multicrystal positron camera. IEEE Trans Nucl Sci. 1972; NS-19(3):201-5.

7. CARLSON, W.D., Denison, C., and Ketcham, R.A. (1998) Visualization, interpretation, and quantitative analysis of rock textures in three dimensions using high-resolution x-ray computed tomography. Eos, 79, S357.

8. CHEN, S.,;H. Avakian, V. Burkert, P. Eugenio, the CLAS collaboration (2006). "Measurement of Deeply Virtual Compton Scattering with a Polarized Proton Target". Physical Review Letters 97.

9. CHRISTILlin, P., "Nuclear Compton scattering". J. Phys. G: Nucl. Phys. 12: 837-851, 1986.

10. COMPTON, A. H. (May 1923). "A Quantum Theory of the Scattering of XRays by Light Elements". The Physical Review 21 (5): 483 - 502. (the original 1923 paper on the AIP website).

11. CONROY, G.C., Vannier, M.W., 1984. Imagem latente tridimensional noninvasive do computador dos skulls fossil matriz-enchidos pelo tomography computado high-resolution. Ciência 226, 456-458. 
12. CORMACK, A.M. Representation of a function by its line integrals, with some radiological applications. J. Appl. Phys., v. 34, p. 2722 - 2727, 1963.

13. DENISON, C., CARLSON, W.D., KETCHAM, R.A., 1997. Three-dimensional quantitative textural analysis of metamorphic rocks using high-resolution computed X-ray tomography; Part I. Methods and techniques. Journal of Metamorphic Geology 15 (1), 29-44.

14. Department of Physics and Technology, University of Bergen. Disponível em: $<$ http://web.ift.uib.no/ie/inst/ptib.html-Last updated March 22, 2004 by BTH Copyright (C) 2004> Acesso em: 27 nov.2007.

15. DYAR, M.D. Agresti, D.G., Schaefer, M., Grant, C.A., and Sklute, E.C. 2006. Mössbauer spectroscopy of earth and planetary materials. Annual Reviews of Earth and Planetary Science, 34, 83-125.

16. FARR, R.F.; ALLISY, R.P.J., Physics for Medical Imaging, W.B. Saunders Co., ISBN 0-702-01770-1,1996

17. FARREL, D. Iterative restoration of SPECT projection images Glick, S.J. Weishi Xia, Massachusetts,Univ.Med.Center,Worcester,MA

18. FOLEY, J. D.; Van Dam, A.; Feiner, K.; Hughes, J. F.: Computer Graphics Principles and Pratice, Second Edition In C, Addison Wesley, 1996.

19. GONZALES, R. C. \& Woods, R. E.: Digital Image Processing, Addison Wesley, New York, 1993.

20. HOFSTADTER R., MCINTYRE, J.A. Measurement of Gamma-Ray Energies with One Crystal, Phys. Rev. 78, 617 - 619 (1950). Disponível em: http://link.aps.org/abstract/PR/v78/p617/s2. Acesso em 21 jul.2008

21. HOLLEBEN, C. "Determinação de Porosidade e Saturações de Fluidos Através da Tomografia Computadorizada de Raios-X", tese de mestrado, CEPETRO (centro de estudos de petróleo), UNICAMP, 1993.

22. HOUNSFIELD, G.N. A method and apparatus for examination for a body by radiation such as $\mathrm{X}$-or gamma radiation. British Patent No. 1,283,915.

23. HOUNSFIELD, G. N. Computerized transverse axial scanning (tomography): Part I. Description of system. Br. J. Radiol, vol. 46, 1016-1022, 1973. 
24. JASZCZAK,R.J., The early years of single photon emission computed tomography (SPECT): an anthology of selected reminiscences, Phys.Med.Biol,51(2006), R99-R115.

25. JENKINS, R.; Gould, R.W.; Gedcke, D. Quantitative X-ray spectrometry. New York: Marcel Dekker, 1981. 586p

26. JOHN, H.E., The Physics of Radiology, Charles C. Thomas - Publisher, 1983.

27. JOHNS, R.A., Steude, J.S., Castanier, L.M., Roberts, P.V., 1993. Nondestructive measurements of fracture aperture in crystalline rock cores using X-ray computed tomography. Journal of Geophysical Research 98 (B2), 18891900.

28. KAMBIC, G.X. e Wake, R.H. Computed Tomography with an X Ray transmission Pencil Beam Scanner,IEEE Transactions on Nuclear Science, vol NS - 24, no. 2, April (1977)

29. KETCHAM, R.A., W.D. Carlson. 2001. Acquisition, optimization and interpretation of X-ray computed tomographic imagery: applications to the geosciences. Computers \& Geosciences 27, 381-400.

30. KETCHAM, R.A. 2001. "Can you scan this?" Principals of computed tomography (CT) and how they apply to the imaging and interpretation of fossilized material. Journal of Vertebrate Paleontology, 21(Suppl. No. 3), 67A.

31. KETCHAM, R.A. (2005) Three-dimensional textural measurements using highresolution X-ray computed tomography. Journal of Structural Geology, 27, 1217-1228.

32. KETCHAM, R.A., Meth, C., Hirsch, D.M., and Carlson, W.D. (2005) Improved methods for quantitative analysis of three-dimensional porphyroblastic textures. Geosphere, 1(1), 42-59.

33. KIRSCH, W.Estimates and anderson localization for alloy-type potentials; Springer Berlin / Heidelberg; Journal Mathematische Zeitschrift; V.221, Number 1 p. 507-512, January, 1996.

34. KNOLL, G.F. Radiation Detection and Measurement. New York, N.Y.: Wiley Intersciense, 1989 
35. KUHL, D.E., and EDWARDS, R.Q.; Image Separation Radioisotope Scanning, Radiology, 80-653-661, 1963.

36. LANGSTRON, M et all, Radiopharmaceuticals for PET studies-Proceedings of a symposium Vienna,21-25,august-1995 - Tomography in Nuclear MedicineUppsala, Sweeden.

37. McCOY, T.J., Carlson, W.D., Nittler, L.R., Stroud, R.M, Bogard, D.D., and Garrison, D.H. (2006) Graves Nunataks 95209: A snapshot of metal segregation and core formation. Geochimica et Cosmochimica Acta, 70, 516-531.

38. MAFRA, O. Y. - Manual Experimental de Técnicas e Medidas Nucleares. São Paulo, IEA, 1970, 141 p. (Informações IEA n⿳ำ 17).

39. MALLARD, J.R., The evolution of medical imaging from Geiger counters tom MRI - a personal saga Perspect.Biol.Med.46, 349-70, 2003.

40. MESQUITA, CH.; LEGOUPIL, S.; HAMADA, MM. Development on na Industrial Computed Tomography Designed with a Plastic Scintillator Position Sensitive Detector. 2005 IEEE Nuclear Science Symposium Conference, Record. N14-91. Estados Unidos, 2005.

41. MOLINE, G.R., Knight, C.R., Ketcham, R.A., 1997. Laboratory measurement of transport processes in a fractured limestone/shale saprolite using solute and colloid tracers. Geological Society of America, Abstracts with Programs 29, 370.

42. MONTANHEIRO, M. N. S.; V. F. Nascimento Filho e F. A. Pinto - Introdução à espectrometria gama. Boletim Didático n⿳000 021, 1977, 37 p., Piracicaba, SP, CENA.

43. NATTERER, F., The Mathematics of computerized tomography, classics in applied mathematics, published by Wiley in 1986.

44. QUOIRIN, N.S.R. Diagnóstico de amostras de madeira por tomografia de raios X. Dissertação (Mestrado) Engenharia e Ciência dos Materiais, Universidade Federal do Paraná. Disponível em: http://www.geocities.com/tomografiademadeira/index.html.Acesso em 01 set.2008 . 
45. PAIVA, Rogério F. e Arruda, Antonio C. F., "Análise de Testemunhos de Rochas Reservatório usando Tomografia Computadorizada de raios-X". $9^{\circ}$ CBECIMAT,Águas de São Pedro, Dezembro/1990.

46. PEAK, C.D.; McMillan, J.E.; Spooner, N.J.C.; Roberts, J.W.NAIAD: an advanced sodium iodide scintillation detector withimproved sensitivity to WIMP dark matter.Nuclear Science Symposium, 1998. Conference Record. 1998 IEEE.

47. PEYTON , R.L., Haeffner , B.A., Anderson, S.H., Gantzer, C.J., 1992. Applying X-ray CT to measure macropore diameters in undisturbed soil cores. Geoderma $53,329-340$.

48. RADON, J. Uber dies Bestimmung von Funktionen durch ihre Integralwerte langs gewisser Mannigfaltigkeiten. Ber. Verh. Sachs. Akad. Wiss. Leipzig, Math.-Nat. K1. 69, 262-277, 1917.

49. ROBILOTTA, C. C., A tomografia por emissão de pósitrons: uma nova modalidade na medicina nuclear brasileira. Positron emission tomography: a new modality in Brazilian nuclear medicine.Rev Panam Salud Publica v.20 n.23 Washington ago./Sep-2006

50. SAUTER, F.E.J.M. On the Behavior of an Electron in the Homogeneous Electric Field in Dirac's Relativistic Theory

51. SOUZA, M.A. Reconstrução $3 D$ de Imagens Tomográficas Aplicadas à Prototipagem Rápida. Dissertação de mestrado, CETEP-PR, 2002.

52. SERWAY, R. A. (1990). Physics for engineers and scientists, $3^{\text {rd }}$ ed. Saunders Publishing.

53. TANAKA, E., Instrumentation for PET and SPECT studies, Proceedings of a symposium Vienna,21-25,august-1995 - Tomography in Nuclear MedicineHamamatsu Photonics K.K. and National Institute of radiological sciences, Tokyo, Japan.

54. VEGLIA, A., \& KECKES, S. - Simultaneous application of radionuclides in tracer experiments. Intern. J. Appl. Rad. Isotopes, 22: 549 - 559, 1971

55. WITHJACK, E.M., 1988. Computed tomography for rock-property determination and fluid-flow visualization. SPE Formation Evaluation 3 (4), 696-704 
56. WELLINGTON, S.L., Vinegar, H.J., 1987. X-ray computerized tomography. Journal of Petroleum Technology 39 (8), 885-898.

57. ZANG, H. C., Joie P. Jones \& Manbir Singh; Foundations of Medical Imaging, John Wiley \& Sons Inc., ISBN 0-471-54573-2, 1993

58. ZINSMEISTER, W.J., De Nooyer, C., 1996. Tomography computado; técnicas non-destructive para visualizar a morfologia interna dos invertebrados. Sociedade geological de América, sumários com programas 28 (7), 294. 